\title{
Informal Economies And International Trade by
}

\author{
Hakan Toksoy \\ Bachelor of Arts, Economics, Gazi University, 2000 \\ Master of Arts, Economics, Ryerson University, 2010
}

A dissertation presented to Ryerson University

in partial fulfillment of the

requirements for the degree of

Doctor of Philosophy

in the program of Economics

Toronto, Ontario, Canada, 2018

(C)Hakan Toksoy, 2018 


\section{AUTHOR'S DECLARATION FOR ELECTRONIC SUBMISSION OF A DISSERTATION}

I hereby declare that I am the sole author of this dissertation. This is a true copy of the dissertation, including any required final revisions, as accepted by my examiners.

I authorize Ryerson University to lend this dissertation to other institutions or individuals for the purpose of scholarly research.

I further authorize Ryerson University to reproduce this dissertation by photocopying or by other means, in total or in part, at the request of other institutions or individuals for the purpose of scholarly research. I understand that my dissertation may be made electronically available to the public. 


\title{
Informal Economies and International Trade
}

Doctor of Philosophy, 2018

Hakan Toksoy

Economics, Ryerson University

\begin{abstract}
This dissertation studies the role of informal producers in determining the pattern of production and the trade structure of developing countries, and provides an understanding of the channels through which informal producers influence the outcome of trade. The second chapter examines the characteristics of informal workers in the Turkish export-oriented manufacturing industries using descriptive statistics and econometric analysis. We find that informality is highest among female workers with lower education levels who mainly operate from home, and report that the textile and clothing industries, which Turkey has a comparative advantage in the world market, have a share of informality. This finding inspires the third and fourth chapters. In the third chapter, informal producers directly export their products in the global market. We build a Ricardian model of trade with labour market frictions that justify the presence of informal producers. We find that the size of the informal sector is affected by not only a country's own labour market structure, but also by its trading partners' labour market frictions. We show that a decrease in trade costs results in an increase in the size of the informal sector in countries with relatively higher labour market rigidities, and a reduction of informality in their trading partners. The fourth chapter, which is joint work with professor Claustre Bajona, develops a theoretical framework with stages of production to investigate the role of informal producers in the supply chain. To quantify the changes in labour and trade policies on the trade structure of countries, we calibrate the model to the Turkish and German economies in 2003. In the model, informal producers may influence the comparative advantage of countries by supplying lower cost inputs to formal producers that compete in the global arena. In our calibrated model, second stage formal production is higher under a protectionist economy in a country with higher labour market frictions. This results in a larger informal sector due to the interlinkage between formal and informal producers in the production chain.
\end{abstract}




\section{Co-Authorship Statement}

This thesis contains Chapter 4 co-authored with Claustre Bajona. Together we worked on the conception of the theoretical model and its resolution, the manipulation of the data required for calibration, the computer programs used to simulate the model, the interpretation of the simulated results and the draft of the manuscript. 


\section{Acknowledgements}

Firstly, I would like to thank my advisor and mentor, Dr. Claustre Bajona for her unwavering support and guidance of my PhD study, and for her patience, supervision, and encouragement. I feel extremely privileged to have been her student. Without her guidance and support, this work would not have been possible. I would also like to thank the rest of my dissertation committee: Dr. German Pupáto and Dr. Derek Stacey for their time and valuable feedback, in addition to their perspectives and challenging questions posed, which helped me to broaden my research. Besides this, I am deeply grateful to Mr. Christopher Brierley who has been a true friend providing constant motivation to me. And last but not least, I would like to thank my wife, Gozde Toksoy for her support and sacrifice throughout this $\mathrm{PhD}$ journey. 


\section{Dedication}

I dedicate this dissertation to my best friend and my love, Gozde Toksoy. 


\section{Contents}

List of Tables $\quad$ ix

List of Figures $\quad$ xi

1 Introduction $\quad 1$

2 Informal Producers in Turkey $\quad 7$

2.1 Introduction . . . . . . . . . . . . . . . . . . . . . 7

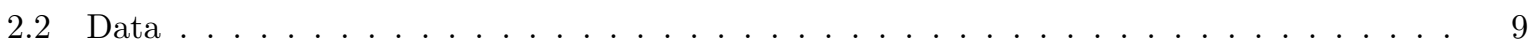

2.3 Descriptive Statistics . . . . . . . . . . . . . . . . . . . . . . 11

2.3.1 Demographic characteristics of individuals . . . . . . . . . . . . . . 11

2.3.2 Employment characteristics of individuals . . . . . . . . . . . . . . . . 13

2.3.3 The demographic and employment characteristics of informal workers . . . . . . 16

2.4 Likelihood of informality . . . . . . . . . . . . . . . . . . . . . 20

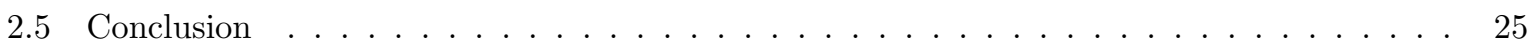

$\begin{array}{llr}3 & \text { Informal trade } & 26\end{array}$

3.1 Introduction . . . . . . . . . . . . . . . . . . . . . . . . 26

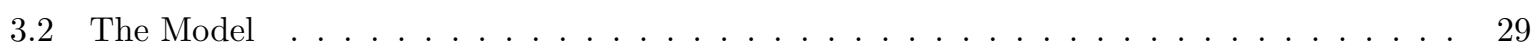

3.2.1 Labour Market ......................... 30

3.2.2 Production Technologies and Producer's Maximization Problem . . . . . . . . . . 32

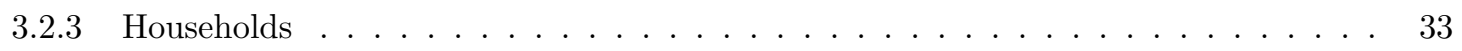

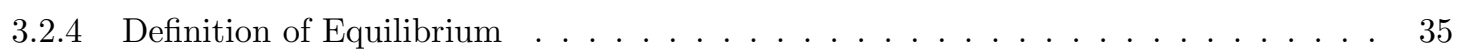

3.3 Resolution of the Model: Characterization of Equilibrium . . . . . . . . . . . . . . . . 36

3.4 Closed economy . . . . . . . . . . . . . . . . . . . . . . . . . . . . . 42

3.5 Open economy with symmetric hiring costs . . . . . . . . . . . . . . . . . . . . 44

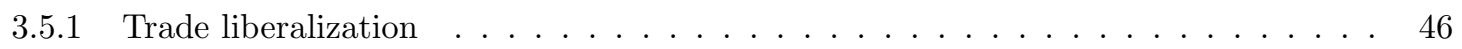

3.5.2 Labour market policy . . . . . . . . . . . . . . . . . . . 48

3.6 Asymmetric hiring costs . . . . . . . . . . . . . . . . . . . . . . . . . . . 49

3.6.1 Free Trade: $\tau=0$. . . . . . . . . . . . . . . . 50 
3.6.2 Restricted Trade: $\tau>0 \ldots \ldots \ldots \ldots \ldots \ldots$

3.6 .3 Comparative Statics . . . . . . . . . . . . . . . . . . 62

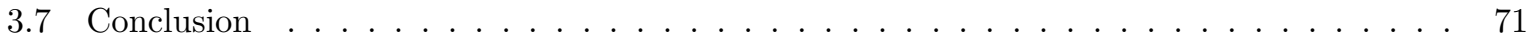

4 The Role of Informal Producers in the Global Supply Chain 73

4.1 Introduction . . . . . . . . . . . . . . . . . . . . . . . 73

4.2 The Model . . . . . . . . . . . . . . . . . . . . . . . . . 75

4.2 .1 Labour Market . . . . . . . . . . . . . . . . . . . . . . 75

4.2.2 Production Technologies and Producer's Maximization Problem . . . . . . . . . 77

4.2 .3 Households . . . . . . . . . . . . . . . . . . . . . . 80

4.2 .4 Definition of Equilibrium _..................... 81

4.3 Resolution of Model: Characterization of Equilibrium . . . . . . . . . . . . . . . 83

4.3.1 The first-stage formal production . . . . . . . . . . . . . . . . . . 83

4.3.2 The second-stage production ..................... 84

4.3.3 Production pattern in the second stage . . . . . . . . . . . . . 85

4.3.4 Production pattern in the first stage . . . . . . . . . . . . . . . 85

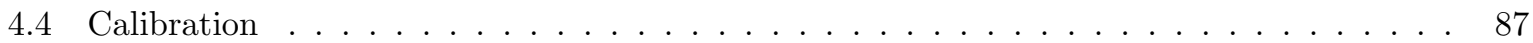

4.4.1 Informal producers and comparative advantages . . . . . . . . . . . . . . 91

4.5 Policy Experiments . . . . . . . . . . . . . . . . . . . . . . . . . 99

4.5.1 Experiment-I: Labour market policy . . . . . . . . . . . . . . . . . . 99

4.5.2 Experiment-II: Trade policy-the Home country with higher labour market frictions 102

4.5.3 Experiment-III Restricted trade with a country having higher labour market

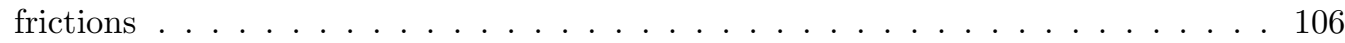

4.6 Conclusion . . . . . . . . . . . . . . . . . . . . . . . 110

5 Conclusion $r \begin{array}{ll}111\end{array}$

6 References $r 13$ 


\section{List of Tables}

2.1 Demographic characteristics of individuals Source: Turkish Household Labour Survey (2013)

2.2 Employment characteristics of individuals Source: Turkish Household Labour Survey

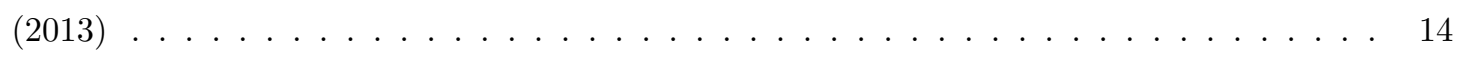

2.3 Reasons for working temporarily Source: Turkish Household Labour Survey (2013) . 15

2.4 Manufacturing industries Source: Turkish Household Labour Survey (2013) . . . . . . . . 16

2.5 The employment status of informal workers Source: Turkish Household Labour Survey (2013)

2.6 The employment status of informal workers Source: Turkish Household Labour Survey (2013)

2.7 Gender of informal workers Source: Turkish Household Labour Survey (2013) . . . . 18

2.8 Married informal workers with their gender status Source: Turkish Household Labour Survey $(2013) \ldots \ldots \ldots \ldots \ldots \ldots \ldots \ldots$

2.9 Married home producers with their gender status Source: Turkish Household Labour Survey $(2013) \ldots \ldots \ldots \ldots \ldots \ldots \ldots$

2.10 Female home producers and their status in the household Source: Turkish Household Labour Survey $(2013) \ldots \ldots \ldots \ldots$. . . . . . . . . . . . . . . . . . . 19

2.11 Logistic regression . . . . . . . . . . . . . . . . . . . . . . . . . 21

2.12 Predicted probabilities with the demographic characteristics of individuals . . . . . . 22

2.13 Predicted probabilities with the employment characteristics of individuals . . . . . . . 23

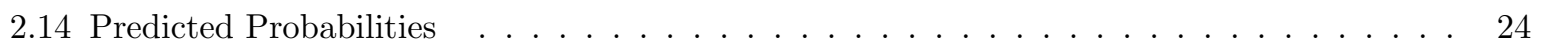

3.1 Parameter Values . . . . . . . . . . . . . . . . . . . . . . . 63

4.1 Productivity Parameters . . . . . . . . . . . . . . . . . . . . . 89

4.2 Calibrated parameters . . . . . . . . . . . . . . . . . . . 90

4.3 The pattern of production in the benchmark economy . . . . . . . . . . . . . . . 91

4.4 The key aggregate variables in the benchmark economy . . . . . . . . . . . . . . 93

4.5 The pattern of production in the Home country without informal producers . . . . . . . 95 
4.6 The pattern of production in the Foreign country without informal producers . . . . . . 95

4.7 The key aggregate variables without informal producers . . . . . . . . . . . . . . 97

4.8 Experiment-I: The pattern of production in the Home country . . . . . . . . . . . . . . 99

4.9 Experiment-I: The pattern of production in the Foreign country . . . . . . . . . . . . . . 100

4.10 The key aggregate variables in Experiment-I . . . . . . . . . . . . . . . . . . 101

4.11 Experiment-II: The pattern of production in the Home country . . . . . . . . . . . . . 102

4.12 Experiment-II: The pattern of production in the Foreign country . . . . . . . . . . . . 103

4.13 The key aggregate variables in Experiment-II . . . . . . . . . . . . . . . . . . . . 104

4.14 Experiment-III: The pattern of production in the Home country . . . . . . . . . . . 106

4.15 Experiment-III: The pattern of production in the Foreign country . . . . . . . . . . . . 106

4.16 The key aggregate variables in Experiment-III . . . . . . . . . . . . . . . . . . 108 


\section{List of Figures}

3.1 Labour market frictions and informal economies . . . . . . . . . . . . . . . . . . 27

3.2 The export threshold and the pattern of production in formal varieties, $z \quad \ldots \ldots$. . . . 38

3.3 The export thresholds and the pattern of production with $\theta>1+\tau \ldots$. . . . . . 58

3.4 The export thresholds and the pattern of production with $\theta<1+\tau$ when $\tilde{z}_{*}^{F}>\tilde{z}^{H} \ldots . .59$

3.5 The export thresholds and the pattern of production with $\theta<1+\tau$ when $\tilde{z}_{*}^{F}<\tilde{z}^{H} \ldots . .59$

3.6 The export thresholds with $\tau>0$ and $\theta>1 \ldots \ldots$. . . . . . . . . . . . . 64

3.7 The composite good price with $\tau>0$ and $\theta>1 \ldots \ldots \ldots$. . . . . . . . . . 64

3.8 Welfare with $\theta>1$ and $\tau>0 \ldots \ldots \ldots \ldots \ldots$

3.9 Total formal employment with $\tau>0$ and $\theta>1 \ldots \ldots$. . . . . . . . . . . 66

3.10 Total informal employment with $\tau>0$ and $\theta>1 \ldots \ldots$. . . . . . . . . . 66

3.11 The value of import with $\tau>0$ and $\theta>1 \ldots \ldots \ldots \ldots$. . . . . . . . . . 67

3.12 The export thresholds with $\tau>0$ and $\theta>1 \ldots \ldots \ldots$. . . . . . . . . . . 68

3.13 The composite good price with with $\tau>0$ and $\theta>1 \ldots \ldots$. . . . . . . . 68

3.14 Welfare with $\theta>1$ and $\tau>0 \ldots \ldots \ldots \ldots \ldots$. . . . . . . . . . . . 69

3.15 Total formal employment with $\theta>1$ and $\tau>0 \ldots \ldots$. . . . . . . . . . . . . 69

3.16 Total informal employment with $\theta>1$ and $\tau>0 \ldots \ldots$. . . . . . . . . . . . 70

3.17 The value of imports with $\theta>1$ and $\tau>0 \ldots \ldots \ldots \ldots \ldots$

4.1 First stage productivity parameters . . . . . . . . . . . . . . . . . . 89

4.2 Second stage productivity parameters _. . . . . . . . . . . . . . . . 90

4.3 The pattern of production in the Home country . . . . . . . . . . . . . . . . . 92

4.4 The pattern of production in the Foreign country . . . . . . . . . . . . . . . . . . 92

4.5 The pattern of production in the Home country . . . . . . . . . . . . . . 96

4.6 The pattern of production in Experiment-I . . . . . . . . . . . . . . . 100

4.7 The pattern of production in Experiment-II . . . . . . . . . . . . . . . . . 103

4.8 The pattern of production in Experiment-III _ . . . . . . . . . . . . . . 107 


\section{Chapter 1}

\section{Introduction}

This dissertation studies the role of informal producers in determining the pattern of production, the trade structure, and the welfare of developing countries and investigates channels through which informal producers influence the trade outcome of developing countries.

Adding to the traditional trade theories which emphasize the flexible labour market as the source of gains from international trade, this dissertation shows that countries with rigid labour markets can still benefit from international trade through their informal producers. The existing literature, which studies the relationship between the informal sector and international trade, examines changes in the size of the informal sector as countries implement trade liberalizations. This dissertation aims to investigate the effect of informal producers on the trade outcome of developing countries. Furthermore, another goal of this dissertation is to explore the channels through which informal producers contribute to the comparative advantage of developing countries.

There are three main chapters in this dissertation (Chapter 2 to 4), and each of which provides unique contributions to the existing literature. The second chapter, which uses descriptive statistic and econometric analysis, documents the main employment and demographic characteristics of informal workers in three Turkish manufacturing industries that compete in the global arena. This chapter is distinct from the existing literature, which mainly examines the size of the informal sector in Turkey or suggests different labour market policies to combat against the Turkish informal economy. Similar to the literature, we report that informality is highest among female workers with lower education. The contribution of this chapter is that we examine characteristics of these informal workers at the sectoral level. We find that these workers mainly operate from home and they are concentrated on the textile and clothing industries. Given that Turkey is one of the worlds biggest exporters of textile and clothing products, this finding suggests that informality may be linked to the comparative advantage of the Turkish textile and clothing industries. Therefore, our findings in this chapter inspire the third and fourth chapters which develop theoretical frameworks to understand how informal producers influence the pattern of trade and the welfare of developing countries. In the third chapter, informal producers enter the global market directly. They can affect the pattern of production and the trade structure by 
exporting their final products to world market. In this regard, informal and formal producers serve in different markets. The third chapter builds a Ricardian model of trade with labour market rigidities. Labour market frictions create segmented labour markets in which formal and informal producers operate. This chapter adds an important contribution to the existing literature by outlining how the size of the informal sector is determined by not only the country's own labour market frictions, but also by the degree of its trading partners' labour market rigidity. In the fourth chapter, which is a joint work with Professor Claustre Bajona, we study the role of informal producers in the supply chain. To the best of our knowledge, this chapter is the first study using a theoretical framework to examine the role of informal producers in the global supply chain. Another important contribution of the fourth chapter is that informal producers can affect the comparative advantage of developing countries by providing lower cost intermediate inputs to formal producers that participate in international trade.

Studies that examine the incentives behind international trade provide differing perspectives on the sources of gains achieved from trade liberalization. In the classical Ricardian trade theory, the benefits from trade are derived from differences in cross-country labour productivity. When countries open to trade, they specialize in the production of goods in which they have a comparative advantage, and specialization requires a successful reallocation of labour across sectors. The Hecksher-Ohlin (H-O) theory of trade focuses on differences in relative factor endowments between countries. A country having abundance in one factor of production trades the good that uses that factor more intensively. After trade liberalization, these exporting sectors expand and the importing sectors contract through reallocation of factors towards the sectors in which the country has comparative advantage. The new trade theory introduced in Krugman (1979) postulates that international trade allows firms to take advantage of economies of scale with workers reallocating into fewer larger firms. Similarly, in Melitz (2003), employment moves from inefficient firms towards efficient firms during trade liberalizations. Therefore, the speed of labour reallocation across sectors is important for a country to exploit the benefits derived from trade reforms. Examining two Latin American countries that had experienced trade reforms, i.e. Mexico with a rigid labour market, and Chile with a flexible labour market, Kambourov (2008) concludes that labour market reforms have to go hand-in-hand with trade liberalization in order for a country to gain from trade. Kambourov (2008) argues that Mexico could have gained more from international trade if its labour market had been more flexible during its trade liberalization period. Furthermore, Cunat and Melitz (2012) shows that the ability to adjust the labour market of a country is essential in order to gain from trade. They find that countries with more flexible labour markets should specialize in sectors in which firms have freedom to hire and fire workers.

All these models assume perfect mobility of labour across sectors. The empirical literature finds mixed results in the relationship between labour market rigidities and international trade. Wacziarg and Wallack (2003) find no evidence of labour reallocation among manufacturing sectors in most developing countries during their trade liberalization periods. Menezes-Filho and Muendler (2007) document that efficient industries did not necessarily attract workers. Using employer-employee data from Brazils labour force 
statistics and the Brazilian monthly employment survey, the researchers examine the outcome of Brazils trade reforms in the 1990s, and the findings contradict the common implications of labour reallocation towards efficient sectors of the classical trade theories. It is found that labour productivity increased in exporting sectors causing firms to use the same amount of employment, and even to dismiss some workers. Moreover, Menezes-Filho and Muendler (2007) conclude that countries such as Brazil could take a long time to transfer labour to efficient industries even though total production might increase with trade. Similarly, Dix-Carneiro (2014) reports that response of the labour market to trade reforms in Brazil took several years, and the authors show that workers' characteristics such as education and age, and their initial employment status are important determinants for welfare gains during trade liberalization. Currie and Harrison (1997) analyse labour mobility across Moroccos manufacturing sectors during trade liberalization in the $1980 \mathrm{~s}$. The authors report that labour reallocation in most manufacturing firms did not occur even though Morocco had a flexible labour market. Their results show that the existence of monopolistic firms in the manufacturing sector, and minimum wage laws, which make it easier to hire temporary workers, led Morocco to experience difficulties in transferring workers towards more productive firms during trade liberalization. Currie and Harrison (1997) also find that publicly held enterprises and the export-oriented firms with market power were the only winners of trade liberalization in Morocco. Government owned firms increased productivity and expanded their employment by hiring temporary workers.

In their cross-country analysis, Botero et al. (2004) report that labour market rigidity varies across countries. The authors introduce the rigidity of employment index which is an average measure of the difficulty of hiring, the difficulty of firing, and a rigidity of working hours. This index ranges from 0 to 100 where higher numbers represent higher labour market rigidity. Moreover, the authors state that the development level and the degree of labour market rigidities of countries are not correlated, that is, a country with a rigid labour market can have a higher income level than another country which has a more flexible labour market. For instance, Spain with a rigid labour market has a higher income level than Morocco which has relatively less rigidity in its labour market. From the labour market rigidity index provided by Botero et al. (2004), it is observed that many developing countries have very rigid labour markets.

The literature which investigates the relationship between labour market structure and international trade mostly focuses on formal economies and ignores the fact that many developing countries have labour market frictions which may impede the successful labour reallocations across sectors to gain from international trade.

The existence of labour market frictions is also the cause of another economic phenomenon which is common in developing countries: the informal economy (Satchi and Temple (2006), Zenoue (2008)). Labour market frictions create a segmentation of the labour market between formal producers which comply with labour market regulations that strain workers' mobility across sectors, and informal producers which do not follow employment regulations. La Porta and Shleifer (2014) document that 
almost half of economic activities are performed by informal producers in developing countries. Moreover, using data from 157 countries gathered between 1999 and 2013, Schneider and Kepler (2016) show that the average contribution of informal economies to the global economy is $33 \%$.

At the same time, developing countries are participating in international trade, and their share of exports has grown significantly since the 1990s as reported in the World Trade Report 2015 issued by the World Trade Organization (WTO). For instance, relative to most countries in the Organisation for Economic Co-operation and Development (OECD), Turkey has large informal economies (Schneider(2012)) and it has been integrating into world trade since the 1980s. The European Commission, which is an institution of the European Union, reports Turkey as the European Union's 4th largest and 5th biggest export and import market respectively.

Therefore, it is natural to ask: what is the potential role of informal producers in shaping the trade structure of developing countries and through what channels do informal producers affect a countrys trade outcome?

Using the fact that developing countries, which have large informal economies, participate in international trade, this dissertation studies the channels through which informal producers affect the outcome of trade in these developing countries. There is no clear consensus in the existing empirical literature on the relationship between trade liberalization and the size of the informal sector. For instance, Goldberg and Pavcnik (2003) argue that the size of the informal sector is not affected by trade liberalization, and it is only determined by the structure of the labour market. Paz (2013) predicts that the effect of trade liberalization on the size of the informal sector solely depends on the initial state of a countrys labour market. Furthermore, using 25 years of employer-employee data from Brazil, Kovak and Dix-Carneiro (2015) report that some local labour markets in Brazil had lower formal employment in the short run and higher informal employment in the long run after trade reform in the 1990s.

The papers cited above investigate how international trade affects the size of the informal sector. This dissertation takes a different direction and investigate the effect of informal producers on the outcome of international trade. Furthermore, it develops theoretical frameworks that identifies mechanisms through which informal producers shape in the trade structure of developing countries.

The second chapter in this dissertation adds to the existing literature which mostly studies the degree of the informality in the Turkish economy or advice different employment policies to reduce the size of informal sector in Turkey. It aims to provide information about the demographic and employment characteristics of informal workers in Turkish manufacturing industries that compete in the global market. In this analysis, we use the Turkish Household Labour Force Survey (THLFS), which was conducted by the Turkish Statistical Institute (TurkStat) in 2013. Using descriptive statistics and econometric analysis in this chapter, our findings are parallel to the existing literature which shows that informal employment is very high among female workers with lower education, and these individuals are mainly home producers. Focusing on the Turkish manufacturing industries, we find that informal workers are mostly operate in the textile and clothing industries. This is a very interesting result since Turkey is one of the worlds 
biggest exporters of textile and clothing products as reported in the World Trade Statistical Review 2017 provided by the World Trade Organisation (WTO). Providing evidence that informal workers are employed in the trading sectors, this chapter motivates the third and fourth chapters which explore the mechanisms through which informal producers influence the trade structure and the welfare of developing countries.

In the third chapter, we develop a Ricardian model of trade with labour market rigidities that create segmented labour markets in which formal and informal producers operate. Labour market frictions are introduced in a similar manner as in Helpman and Itskhoki (2010), and the frictions in this chapter provide the rationale for the existence of informal producers.

However, our model differs from Helpman and Itskhoki (2010) which uses the framework that firms engage in monopolistic competition. In our model, each country has both informal producers, which take prices as given and produce homogeneous informal goods (low quality, second-hand or counterfeit goods), and formal producers, which experience frictions in labour mobility, and produce differentiated formal varieties. Both informal and formal producers serve in different markets and produce consumption goods that can be traded. Using the evidence from the second chapter, informal economic activities can be performed by micro or small enterprises and by home producers. Therefore, these producers may be the outside of the governments radar and do not need to comply with employment regulations.

The main contribution of this chapter is to show that the size of the informal sector is determined by not only the country's own labour market frictions, but also by the degree of its trading partners' labour market rigidity. Once a country with rigid labour markets engages in international trade with a country having lower labour market frictions, its formal sector shrinks, while its informal sector expands. Another contribution of this chapter is to show that in our framework a reduction in trade barriers results in an increase in the size of the informal sector in a country having relatively higher labour market frictions, and a decrease in the informal sector in its trading partner. Workers in the country with high labour market rigidities move towards the informal sector from the formal sector during trade liberalization, and it becomes a net exporter of informal goods and a net importer of formal goods. An important implication in this chapter is that once two countries with different degrees of labour market rigidity liberalize trade, changes in labour market policy in a country that has relatively higher labour market frictions, impact not only its own labour market and welfare, but also these of its trading partners. For instance, a further increase in labour market frictions in the country that has initially higher labour market frictions, increases the size of its informal sector and decreases the size of the informal sector in its trading partner. Moreover, both countries experience lower welfare as labour market frictions in one country increase. However, welfare in the country with higher labour market frictions decreases more than that of its trading partner.

To the best of our knowledge, the fourth chapter is the first study of its kind that develops a theoretical framework to analyze the potential role of informal producers in determining the outcome of trade when informal producers are interlinked with formal ones in the production chain. We develop a two-country 
model of trade with stages of production and segmented labour markets, in which informal and formal producers operate. Similar to the model in the third chapter, labour market frictions provide the rationale for the informal sector. In the model, countries produce a differentiated good which has a continuum of varieties, and each variety is produced using labour and a first-stage intermediate input which is variety-specific, as in Yi (2003). This intermediate input can either be produced by formal or informal producers. All formal goods are traded, whereas inputs produced by informal producers are not traded. In order to quantify the effect of the labour market and trade policies on the pattern of production and welfare of countries, we calibrate our model economy to the Turkish and German economies in 2003. We find that informal producers can determine the comparative advantage of developing countries by providing intermediate inputs at lower costs to formal producers which compete in the global arena. Furthermore, as in the third chapter, this chapter shows that the size of the informal sector of a country is not only determined by its own labour market structure, but also the its trading partners' labour market characteristics. Another contribution of the fourth chapter is that the size of the informal sector is larger under the protectionist economy relative to the liberalized trade.

The plan for this dissertation is as follows. Chapter 2 provides the demographic and employment characteristics of informal workers in the Turkish economy using the descriptive statistics and perform econometric analysis to investigate the likelihood of being informal worker in the Turkish manufacturing industries. Chapter 3 develops a Ricardian model of trade with labour market frictions to examine the effect of informal producers on the pattern of trade as these producers directly compete in the world market. Chapter 4 builds a two-country model of trade with stages of production and segmented labour markets to examine the interlinkage between formal and informal producers in the global supply chain. Chapter 5 concludes this dissertation. 


\section{Chapter 2}

\section{Informal Producers in Turkey}

\subsection{Introduction}

In this chapter, we investigate the employment and demographic characteristics of informal employment in Turkish manufacturing industries which compete in the world market. This chapter differs from the existing literature which only provides the main characteristics of informal workers (Aydin et al. (2010), Tansel and Acar (2014)) and/or suggest different employment policies to combat against informal economies (Elgin and Sezgin (2017), Oviedo et al. (2009)).

The motivation of this chapter is to determine the characteristics of informal workers who may participate in international trade. This chapter goes a step further than the existing literature by examining employment-based characteristics such as employment status of informal workers, the type of manufacturing economic activities and the type of workplace in which informal workers are employed. Our findings in the second chapter inspire the second and the fourth chapters which investigate the role of informal producers in determining the trade structure of developing countries.

As mentioned in the main introduction, developing countries with large informal economies have been participating in international trade. Therefore, the employment and demographic characteristics of producers should be examined first to understand the role of informal workers in a country's economy. However, identifying informality is challenging since it is multifaceted. Informality may have different meanings for policy makers and for researchers, and even among researchers such as sociologists, anthropologists and economists, informality may have a different definition. In the literature, the enterprise-based definition of informality focuses on the size of firms, in this regard, micro and small firms, which employ less than ten workers, are considered informal. In addition, self-employed individuals and unpaid family workers fall into this definition of informality. Another criterion to identify informality is based on the social security registration status of workers. In this definition, workers who are not registered with any social security institution, are considered informal. In our analysis, we use the social security-based definition of informality and we regard individuals as informal if they are not registered with any social security program. This definition is widely used, and it is considered a better metric than 
other measures used to define informal economic activities in Turkey (Tansel and Acar (2014)).

This analysis uses the Turkish Household Labour Force Survey (THLFS), which was conducted by the Turkish Statistical Institute (TurkStat) in 2013 to determine the characteristics of informal workers in Turkish manufacturing industries which have an important contribution in foreign trade. First, we use descriptive statistics to provide information about the demographic and employment characteristics of informal producers, and then we conduct an econometric analysis to determine the likelihood of being informal workers in Turkish manufacturing industries. We use the education level, gender and the marital status as our main demographic characteristics, and the size and type of the firms, and the employment status of individuals as our main employment characteristics. We find that married female individuals with a low education engage in informal home production and, particularly, these individuals operate in textile and clothing production, which has a large contribution to world trade.

Although our general findings are similar to those provided by the existing literature (Aydin et al. (2010), Ercan (2010), Tansel and Acar (2014)), which documents the main characteristics of informal workers in the Turkish economy, our contribution is that we combine the main demographic with employment characteristics of informal workers focusing on the manufacturing sectors that participate in international trade. We find that informal workers are predominantly employed in the Textile and Clothing industry which is an important result since Turkey is one of the biggest exporters of textile and clothing products in the world, as reported by WTO. Therefore, it may be the case that the informal sector is a contributor to international trade. Using the findings in this chapter, we motivate the third and fourth chapters which investigate the role of informal producers in determining the pattern of production, welfare and the trade structure of developing countries.

This chapter is structured as follows: In Section 2, we show our data. In Section 3, we provide the descriptive statistics. In Section 4, we present our econometric analysis, and in Section 5, we conclude. 


\subsection{Data}

In our analysis, we use the Turkish Household Labour Force Survey (THLFS), conducted since 1966 by the Turkish Statistical Institute (TurkStat). With this micro-level data, we study the nature of Turkish informal employment in 2013 using descriptive statistics, and then show the likelihood of a worker being informal based on relevant variables by applying logistic regression. In the survey, 379,742 individuals were given questionnaires related to their employment status, their past work experience, their income and their demographic characteristics. This nation-wide representative survey covers twelve regions in Turkey also collects information on the economic activities of individuals in the agricultural, service, and manufacturing sectors at the 2-digits Statistical Classification of Economic Activities in the European Community (NACE Rev.2). In this study, we use the social-security based definition of informality, which regards producers as informal if they are not registered with any social security program.

Manufacturing industries are one of the main driving forces in the Turkish economy, and their share of the export market is the highest, particularly in the Textile and Clothing and the Automotive sectors (World Trade Organization (2016)). Given that our main interest is in characterizing informality in manufacturing, we restrict our sample to working-age individuals (15-65 and over) employed in manufacturing industries, and this leaves 27,757 people in our sample, of which 21,757 of them are registered (formal), while 5,966 of them are not registered to any social security institution (informal). We choose information related to gender, education, the marital status and position within the household as the relevant demographic characteristics of individuals, and we select employment status, the size of the workplace, the type of the workplace, and types of employment and economic activities as the relevant employment characteristics of individuals. In the original data, the relationship to the reference person in the household is grouped into (i) Reference person, (ii) Spouse, (iii) Child of reference person, (iv) Bride or bridegroom, (v) Grandchild, (vi) Mother/father in law, (vii) Other relatives and (viii) Non-relatives. Most of the observations fall into the first two categories; therefore, we structure this data set into three groups: (i) Head of the household, (ii) Spouse of the reference person and (iii) Relatives that include the rest of the categories in this data set.

The education status of individuals has seven levels in the dataset: (i) Less than five years, (ii) Literate but not completed any educational institution, (iii) Primary school (5 year), (iv) Secondary school, (v) vocational school at secondary school level or primary education (8 year), (vi) High school, (vii) Vocational or technical high school, (viii) Higher education (university, faculty or upper). We combine the first two levels since each category has few observations, and we relabel the education status of individuals as (i) Literate, (ii) Primary school, (iii) Secondary school, (iv) High school, (v) Technical high school and (vi) Higher education.

The marital status of individuals in the data set is given in four categories: (i) Single, (ii) Married, (iii) Divorced and (iv) Widowed. We also regroup the marital status of individuals in the data sets combining Divorced and Widowed individual into one group since each status has few observations. Therefore, we 
use three categories to examine the marital status of individuals: (i) Single, (ii) Married and (iii) Divorced or Widowed.

In the data set, the number of persons employed in the workplace is grouped into: (i) Less than 10, (ii) 10-24, (iii) 25-49, (iv) 50-249, (v) 250-499, (vi) 500 and more. Since there are not sufficient observations in some categories, we regroup these workplaces into four categories. From the definition of small and medium-sized enterprises (SME) used in the European Union (EU), we structure the size of the workplace in four categories: (i) Micro size (less than 10 workers), (ii) Small size (between 10 and 49 workers), (iii) Medium size (between 50 and 249 workers) and (iv) Large size (more than 250 workers).

The type of workplace in which individuals are employed have five categories in the data set: (i) Field / garden, (ii) Regular workplace, (iii) Market place, (iv) Mobile or irregular workplace and (v) At home. We exclude people employed in Field and/or garden and put those working in the market place and irregular place into one category: Mobile or irregular workplace since our main interest is on informal individuals working in a regular place and producing at home. Moreover, excluding service and agricultural sectors leave less observation in these groups; therefore, we redefine the type of the workplace with three categories: (i) Regular workplace, (ii) Mobile workplace and (iii) At Home.

Employment status in the workplace is grouped into (i) Full time and (ii) Part time, and the permanency of jobs is categorized as (i) Permanent and (ii) Temporary. Moreover, the reasons given by individuals, who work temporarily are grouped into (i) Could not find a permanent job, (ii) Did not want a permanent job, (iii) The contract covers training period (trainee or apprentice etc.), (iv) His/her own preference and (v) Other.

Economic activities related to manufacturing that an individual performs are defined by NACE Rev. 2. We divide the manufacturing sector into three sub-sectors: (i) Food-Beverages-Tobacco Products, (ii) Textile-Apparel-Leather Products, and (iii) Other Manufactured Products (which includes sectors such as basic metals, rubber and plastic products, electrical, chemical and furniture). We grouped manufacturing sectors in this way since we want to focus on the textile and clothing sector since it is one of the best-performing sectors in the Turkish economy. In 2015, Turkey was the fifth-biggest exporter of textiles and the seventh-biggest exporter of clothing in the world (World Trade Organization (WTO) Reports World Textile and Apparel Trade in 2015).

The analysis in this chapter is twofold. The first part is descriptive in nature, whereas the second part uses econometric techniques to determine the likelihood of being an informal worker as a function of the characteristics described above. Using both methodologies, we find that some characteristics are strongly associated with higher informal employment. In terms of the demographic characteristics of individuals, informal employment is higher among females, married individuals, and individuals with lower education. Regarding the employment characteristics, informal employment is more likely to be found in micro and small sized firms. Working at home has a very strong relationship with being an informal worker. Moreover, relative to the other manufacturing sectors, the share of informal employment in the production of textiles, apparel, and leather with related products, is large. Once we focus on this 
sector, we observe that a large fraction of the labour force is composed of self-employed married females with low levels of education who work informally from home.

The next two sections present the data analysis. Section 3 provides the descriptive statistics, and section 4 shows uses a logistic regression to determine the likelihood of being an informal worker based on the relevant characteristics.

\subsection{Descriptive Statistics}

In this section, we report general statistics for the demographic and employment characteristics of individuals in the Turkish manufacturing industries.

\subsubsection{Demographic characteristics of individuals}

Demographic characteristics of individuals are given in Table 2.1. In our sample, notice that $75 \%$ of individuals are male; $26 \%, 71 \%$ and $3 \%$ of workers are single, married and divorced or widowed respectively. Moreover, observe that more than half of the workers in our sample do not have high school degrees $(5 \%$ of them have no education, $38 \%$ of them completed primary school and $23 \%$ of them finished secondary school). Considering informality within each gender, it can be observed that women are more likely to work as informal workers: $40 \%$ of females work in the informal sector compared to only $16 \%$ of males. This tendency of women to work in the informal sector also appears in the gender composition of each type of employment, that is, females represent $46 \%$ of informal employment but only $19 \%$ of formal employment. Therefore, informal employment is more prominent among female workers in the Turkish manufacturing industries.

Looking at the marital status of individuals, Table 2.1 shows that $24 \%$ of formal workers are single and and $73 \%$ are married. Only $3 \%$ of all formal workers are divorced or widowed. In the informal sector, $31 \%$ of the individuals are single, $64 \%$ of them are married, and $5 \%$ of them are divorced or widowed. The data shows that informal employment is higher for single individuals, married people have less tendency to participate in the informal sector. Furthermore, the share of informal employment to total employment is $26 \%, 19 \%$ and $33 \%$ in single, married and divorced or widowed individuals respectively.

Observe from Table 2.1 that $3 \%$ of formal workers only know how to read and write, $35 \%$ of formal workers completed primary school, and $22 \%$ of these individuals have a secondary school diploma. Furthermore, $10 \%, 17 \%$ and $13 \%$ of formal workers have high school, technical high school and higher eduction respectively. In the informal sector, the shares more heavily weighted towards lower education: $13 \%$ of workers do not have any education, $44 \%$ have primary school degree, and $29 \%$ have a secondary school diploma. Moreover, $56 \%$ of literate individuals, $25 \%$ of individuals who have only primary education, and $26 \%$ of individuals with secondary education have informal employment. As education level increases, the share of informal employment declines: $15 \%$ of individuals have high school degrees, $8 \%$ of them have technical high school, and only $5 \%$ of them have higher education. 


\section{Gender}

Male

Female
$81 \%$

$19 \%$

Married

$73 \%$

$64 \%$

$19 \%$

$71 \%$

Divorced or widowed

$5 \%$

$13 \%$

$44 \%$

$29 \%$

$6 \%$

$6 \%$

$2 \%$

$33 \%$

$3 \%$

\section{Education}

\begin{tabular}{lcccc} 
Literate & $3 \%$ & $13 \%$ & $56 \%$ & $5 \%$ \\
Primary school & $35 \%$ & $44 \%$ & $25 \%$ & $38 \%$ \\
Secondary school & $22 \%$ & $29 \%$ & $26 \%$ & $23 \%$ \\
High school & $10 \%$ & $6 \%$ & $15 \%$ & $9 \%$ \\
Technical high school & $17 \%$ & $6 \%$ & $8 \%$ & $14 \%$ \\
Higher education & $13 \%$ & $2 \%$ & $5 \%$ & $11 \%$ \\
\hline
\end{tabular}

Table 2.1: Demographic characteristics of individuals Source: Turkish Household Labour Survey (2013)

In summary, the data show that female workers have a higher tendency to be involved in informal employment. Male employment is four times higher than female employment in the formal sector, whereas male employment is slightly higher than female employment in the informal sector. Within each gender, most males are employed in the formal sector and female informal employment is considerably high. Our findings are consistent with the literature which documents higher informal employment among women in developing countries (Steel and Snodgrass (2008), Adams, de Silva, and Razmara, (2013) and Chen et al. (2007)).

Higher married female participation in the informal sector may be a result of the fact that they can not find a job in the formal sector due to a lack of open vacancies or occupational discrimination. Moreover, domestic responsibilities that burden women may be the other reason for them to choose informal employment, as they are not considered to be breadwinners, but they are considered to be homemakers or mothers. The data suggest that most married individuals are employed in the formal sector; however, the share of informal employment is higher in married individuals relative to single and divorced or widowed workers. It may be the case that informal employment can be a secondary option for those whose partners are employed in the formal sector. From the data, we notice that informal employment decreases as the level of education of individuals increases, and this is not a surprising result since informal economic activities are mostly labour intensive. Furthermore, lower education and informality in each gender has a strong relationship. The higher education that individuals attain, the lower informal economic activity they engage in. 


\subsubsection{Employment characteristics of individuals}

Table 2.2. reports the employment status of individuals in the formal and informal sector. In our sample, regular employees constitute $85 \%$ share of total employment, while the share of total employment in employers, self-employed individuals and unpaid-family workers are $5 \%, 8 \%$ and $2 \%$ respectively. Regarding workplace, $30 \%$ are micro firms in which less than 10 workers are employed, and $25 \%$ of them are small size enterprises. Moreover, $26 \%$ of the workplaces are medium firms and $19 \%$ of them are large size firms. Notice that $93 \%$ of workers are employed in a regular workplace, and $6 \%$ of them work at home. Finally, in our sample, $93 \%$ of employment is full time and $95 \%$ of total employment is permanent. In the formal sector, $90.5 \%$ of individuals are regular employees, $6 \%$ of them are employers, $3 \%$ of them are self-employed and only .5\% are unpaid-family workers. Furthermore, in the informal sector, $64 \%, 27 \%, 3.5 \%$ and $5.5 \%$ of them are regular employees, employers, self-employed individuals, and unpaid-family workers respectively. Notice that regular employees have the highest share both in the formal and informal sector, and self-employed and unpaid-family workers have the lower share in the formal sector. Examining each category of employment status, notice that regular employees represent $16 \%$ of informal employment, while $14 \%$ of employers work in the informal sector. Self employed and unpaid family workers tend to engage in more informal economic activities relative to regular employees and employers. The share of informal employment among self-employed individuals and those who work in family businesses without pay are $72 \%$ and $76 \%$ respectively.

In the formal sector, $19 \%$ and $27 \%$ of the workplaces are micro sized and small sized enterprises respectively, whereas $31 \%$ of them are medium firms and $23 \%$ of them large sized firms. In the informal sector, $71 \%$ of employment occurs in the micro sized firms while $20 \%$ of it take places in small sized enterprises. In addition, only $7 \%$ and $2 \%$ of informal employment occurs in medium sized and large sized firms respectively. As reported in the literature, informal employment is strongly associated with micro and small sized enterprises. Furthermore, $51 \%$ of micro sized firms perform informal economic activities while $17 \%$ of small sized firms operate in the informal sector. $5 \%$ of medium sized firms and $2 \%$ of large firms operate in the informal sector.

Considering the type of workplace, regular workplace has the highest share of formal employment. Moreover, $71 \%, 1 \%$ and $28 \%$ of informal employment occurs in regular workplaces, mobile workplace and at home respectively. Examining each category of the workplace, $16 \%$ of regular workplace, $81 \%$ of mobile workplace and $99 \%$ of home production performed informal economic activities. Notice that individuals, who work in the mobile workplace and at home, have a large share of informality. Moreover, regular employees have the highest proportion in the informal sector.

In terms of the employment types, $99 \%$ of formal employment and $72 \%$ of informal employment is full time. In addition, $88 \%$ of informal employment in total employment is part-time. For the permanency of the employment, $98 \%$ of formal workers are permanent. In the informal sector, $79 \%$ of workers are permanent, and $21 \%$ of them are temporary workers. Moreover, the share of informal employment to 
total employment is $65 \%$ among temporary workers.

\begin{tabular}{|c|c|c|c|c|}
\hline & $\frac{\text { Formal }}{\text { Total Formal }}$ & $\frac{\text { Informal }}{\text { Total Informal }}$ & $\frac{\text { Informal }}{\text { Formal+ Informal }}$ & Total \\
\hline \multicolumn{5}{|l|}{ Employment Status } \\
\hline Regular employees & $90.5 \%$ & $64 \%$ & $16 \%$ & $85 \%$ \\
\hline Employers & $6 \%$ & $3.5 \%$ & $14 \%$ & $5 \%$ \\
\hline Self-employed & $3 \%$ & $27 \%$ & $72 \%$ & $8 \%$ \\
\hline Unpaid-family workers & $0.5 \%$ & $5.5 \%$ & $76 \%$ & $2 \%$ \\
\hline \multicolumn{5}{|l|}{ The firm size } \\
\hline Micro size & $19 \%$ & $71 \%$ & $51 \%$ & $30 \%$ \\
\hline Small size & $27 \%$ & $20 \%$ & $17 \%$ & $25 \%$ \\
\hline Medium size & $31 \%$ & $7 \%$ & $5 \%$ & $26 \%$ \\
\hline Large size & $23 \%$ & $2 \%$ & $2 \%$ & $19 \%$ \\
\hline \multicolumn{5}{|l|}{ Type of Workplace } \\
\hline Regular workplace & $100 \%$ & $71 \%$ & $16 \%$ & $93 \%$ \\
\hline Mobile workplace & $0 \%$ & $1 \%$ & $81 \%$ & $1 \%$ \\
\hline At Home & $0 \%$ & $28 \%$ & $99 \%$ & $6 \%$ \\
\hline \multicolumn{5}{|l|}{ Employment Type } \\
\hline Full time & $99 \%$ & $72 \%$ & $17 \%$ & $93 \%$ \\
\hline Part time & $1 \%$ & $28 \%$ & $88 \%$ & $7 \%$ \\
\hline \multicolumn{5}{|c|}{ Permanency of the job } \\
\hline Permanent & $98 \%$ & $79 \%$ & $14 \%$ & $95 \%$ \\
\hline Temporary & $2 \%$ & $21 \%$ & $65 \%$ & $5 \%$ \\
\hline
\end{tabular}

Table 2.2: Employment characteristics of individuals Source: Turkish Household Labour Survey (2013)

The data suggest that regular employees have a higher share of employment than other workers with different employment status in both the formal and the informal sector. Regular informal workers may be those who are outsourced by the formal firms, and they are part of the formal production. Furthermore, it is noticeable that self-employed and unpaid family workers have a higher share of informal economic activities, and informal employment in these groups is approximately three times bigger than formal employment. This result is parallel to what the existent literature documents ( Ercan (2010), Bargain et al (2012), Maloney, (2004), Becker (2004), Haan (2006)). As expected based on the enterprise definition of informality, we observe that informal employment declines as the firm size increases, and the share of informal employment in micro-sized and small enterprises is higher than those which employ more than 50 workers. Moreover, the informal employment is the highest in micro-sized firms which employ 10 or less individuals. Since informal employment is noticeable as the firm size increases, it is the case that informal 
employment is crowded in smaller sized firms. All formal employment take place in regular workplaces. Furthermore, all home production occur in the informal sector and this finding is consistent with the existing literature: Sinha, Shalini. (2013), Govindan and Vanek (2013), Martha (2014), Marilyn et al. (2000) and Manjul (1999). Both the formal and the informal sector have higher full-time workers than part-time workers. Most part-time workers are informal, and most formal employment is permanent in nature. Among temporary workers, informal employment is almost two times bigger than formal employment, and it may result from the fact that firms can effortlessly hire or fire temporary workers. In what follows, we report the reasons for working temporarily in the formal and informal sectors in Table 2.3. Observe that $66 \%$ of these individuals look for a permanent job, but are not able to find one, whereas $14 \%$ of these individuals do not want a permanent job, and for $14 \%$ of them the contract covers a training period. In the formal sector, $64 \%$ of individuals want to have a permanent job, $5 \%$ do not want to work permanently, $26 \%$ have the contracts, $2 \%$ prefer temporary work and $3 \%$ have different reasons. In the informal sector, $67 \%$ of temporary workers wish to have a permanent position, and $20 \%$ of temporary workers do not want to have a permanent job. In addition, $8 \%$ of informal workers have contract and $5 \%$ of them have other reasons to work temporarily. Examining each category, from all temporary workers who would rather work permanently, $66 \%$ of them are employed in the informal sector. From those who prefer to remain as temporary workers, $87 \%$ of them work in the informal sector. Moreover, $35 \%$ of these informal workers have contract and $25 \%$ of them prefer to have temporary employment.

\begin{tabular}{|c|c|c|c|c|}
\hline & $\frac{\text { Formal }}{\text { Total Formal }}$ & $\frac{\text { Informal }}{\text { Total Informal }}$ & $\frac{\text { Informal }}{\text { Formal+ Informal }}$ & Total \\
\hline \multicolumn{5}{|l|}{ Reasons for work temporary } \\
\hline Could not find a permanent job & $64 \%$ & $67 \%$ & $66 \%$ & $66 \%$ \\
\hline Did not want a permanent job & $5 \%$ & $20 \%$ & $87 \%$ & $14 \%$ \\
\hline The contract covers training period & $26 \%$ & $8 \%$ & $35 \%$ & $14 \%$ \\
\hline His/her own preference & $2 \%$ & $0 \%$ & $25 \%$ & $1 \%$ \\
\hline Other & $3 \%$ & $5 \%$ & $75 \%$ & $5 \%$ \\
\hline
\end{tabular}

Table 2.3: Reasons for working temporarily Source: Turkish Household Labour Survey (2013)

It is noticeable that most of those, who are happy to remain as temporary workers, are employed in the informal sector. These informal may want to have more flexible employment relative to those working permanently.

Furthermore, Table 2.4 presents economic activities in manufacturing sectors with formal and informal sectors. In our sample, $15 \%$ and $32 \%$ of total informal employment in manufacturing occur in Food-Beverage-Tobacco and Other Manufacturing sectors respectively. Besides this, 53\% of informal employment takes place in the Textile and Clothing sectors. In the formal sector, the Food-Beverage-Tobacco sectors have lower share of employment (15\%) than the Textile and Clothing 
sectors (26\%), and the Other Manufacturing sectors have the highest share of employment (59\%). In the informal sector, $15 \%$ of employment is in the Food-Beverages-Tobacco sectors, $54 \%$ of employment is in the Textile and Clothing sectors and $31 \%$ of employment in the Other Manufacturing sectors. Notice that textile and clothing production has the highest proportion of informal employment. Furthermore, in each manufacturing category, the Food-Beverages-Tobacco sectors have $22 \%$ of the informal employment. In Textile and Clothing sectors, $36 \%$ of individuals work informally and in Other Manufacturing sectors, $13 \%$ of workers are informal.

\begin{tabular}{lcccc} 
& $\frac{\text { Formal }}{\text { Total Formal }}$ & $\frac{\text { Informal }}{\text { Total Informal }}$ & Formal+ Informal & Total \\
\hline Employment activity & & & & \\
Food-Beverages-Tobacco Products & $15 \%$ & $15 \%$ & $22 \%$ & $15 \%$ \\
Textile and Clothing Products & $26 \%$ & $54 \%$ & $36 \%$ & $32 \%$ \\
Other Manufacturing Products & $59 \%$ & $31 \%$ & $13 \%$ & $53 \%$ \\
\hline
\end{tabular}

Table 2.4: Manufacturing industries Source: Turkish Household Labour Survey (2013)

Therefore, informal producers have a higher share in the Textile and Clothing sectors relative to the Food-Beverage-Tobacco and the Other Manufacturing sectors. This is a very interesting result since Turkey is one of the leading exporter of textile and clothing products in the world (WTO (2016)). Therefore, it is worthwhile to conduct further research to determine through which channels informal producers influence the outcome of trade in the Textile and Clothing sectors.

Finding large informality in the Textile and Clothing sectors leads us to investigate who engages in informal economic activities in Turkish manufacturing industries, and how informal workers participate in manufacturing production.

\subsubsection{The demographic and employment characteristics of informal workers}

In this subsection, we restrict the sample to informal workers and examine their demographic and employment characteristics with their economic activities.

Table 2.5 shows the employment characteristics of informal workers and their economic activities in manufacturing sectors. Observe that $17 \%$ of regular employees work in the Food-Beverages-Tobacco sectors, $48 \%$ of them are employed in the Textile and Clothing sectors and $35 \%$ of them work in the Other Manufacturing sectors. Furthermore, the Food-Beverages-Tobacco sectors have slightly higher informal employers than the Textile and Clothing sectors" $25 \%$ and $24 \%$ respectively, and the share of informal employers in Other Manufacturing sector is 51\%. Furthermore, $6 \%$ and $77 \%$ of self-employed individuals work in the Food-Beverages-Tobacco and the Textile and Clothing sectors and $17 \%$ of them work in the Other Manufacturing sectors. Finally, 32\%, $28 \%$ and $40 \%$ of unpaid-family workers are 
employed in the Food-Beverages-Tobacco, the Textile and the Clothing and Other Manufacturing sectors respectively.

Regular employees Employers Self-employed Unpaid-family

\begin{tabular}{lcccc}
\hline The employment status & & & & \\
Food-Beverages-Tobacco Products & $17 \%$ & $25 \%$ & $6 \%$ & $32 \%$ \\
Textile and Clothing Products & $48 \%$ & $24 \%$ & $77 \%$ & $28 \%$ \\
Other Manufacturing Products & $35 \%$ & $51 \%$ & $17 \%$ & $40 \%$ \\
\hline
\end{tabular}

Table 2.5: The employment status of informal workers

Source: Turkish Household Labour Survey (2013)

Using the data, observe that the Textile and Clothing sectors have the highest share of regular informal employees relative to the rest of the manufacturing sectors. These individuals may perform informal economic activities on a regular base in the formal sector, but they are not registered in any social security institutions. Moreover, informal employers have the highest share in the Other Manufacturing sectors than the Food-Beverages-Tobacco and the Textile and Clothing sectors. It turn out that the Textile and Clothing sectors has more self-employed informal workers than the rest of the manufacturing sectors. Focusing on the Textile and Clothing sectors, employers and self-employed individuals may be subcontract producers supplying intermediate goods to formal producers in the production chain, or these producers may produce informal goods, such as second hand or counterfeit goods for different markets. Furthermore, Table 2.6. presents manufacturing economic activities, and the types of workplaces in which informal producers operate. Notice that $19 \%$ and $40 \%$ of regular workplaces engage in informal economic activities in the Food-Beverages-Tobacco and the Textile and Clothing sectors respectively, whereas $41 \%$ of these work places operate in the Other Manufacturing sectors. $29 \%$ and $71 \%$ of mobile workplaces operate in the Food-Beverages-Tobacco sectors and the Other Manufacturing sectors respectively. Furthermore, $6 \%$ of home production takes place in Food-Beverages-Tobacco and in the Other Manufacturing sectors. Importantly, $88 \%$ of home production occurs in the Textile and Clothing sector.

\section{Regular workplace Mobile workplace At Home}

\section{Economic Activity}

Food-Beverages-Tobacco Products

$19 \%$

$29 \%$

$6 \%$

Textile and Clothing Products

$40 \%$

$0 \%$

$88 \%$

Other Manufacturing Products

$41 \%$

$71 \%$

$6 \%$

Table 2.6: The employment status of informal workers

Source: Turkish Household Labour Survey (2013) 
It turns out that most informal home producers operate in the Textile and Clothing sectors. This result may suggest that formal producers in this sector outsource some parts of the production to home producers.

Table 2.7 presents manufacturing sectors considering gender differences. Notice that $18 \%$ and $32 \%$ of male workers are employed in the Food-Beverages-Tobacco and the Textile and Clothing sectors respectively, and $50 \%$ of them work in the Other manufacturing sectors. Moreover, $12 \%$ and $79 \%$ of females work in the Food-Beverages-Tobacco and the Textile and Clothing sectors respectively, and $36 \%$ of them are employed in the Other Manufacturing sectors.

Male Female

\begin{tabular}{lll}
\hline Economic Activity & & \\
Food-Beverages-Tobacco Products & $18 \%$ & $12 \%$ \\
Textile and Clothing Products & $32 \%$ & $79 \%$ \\
Other Manufacturing Product & $50 \%$ & $9 \%$ \\
\hline
\end{tabular}

Table 2.7: Gender of informal workers

Source: Turkish Household Labour Survey (2013)

Female informal employment is higher in the Textile and Clothing sectors relative to the Other Manufacturing sectors. This finding is consistent with the existent literature which documents high female participation in the informal sector in the textile and clothing production.

Furthermore, in Table 2.8., we look at informal employment in manufacturing sectors considering married informal workers with gender differences. Notice that $19 \%$ of married-males are employed in the Food-Beverages-Tobacco sectors and in the Textile and Clothing sectors, and $50 \%$ of married-males are employed in the Other Manufacturing sectors. $12 \%$ and $80 \%$ of married females are employed in the Food-Beverages-Tobacco and the Textile and Clothing sectors, while $8 \%$ of them work in the Other manufacturing sectors.

Male Female

\begin{tabular}{lll}
\hline Economic Activity & & \\
Food-Beverages-Tobacco Products & $19 \%$ & $12 \%$ \\
Textile and Clothing Products & $19 \%$ & $80 \%$ \\
Other Manufacturing Products & $50 \%$ & $8 \%$ \\
\hline
\end{tabular}

Table 2.8: Married informal workers with their gender status Source: Turkish Household Labour Survey (2013)

The share of informal employment in Textile and Clothing sectors is more pronounced for female married workers relative to male married workers. It may be a result of the fact that female-married individuals, 
whose spouse have formal employment, perform informal economic activities to support the family. These individuals can be self-employed or unpaid family workers. Moreover, they may be serving the Textile and Clothing sectors by working from home.

In what follows, we report informal economic activities performed at home by married individuals with gender status in Table 2.9. Notice that $39 \%, 36 \%$ and $25 \%$ of married male home producers operate in the Food-Beverages-Tobacco, The Textile and Clothing and the Other manufacturing sectors respectively. Moreover, $6 \%, 89 \%$ and $5 \%$ of married-female workers are home producers in the Food-Beverages-Tobacco, the Textile and Clothing and the Other manufacturing sectors respectively.

Male Female

\begin{tabular}{lll}
\hline Economic Activity & & \\
Food-Beverages-Tobacco Products & $39 \%$ & $6 \%$ \\
Textile and Clothing Products & $36 \%$ & $89 \%$ \\
Other Manufacturing Products & $25 \%$ & $5 \%$ \\
\hline
\end{tabular}

Table 2.9: Married home producers with their gender status Source: Turkish Household Labour Survey (2013)

Therefore, the data suggests that married female individuals engage in higher informal home production relative to married males in the Textile and Clothing sectors.

Table 2.10. presents informal female workers and their relationship with the head of the household, these workers perform home production in the manufacturing sectors. Observe that $6 \%, 85 \%$ and $9 \%$ of head of the households operate in the Food-Beverages-Tobacco, the Textile and Clothing and the Other manufacturing sectors respectively. Moreover, $5 \%$ of spouse of the reference person are employed in the Food-Beverages-Tobacco and the Other Manufacturing sectors sectors, while 90\% of them are employed in the Textile and Clothing sectors. Moreover, $10 \%$ of relatives are employed in the the Food-Beverages-Tobacco, $81 \%$ of them work in the Textile and Clothing sectors, and $9 \%$ of them are employed in the Other Manufacturing sectors.

Head of the household Spouse of the reference person Relatives

\begin{tabular}{lccc}
\hline Economic Activity & & & \\
Food-Beverages-Tobacco Products & $6 \%$ & $5 \%$ & $10 \%$ \\
Textile and Clothing Products & $85 \%$ & $90 \%$ & $81 \%$ \\
Other Manufacturing Products & $9 \%$ & $5 \%$ & $9 \%$ \\
\hline
\end{tabular}

Table 2.10: Female home producers and their status in the household

Source: Turkish Household Labour Survey (2013) 
Therefore, in the Textile and Clothing sectors, informal home production is performed mostly by females who are both spouse of the main earner and the head of the household.

In summary, informal employment is higher in the Textile and Clothing sector relative to the Food-Beverages-Tobacco and Other Manufacturing sectors. In these sectors, married female workers have the higher share of informal employment relative to male workers, and these individuals are mostly self-employed. Moreover, informal economies are strongly associated with home production which is mostly performed by female workers

\subsection{Likelihood of informality}

In this section, we use econometric techniques to examine the likelihood of working in the informal sector given explanatory variables related to the demographic and employment characteristics of households in Turkey. In our model, being informal (based on the social-security definition) is the dependent variable, and the selected the demographic and employment characteristics of individuals are used as explanatory variables. In our model, we assume that the probability of being an informal worker, conditional on workers demographic and employment characteristics given that response variable, $y_{i}$ is binary:

$$
y= \begin{cases}1, & \text { if if the respondent is informal worker } \\ 0, & \text { if if the respondent is formal worker }\end{cases}
$$

where $y$ is the observed value of a random variable $Y$ which can take only two potential outcomes: one with probability $p$, and zero with probability $1-p$. From here, the odds of respondent to be informal worker is given by:

$$
\text { odds }=\frac{p}{1-p}
$$

Assume further that the logit of the probability $p$ is a linear function of the explanatory variables:

$$
\log \left(\frac{p}{1-p}\right)=\beta \boldsymbol{X}
$$

where $\boldsymbol{X}$ is the vector which indicates the explanatory variables. The explanatory variables related to the demographic and employment characteristics of individuals are as follows: the level of education (Educ), gender (Gen), marital status (Mart), the type of the workplace (Type), the size of the workplace (Size), the status of the employment (Stat) and economic activities in manufacturing sector (Manu). Moreover, $\beta$ is the vector defining the coefficients of the independent variables in the regression. 
Equation 2.1 in extended form is:

$$
\log \left(\frac{p}{1-p}\right)=\beta_{\mathbf{0}}+\boldsymbol{\beta}_{\mathbf{1}}(\text { Educ })+\boldsymbol{\beta}_{\mathbf{2}}(\text { Gen })+\boldsymbol{\beta}_{\mathbf{3}}(\text { Mart })+\boldsymbol{\beta}_{\mathbf{4}}(\text { Type })+\boldsymbol{\beta}_{\mathbf{5}}(\text { Size })+\boldsymbol{\beta}_{\mathbf{6}}(\text { Stat })+\boldsymbol{\beta}_{\mathbf{7}}(\text { Manu })
$$

Table 2.11 shows the results of the logistic regression:

\begin{tabular}{lccccr} 
Informality & Coef. & Std. Error & z & p $>$ z & $95 \%$ Conf. Interval \\
\hline Constant & 1.165 & 0.089 & 13.01 & 0.000 & 0.9891 .340
\end{tabular}

\section{Gender}

Female

$0.271 \quad 0.050$

\section{Marital Status}

Married

Divorced or widowed

$$
-0.858
$$

0.047

$-0.435$

0.110

\section{Education}

Primary school

Secondary school

$-0.970$

0.007

$-0.829$

0.077

High school

$-1.468$

0.100

Technical high school

$-1.651$

0.099

Higher education

$-2.183$

0.121

Employers

$-0.698 \quad 0.084$

$0.212 \quad 0.075$

Unpaid-family workers

1.524

0.129

The firm size

Micro size

$\begin{array}{ll}0.421 & 0.008 \\ 0.172 & 0.005 \\ 0.053 & 0.002 \\ 0.028 & 0.003\end{array}$

$0.107 \quad 0.002$

0.488

0.103

0.910

0.020

At Home

Manufacturing

Textile and Clothing

$0.403 \quad 0.057$

$-0.338$

0.055

Other Manufacturing
Self-employed

$$
\begin{array}{llll}
-18.14 & 0.000 & -0.951 & -0.765 \\
-3.95 & 0.000 & -0.651 & -0.219
\end{array}
$$

$$
\begin{array}{rrr}
-12.53 & 0.000 & -1.122-0.818 \\
-10.66 & 0.000 & -0.981-0.676 \\
-14.65 & 0.000 & -1.665-1.272 \\
-16.52 & 0.000 & -1.847-1.455 \\
-18.01 & 0.000 & -2.421-1.946 \\
-8.27 & 0.000 & -0.863-0.532 \\
2.81 & 0.005 & 0.0640 .360 \\
11.82 & 0.000 & 1.2721 .777
\end{array}
$$

$51.18 \quad 0.000$

0.4050 .438

$30.57 \quad 0.000$

0.1610 .183

$19.65 \quad 0.000$

0.0480 .059

$\begin{array}{ll}7.68 & 0.000\end{array}$

0.0210 .036
0.1020 .370

0.2860 .691

$\begin{array}{llll}45.38 & 0.000 & 0.871 & 0.949\end{array}$

Number of obs. $=27,448$, LR $\chi^{2}(18)=11204.41$, Prob. $>\chi^{2}=0.000$, Pseudo $R^{2}=0.389$ 
Since coefficients in the logistic regression are difficult to interpret, we provide predicted probabilities to examine the likelihood of there being informal workers at different levels of the demographic and employment characteristics of individuals. We transform odds ratios to a simple probability using our logistic regression, which is given in equation 2.1, and obtain:

$$
p=\frac{e^{\boldsymbol{\beta} \boldsymbol{X}}}{1+e^{\boldsymbol{\beta} \boldsymbol{X}}} \text { for } 0 \leq p \leq 1
$$

In Table 2.12, we report the probability of working in the informal sector as all independent variables are set to their mean values. Observe that the likelihood of being an informal worker is approximately $14 \%$. The likelihood of being informal is slightly higher for female workers $(16 \%)$ than for male workers (13\%), and the likelihood of being informal is higher for single workers $(22 \%)$ than for married $(16 \%)$ or for divorced/widowed workers $(11 \%)$. Furthermore, the likelihood of working in the informal sector decreases as individuals attain higher education: workers having higher education have only $5 \%$ chance to be employed in the informal sector, whereas individuals, without any education have a $33 \%$ of probability to work in the informal sector. The probability of working in the informal sector is $16 \%$ for individuals who have primary school degree, and $18 \%$ for those who have secondary school degree.

Pred. Prob. $\quad$ Std. Error z $\quad$ p $>$ z $95 \%$ Conf. Interval

\begin{tabular}{lccccc}
\hline Constant & 0.138 & 0.003 & 38.15 & 0.000 & 0.1300 .145 \\
Gender & & & & & \\
Male & 0.130 & 0.003 & 34.18 & 0.000 & 0.1220 .137 \\
Female & 0.164 & 0.006 & 25.37 & 0.000 & 0.1300 .145
\end{tabular}

Marital Status

Single

Married

Divorced or widowed

\section{Education}

Literate

0.338

0.162

0.0165

Primary school

Secondary school

0.182

0.105

0.089

0.054

Technical high school

Higher education
0.005

0.006

0.007

0.005

30.46

32.29

11.25

20.41

30.63

28.15

14.81

15.08

0.005

10.46
0.000

0.2150 .244

0.000

0.1050 .119

0.000

0.1330 .190

0.000

0.3050 .370

Table 2.12: Predicted probabilities with the demographic characteristics of individuals 
Furthermore, Table 2.13 reports the predicted probabilities of being informal as a function of the employment characteristic of individuals. Regarding occupation status, unpaid family workers and self-employed people are more likely to be informal. In particular, the likelihood of being informal is $42 \%$ for unpaid family workers, $16 \%$ for self-employed individuals, and $13 \%$ for those who work as regular employees. Furthermore, the probability of informal employment in a regular workplace is $10 \%$, whereas the likelihood of being informal for an individual who works at home is $91 \%$. Our results also indicate that the size of the firm where an individual works matters for informality. The likelihood of working informally is $42 \%$ for workers employed in micro enterprises, $17 \%$ for those employed in small enterprises and $5 \%$ for those in medium enterprises. That is, the likelihood of informal employment declines as the size of the firm increases. Finally, in terms of industries, the likelihood of informal employment in the Textile and Clothing sectors is $20 \%$, while the probability of being informal is $20 \%$ and $10 \%$ in the Food-Beverage-Tobacco and the Other Manufacturing sectors respectively.

Pred. Prob. Std. Error $\quad$ z $\quad$ p $>$ z $\quad 95 \%$ Conf. Interval

\section{Employment Status}

\begin{tabular}{|c|c|c|c|c|c|}
\hline Regular employees & 0.137 & 0.003 & 36.66 & 0.000 & 0.1300 .145 \\
\hline Employers & 0.073 & 0.005 & 12.67 & 0.000 & 0.0620 .085 \\
\hline Self-employed & 0.165 & 0.010 & 16.09 & 0.000 & 0.1440 .185 \\
\hline Unpaid-family workers & 0.423 & 0.031 & 13.31 & 0.000 & 0.3610 .485 \\
\hline
\end{tabular}

The firm size

$\begin{array}{lllccc}\text { Micro size } & 0.421 & 0.008 & 51.18 & 0.000 & 0.4050 .438 \\ \text { Small size } & 0.172 & 0.005 & 30.57 & 0.000 & 0.1610 .183 \\ \text { Medium size } & 0.053 & 0.002 & 19.65 & 0.000 & 0.0480 .059 \\ \text { Large size } & 0.028 & 0.003 & 7.68 & 0.000 & 0.0210 .036\end{array}$

\section{Type of Workplace}

$\begin{array}{lccccc}\text { Regular workplace } & 0.107 & 0.002 & 41.59 & 0.000 & 0.1020 .370 \\ \text { Mobile workplace } & 0.488 & 0.103 & 4.73 & 0.000 & 0.2860 .691 \\ \text { At Home } & 0.910 & 0.020 & 45.38 & 0.000 & 0.8710 .949\end{array}$

\section{Manufacturing}

\begin{tabular}{llllll} 
Food-Beverage-Tobacco & 0.143 & 0.006 & 22.08 & 0.000 & 0.1310 .156 \\
Textile and Clothing & 0.201 & 0.006 & 31.71 & 0.000 & 0.1310 .156 \\
Other Manufacturing & 0.106 & 0.003 & 29.42 & 0.000 & 0.1310 .156 \\
\hline
\end{tabular}

Table 2.13: Predicted probabilities with the employment characteristics of individuals

Our previous results show that some of the independent variables in our model have a stronger relationship with informal employment: individuals with lower education, married and female workers are more likely to work in the informal sector. Furthermore, informal economic activities are more likely to occur in 
micro and small size firms, and the probability of informal employment is higher for those who work at home relative to employees who work in a regular workplace. Among our three aggregate manufacturing sectors, the probability of being informal is higher in the Textile and Clothing sector. Observe that the likelihood of informal employment in the Textile and Clothing sectors is $20 \%$ when that all explanatory variables are set at their mean values.

Since the Textile and Clothing is one of the strongest sector in the Turkish economy, we focus on the characteristics of informal workers in this sector. In Table 2.14, we explore informal employment in the Textile and Clothing sectors in more detail. Notice that only for female workers, the likelihood of being informal increases to $23 \%$. Then, for female workers with primary school education, the probability of informal employment of female workers goes up to $27 \%$. Moreover, if these female workers are self-employed, the likelihood of being informal worker increases to $68 \%$. Finally, the probability of being informal worker increases to $96 \%$ as we these workers engage in home production.

\begin{tabular}{lccccc} 
& Pred. Prob. & Std. Error & $\mathrm{z}$ & $\mathrm{p}>\mathrm{z}$ & $95 \%$ Conf. Interval \\
\hline Manufacturing of textile and clothing & 0.201 & 0.006 & 31.71 & 0.000 & 0.1880 .213 \\
Female & 0.235 & 0.008 & 27.27 & 0.000 & 0.2180 .252 \\
Female with primary school & 0.271 & 0.010 & 25.99 & 0.000 & 0.2510 .291 \\
Self-empl.female with primary school & 0.689 & 0.089 & 7.74 & 0.000 & 0.5150 .864 \\
Self-empl.female with primary school work at home & 0.960 & 0.009 & 103.75 & 0.000 & 0.9420 .978 \\
\hline
\end{tabular}

Table 2.14: Predicted Probabilities

In conclusion, in the Textile and Clothing sectors, the likelihood of being informal is very high for married female self-employed individuals which engage in home production.

This chapter has an important contribution to the existing literature. It provides the demographic and employment characteristics of informal producers in textile and clothing production. Since Turkey is one of the leading exporters of textile and clothing products, our results suggest that it is important to investigate the role of informal producers in shaping Turkeys comparative advantage in the textile and clothing industry. Based on our findings in this chapter, we develop chapter III and IV to examine through which mechanism informal producers influence the pattern of trade and welfare of countries. 


\subsection{Conclusion}

This chapter examines the employment and demographic characteristics of informal employment in Turkish manufacturing industries which potentially participate in foreign trade. This chapter differs from the existing literature which reports the size of the informal sector in the Turkish economy and/or advises labour market policies to reduce the size of the informal sector in Turkey.

In this chapter, we aim to have a better understanding of the employment and demographic characteristics of informal workers who may participate in international trade. Our findings in the second chapter motivate the second and the fourth chapters which explore the effect of informal producers on the trade structure and the welfare of developing countries.

As mentioned in the main introduction, developing countries have been participating in international trade, and their share of exports has grown significantly since the 1990s. Therefore, informal producers may influence the trade outcomes of developing countries. In order to identify informality, we use the social security-based definition of informality and we consider individuals as informal if they do not have registration in any social security program.

We use the Turkish Household Labour Force Survey (THLFS), which was carried out by the Turkish Statistical Institute (TurkStat) in 2013. Focusing on the manufacturing industries in Turkey, we report the employment and the demographic characteristics of informal workers who may have contribution to foreign trade. This chapter has two parts: the first part is descriptive in nature, and it aims to provide information about the demographic and employment characteristics of informal producers, and the second part performs econometric analysis to determine the likelihood of there being informal workers in Turkish manufacturing industries. In our analysis, we find that married female individuals with a low education engage in informal home production activities. In particular, these informal workers are employed in textile and clothing production which has an important contribution in foreign trade. Our findings in this chapter motivate the third and fourth chapters which study the role of informal producers in determining the trade structure of developing countries. 


\section{Chapter 3}

\section{Informal trade}

\subsection{Introduction}

This chapter complements the trade literature with flexible labour markets by arguing that developing countries with high labour market frictions can still benefit from international trade through their informal economies. It explores the effects of informal producers on the pattern of production and the welfare of countries and it studies how informal producers can influence the trade structure of developing countries in the extent to which they directly export their product to the world market. In this chapter, we develop a Ricardian model of trade with labour market frictions. The frictions create dual labour markets in which formal and informal producers operate. The existence of labour market frictions, which are introduced in a same manner in Helpman and Itskhoki (2010), are the rational for the presence of informal producers in our model ${ }^{1}$.

Figure 3.1 shows that there exists a positive relationship between labour market rigidities and informality. This figure plots the labour market rigidity index which is a combination of hiring costs, firing costs and the cost of increasing hours worked in Botero et al. (2004) against the size of the informal economy as a percentage of GDP for 84 countries in Schneider and Enste (2000).

\footnotetext{
${ }^{1}$ Informal economies can be resulted from high employment taxes as in Tansit and Kan (2012) and Levy (2008), difficulties to access capital as in Gibson and Kelly (1994) or the lack of property rights as in De Soto (1989). In our analysis, the presence of informal economies is derived from labour market related issues.
} 


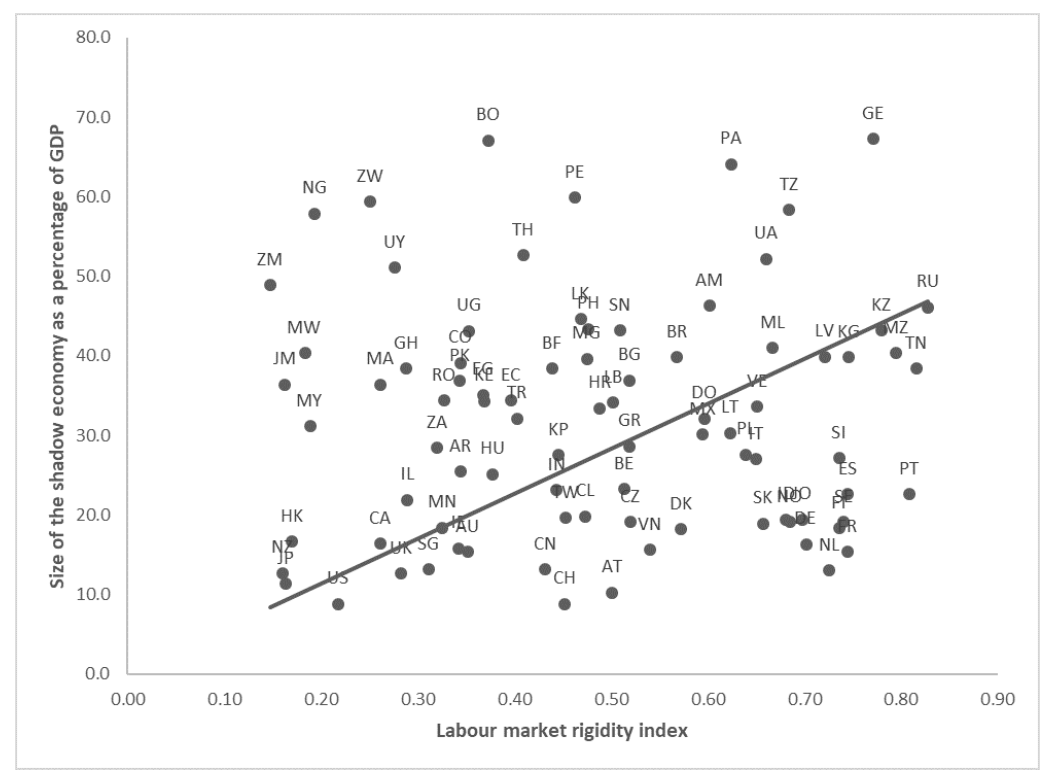

Figure 3.1: Labour market frictions and informal economies

The existence of labour market frictions in developing countries create a segmented labour market in which formal and informal producers operate. Formal producers are subject to labour market regulations that strain workers' mobility, whereas informal producers do not comply with employment regulations. As it is reported in the main introduction, informal economies are a prominent characteristic of developing countries. Developing countries with rigid labour markets have been engaging in international trade, and their volume of exports has been increasing since the 1990s. Therefore, we argue that it is worthwhile to examine the role of informal producers on the outcome of trade.

In our model, both informal and formal producers operate in different markets and produce consumption goods. Informal goods can be regarded as the second hand, low quality or counterfeit goods that are traded in global market. Informal producers take prices as given and produce homogeneous informal goods. Using the evidence provided in the second chapter, informal producers can be interpreted as those that operate in the micro, small enterprises or at home. Informal producers do not experience labour frictions since they do not follow employment regulations ${ }^{2}$.

Formal producers experience labour frictions and produce differentiated formal varieties. We use this framework to study the potential role of informal producers in determining the pattern of production and the welfare of countries during trade liberalizations. We find that countries with different degrees of informal economies benefit from international trade once they reduce trade barriers. The main contribution of this chapter is to show that the size of the informal sector is determined by not only the country's own labour market frictions, but also the degree of its trading partners' labour market rigidity. If a country with higher (lower) labour market frictions trades with a country having relatively lower (higher) labour market rigidity, its informal sector will be larger (smaller) than that of its trading partner. Another contribution of this chapter is that a reduction in trade barriers results in an increase in the size of the informal sector in the country having relatively higher labour market frictions, and a

\footnotetext{
${ }^{2}$ The assumption of no labour market frictions in the informal sector is made for simplicity. The informal sector can have labour market frictions; as long as they are lower than in the formal sector, the qualitative results will be the same.
} 
decrease in the informal sector in its trading partner. Moreover, another important result in this chapter is that once two countries with different degrees of labour market rigidity trade, changes in a countrys labour market policy, impacts not only its own labour market and welfare, but also its trading partners. For instance, a further increase in labour market frictions in the country that has initially higher labour market frictions, increases the size of its informal sector and decreases the size of the informal sector in its trading partner. Furthermore, both countries face with lower welfare, but the country having relatively higher labour market frictions experience lower welfare than its trading partner.

Our modelling framework is similar to Helpman and Itskhoki (2010) if we interpret their homogeneous sector as the informal sector and the differentiated sector as the formal sector. The main difference is that they assume increasing returns to scale in the differentiate goods sector (the formal sector), and monopolistic competition; whereas, we assume constant returns to scale and perfect competition in the production of each variety in the differentiated goods sector (the formal sector). Similar to their results, in our model, lower search frictions are a source of comparative advantage, and reducing trade barriers is welfare improving in both countries. However, in our model, an unilateral reduction of labour market frictions increases welfare in both countries,; whereas, in their model, it benefits the source country reducing the frictions and hurts its trading partner.

The existing literature, which studies the behaviour of the informal sector during trade liberalizations, is mainly empirical and investigate the effect of trade liberalization on the size of the informal sector and does not provide a clear idea about the role of informal producers in shaping countries pattern of trade and welfare (Goldberg and Pavcnik (2003), Paz (2013), Kovak and Dix-Carneiro (2015)). Furthermore, there is an empirical literature documents that trade in informal goods is widespread in developing countries. These traded informal goods may be mostly low-quality, second-hand or counterfeit goods which are attractive for many consumers due to their lower prices (Cantens at al. (2016)). Focusing on the Turkish-Russian Suitcase or Shuttle trade, Eder et al. (2003) highlight the importance of informal trade in the Caspian and the Black Sea region. Furthermore, Lesser and Leeman (2008) report that an important part of regional trade in Sub-Saharan African countries is derived from informal cross-border trade. The Uganda Petroleum Dealers Association estimates that $25 \%$ of petroleum fuel was imported by informal producers in Kenya. According to Afrika and Ajumbo (2012), the contribution of informal cross-border trade is around $40 \%$ of total trade in the Southern African Development Community. In this region, Kenya is the main exporter of informal goods. In addition, it is documented that informal trade in West Africa is also strong: for instance, informal trade helped Nigeria to be a leading economic power in West Africa. Barrosa and Chivangue (2017) examine the role of informal producers in Mozambique and claim that informal trade can be considered as an important strategy to create income and to reduce poverty in African countries. This chapter fills this gap. In order to explore the potential role of informal producers on the pattern of production and welfare of countries, we develop a Ricardian model of trade with labour market rigidities that result in segmented labour markets in which formal and informal producers operate. In our model, informal producers do not face with labour market frictions, and they 
operate in the different market than formal ones. they produce their final goods for the domestic and the foreign market.

Parallel to the existing literature, we find that countries with different degrees of informal economies benefit from international trade once they reduce their trade costs. This chapter adds to the existing literature showing that the size of the informal sector is determined by not only the country's own labour market frictions, but also the degree of its trading partners' labour market rigidity. When a country with higher labour market rigidities engages in trade with a country having relatively lower labour market frictions, its informal sector expands whereas the size of the informal sector in its trading partner shrink. This explains why there is no consensus in the existing literature about the role of trade liberalization on the size of the informal sector. Moreover, this chapter finds that a decrease in trade costs causes an increase in the size of the informal sector in a country having relatively higher labour market rigidities, and a decrease in the informal sector in its trading partner. Another important contribution of this chapter is that once two countries with different degrees of labour market frictions implement trade reforms, changes in labour market policy in a country that has relatively higher labour market frictions, affect not only its own labour markets and welfare, but also its trading partners.

We structure this chapter as follows: In section 2, we develop our model economy. In section 3, we provide the analytical results of the model. In section 4, we study the effect of trade liberalization and labour market reforms on a country's economy. In section 5, we conclude.

\subsection{The Model}

There are two countries in the model: Home and Foreign, indexed by $i=H, F$. Each country is populated by a measure one of identical households endowed with $M^{i}$ units of labour. There are three types of producers: formal producers, informal producers, both of which produce consumption goods that are traded, and recruitment agencies, which offer non-traded recruitment services to formal producers. Informal firms produce an homogeneous product, and formal firms produce one of a continuum of differentiated products $z \in[0,1]$. All markets are perfectly competitive, and all formal firms producing a given variety $z$ are identical. Informal and formal producers differ in terms of the flexibility of their labour markets. Differentiated formal producers are subject to employment regulations, whereas homogeneous informal producers do not experience rigidity in the labour market. Employment regulations for formal producers are modeled as search and matching frictions that are captured by a matching production function and a cost of opening vacancies. Formal firms need to post vacancies and search for available workers. This recruitment procedure is given to the recruitment agencies, which for simplicity, we assume that do not experience labour market frictions.

Initially, each household decides the proportion of labour that it sends to search for employment with each type of producer. Due to search frictions, some of the workers sent to search in the formal producers' market do not find a job and become unemployed. Unemployed workers cannot search for jobs with other 
producers. Once workers are matched with a formal producer, they engage in multilateral wage bargaining over total output. In the bargaining process, workers either jointly accept the share of production, and are paid a wage $w^{i}$, or they do not accept it and become unemployed. In equilibrium, expected wages are the same in all production activities.

We assume that preferences are identical across countries; however, countries may differ in terms of their labour market structure and in their production technologies. Moreover, there is an iceberg transportation cost, $\tau$ on all traded formal varieties. We provide detailed explanations of labour market characteristics, wage determination, producers' technologies, and consumer's preferences in the following sub-sections.

\subsubsection{Labour Market}

The labour market is fragmented due to the existence of search and matching frictions that formal producers experience ${ }^{3}$. We model these frictions using the Diamond-Mortensen-Pissarides search model. The labour allocation for the formal producers in country $i$ is determined by the following matching function:

$$
L^{i}=\phi^{i}\left(V^{i}\right)^{\eta}\left(N^{i}\right)^{1-\eta} \text { for } i=H, F
$$

where $V^{i}$ denotes the number of vacancies posted to attract workers in country $i, N^{i}$ indicates the number of people searching for a formal job, and $L^{i}$ shows the formally employed people. $\eta \in(0,1)$ is the share parameter of opening vacancies, and $\phi^{i}>0$ is the technology parameter in the matching function. We assume that $\eta$ is the same across countries, but $\phi^{i}$ may differ.

If we define the probability of finding a job in country $i=H, F$ as

$$
\lambda^{i}=\frac{L^{i}}{N^{i}}
$$

the number of vacancies in country $i$ can be written as:

$$
V^{i}\left(L^{i}, \lambda^{i}\right)=L^{i}\left(\phi^{i}\right)^{-1 / \eta}\left(\lambda^{i}\right)^{(1-\eta) / \eta}
$$

Moreover, if we denote the cost of posting a vacancy by $p_{r}^{i}$, the cost to a firm of hiring $L^{i}$ workers is given by $p_{r}^{i} V^{i}$. Therefore, the cost of hiring one worker in country $i, h^{i}$, is given by

$$
h^{i}=\frac{p_{r}^{i} V^{i}}{L^{i}}=p_{r}^{i}\left(\phi^{i}\right)^{-1 / \eta}\left(\lambda^{i}\right)^{(1-\eta) / \eta}
$$

Observe that a cost of hiring a worker are determined by the cost of posting vacancies $p_{r}^{i}$, the matching parameter $\eta$, the productivity parameter of the matching function $\phi^{i}$, and the probability of finding a job $\lambda^{i}$. Higher cost of posting vacancies, $p_{r}^{i}$ and/or lower productivity of the matching function $\phi^{i}$ imply

\footnotetext{
${ }^{3}$ Labour market frictions are defined a general way in our model. These frictions can result from higher hiring or firing costs or minimum wage policy.
} 
greater labour market frictions for formal producers.

\section{Recruitment agencies}

Formal producers outsource their hiring to the recruitment agencies. The recruitment sector in each country consists of infinitely many firms, operating a constant returns to scale technology in a perfectly competitive market: $V^{i}=A_{r}^{i} L_{r}^{i}$ where $A_{r}^{i}$ is a technology parameter, $L_{r}^{i}$ is labour hired, and $V^{i}$ is the number of vacancy postings produced.

Each firm in this sector maximizes profits:

$$
\max _{L_{r}^{i}}\left\{p_{r}^{i} A_{r}^{i} L_{r}^{i}-w_{r}^{i} L_{r}^{i}\right\} \text { for } i=H, F .
$$

In equilibrium, the solution of this problem reflects that the unit cost of processing a vacancy equals the cost of opening a vacancy:

$$
p_{r}^{i}=\frac{w_{r}^{i}}{A_{r}^{i}} .
$$

Therefore, the cost of posting a vacancy is determined by the productivity of the recruitment agencies, and the competitive wage. At any given wage, higher productivity parameters result in lower costs of opening vacancies.

\section{Multilateral wage bargaining}

Given that a formal producer has search and matching frictions, it faces hiring costs, along with the cost of production. Formal workers have wage bargaining power due to the fact that finding a new worker is costly. Once a successful match occurs, the firm and the workers engage in multilateral wage negotiations over total surplus. After bargaining, workers either accept the firm's offer or choose to be unemployed, but they cannot look for work in another firm. We use strategic Nash wage bargaining to determine the share of total surplus that the workers and the firm obtain. The bargaining problem between a firm producing variety $z$ and its workers is:

$$
\max _{w^{i}}\left\{\left(p^{i}(z) y^{i}(z)-w^{i} l^{i}(z)\right)^{1-\sigma}\left(w^{i} l^{i}(z)\right)^{\sigma}\right\} \text { for } i=H, F,
$$

where $p^{i}(z) y^{i}(z)$ is the formal firm's revenue, $w^{i} l^{i}(z)$ is the wage bill that the formal firm pays to its workers, and $\sigma \in(0,1)$ indicates the worker's "bargaining power" over total surplus. 
The solution to this problem provides the workers' share of total surplus: $\sigma p^{i}(z) y^{i}(z)$, and the firm's share of the total surplus: $(1-\sigma) p^{i}(z) y^{i}(z)$.

\subsubsection{Production Technologies and Producer's Maximization Problem}

We assume that firms are perfectly competitive; therefore, they take output prices as given. Moreover, labour is the only factor of production.

\section{Informal producers}

Informal firms produce output $Y_{n}^{i}$ using the technology $Y_{n}^{i}=A_{n}^{i} L_{n}^{i}$. They solve the following profit maximization problem:

$$
\max _{L_{n}^{i}}\left\{p_{n}^{i} A_{n}^{i} L_{n}^{i}-w_{n}^{i} L_{n}^{i}\right\} \text { for } i=H, F
$$

where $p_{n}^{i}$ is the domestic producer's price of the informal good.

In equilibrium, if the informal good is produced in country $i$, it is the case that:

$$
p_{n}^{i}=\frac{w_{n}^{i}}{A_{n}^{i}}
$$

That is, the producer's price of the good has to equal its unit cost.

\section{Formal producers}

We model the production of formal varieties following Dornbush, et al. (1977). There is a continuum of varieties of the formal good, $z \in[0,1]$ which can be produced in both countries. A potential producer for variety $z$ in country $i$ operates the technology $y^{i}(z)=a^{i}(z) l^{i}(z)$ where $a^{i}(z)$ is a technology parameter that differs across countries, and $l^{i}(z)$ is the amount of labour hired.

We assume that each country levies an identical trade cost, $\tau$ on imports of formal varieties which is modelled as an iceberg costs following Helpman and Itskhoki (2010). That is, the country needs to ship $1+\tau$ units of a formal variety to the importing country for the latter to receive 1 unit of the good . Tariff revenue is collected by the government and thrown in the ocean; that is, it is not returned to the consumers.

After multilateral bargaining with the workers, the firm chooses its labour input to maximize profits after considering hiring costs $h^{i}$ :

$$
\max _{l^{i}(z)}\left\{(1-\sigma) p^{i}(z) y^{i}(z)-h^{i} l^{i}(z)\right\}
$$

where $p^{i}(z)$ denotes formal producer's price. 
From here, we obtain:

$$
p^{i}(z) \leq \frac{h^{i}}{(1-\sigma) a^{i}(z)} .
$$

In equilibrium, if a variety $z$ is produced, its price equals its unit cost of production, and equation (5) is satisfied with equality.

\section{The composite consumption good}

The representative household in each country purchases a composite of the formal varieties $z \in[0,1]$. This good is produced domestically, and not traded ${ }^{4}$. The aggregation technology is given by

$$
Y^{i}=\left(\int_{0}^{1} x^{i}(z)^{\frac{\alpha-1}{\alpha}} d z\right)^{\frac{\alpha}{\alpha-1}}
$$

where $x^{i}(z)$ denotes the demand of each formal variety and $\alpha>1$.

The amount of each variety demanded solves the maximization problem

$$
\max _{x^{i}(z)}\left\{P^{i} Y^{i}-\int_{0}^{1} q^{i}(z) x^{i}(z) d z\right\}
$$

where $P^{i}$ is the composite-good price and $q^{i}(z)$ denotes the user's price. The solution to this problem provides the demand of each variety $x^{i}(z)$ :

$$
x^{i}(z)=Y^{i}\left(\frac{P^{i}}{q^{i}(z)}\right)^{\alpha} .
$$

The composite good price $P^{i}$ is given by

$$
P^{i}=\left(\int_{0}^{1} q^{i}(z)^{(1-\alpha)} d z\right)^{1 /(1-\alpha)}
$$

where the user's price is $q^{i}(z)=\min \left\{p^{i}(z),(1+\tau) p^{j}(z)\right\}, i \neq j$, since each formal variety is purchased from the country that produces the good at the lowest cost.

\subsubsection{Households}

Each country has an identical representative household. The representative household consists of $M^{i}$ individuals that derive utility from joint household consumption of the informal good, $C_{n}^{i}$, and the composite good, $C^{i}$.

Preferences of the representative household in each country over consumption of the two goods are

\footnotetext{
${ }^{4}$ It is equivalent to say that the representative household purchases all the traded varieties $z$ from formal producers, and obtains a utility over the composite $Y^{i}$.
} 
represented by the Cobb-Douglas utility function:

$$
u^{i}\left(C_{n}^{i}, C^{i}\right)=\left(C_{n}^{i}\right)^{\mu}\left(C^{i}\right)^{1-\mu}
$$

where $\mu \in(0,1)$ denotes the consumption share of the informal good ${ }^{5}$.

Each person in the household is endowed with one unit of time. The representative household chooses how to allocate its members into employment in each type of producers: recruitment agencies $L_{r}^{i}$, informal producers $L_{n}^{i}$, and formal producers $N^{i}$.

Besides this, the household decides how much to consume of the composite good $C^{i}$ and of the informal good $C_{n}^{i}$ to maximize its utility subject to the following budget and resource constraints:

$$
\begin{aligned}
P_{n}^{i} C_{n}^{i}+P^{i} C^{i} & =w_{n}^{i} L_{n}^{i}+\lambda^{i} w^{i} N^{i}+w_{r}^{i} L_{r}^{i} \\
M^{i} & \geq N^{i}+L_{n}^{i}+L_{r}^{i} \geq 0 \\
C_{n}^{i} & \geq 0 \text { and } C^{i} \geq 0
\end{aligned}
$$

where $P^{i}$ is the price of the composite good, and $P_{n}^{i}, i \neq j$ is the price of the informal good. $w_{n}^{i}$ and $w_{r}^{i}$ are the wages of informal producers and recruitment agencies respectively, $w^{i}$ is the wage that formal producers pay to their workers, and $\lambda^{i}$ represents the probability of finding a formal job.

Moreover, the difference between the number of people searching for formal jobs, and the number of people who actually find formal employment determines the amount of unemployed people in the economy, $U^{i}=N^{i}-L^{i}$

In equilibrium, assuming that both the informal good and some formal varieties are produced by country $i$, the household chooses the proportion of individuals searching for an employment with formal and informal producers and with recruitment agencies in such a way that the expected labour income of each worker is identical, that is

$$
w_{n}^{i}=w_{r}^{i}=\lambda^{i} w^{i}
$$

Therefore, the household's labour income can be written as $w_{r}^{i} M^{i}$ using equation (3.10) and the budget constraint. Furthermore, given our technology assumptions, wages in the frictionless labour market in each country are determined by the technology of informal producers, $w_{n}^{i}=w_{r}^{i}=A_{n}^{i}$.

Furthermore, assuming that parameter values are such that both countries produce the homogeneous informal good, we can normalize the price of informal goods, $P_{n}^{i}=P_{n}=1$. From here, the solution to the consumer's maximization problem provides the demand function of each good:

$$
C_{n}^{i}=\mu A_{n}^{i} M^{i}
$$

\footnotetext{
${ }^{5}$ In our model, the representative household consumes both formal and informal goods. In the aggregate data, consumers are heterogeneous in terms of their consumption habits and their income, and often they do not consider formal and informal goods (counterfeit goods) substitutable.
} 
and

$$
C^{i}=\frac{(1-\mu) A_{n}^{i} M^{i}}{P^{i}}
$$

Replacing the optimal consumption of each good in the utility function, we can write the welfare of each country as a function of the price of the composite good and model parameters:

$$
W^{i}=\mu^{\mu}\left(\frac{1-\mu}{P^{i}}\right)^{1-\mu} A_{n}^{i} M^{i}
$$

Observe that welfare is decreasing in the price of the composite good $P^{i}$.

\subsubsection{Definition of Equilibrium}

Given a tariff rate $\tau$, a competitive equilibrium for this economy is a set of allocations for the representative household $\left\{C^{i}, C_{n}^{i}, N^{i}, L_{n}^{i}, L_{r}^{i}\right\}$, for recruitment agencies $\left\{V^{i}, L_{r}^{i}\right\}$, for informal producers $\left\{Y_{n}^{i}, L_{n}^{i}\right\}$, for formal producers $\left\{y^{i}(z), l^{i}(z)\right\}_{z \in[0,1]}$, and for composite-good users $\left\{x^{i}(z), Y^{i}\right\}_{z \in[0,1]}$, a set of prices $\left\{p^{i}(z), q^{i}(z), P^{i}, P_{n}^{i}, p_{n}^{i}, p_{r}^{i}, w^{i}, w_{n}^{i}, w_{r}^{i}\right\}_{z \in[0,1]}$, hiring cost $h^{i}$, probability of formal employment $\lambda^{i}$ and unemployment level $U^{i}$ for $i=H, F$ such that:

(a) Given goods' prices, the household's allocations solve the household's maximization problem.

(b) Given goods' prices and hiring costs, each type of producer's allocations solve the respective producer's maximization problem.

(c) Given goods' prices, the wage $w^{i}$ solves the bargaining problem.

(d) The following market clearing conditions are satisfied

$i$. for formal varieties:

$$
y^{i}(z)=x^{i}(z)+(1+\tau) x^{j}(z) \text { for } i=H, F \text { and } i \neq j \text { for all } z \in[0,1]
$$

$i i$. for the composite good:

$$
Y^{i}=C^{i},
$$

iii. for informal good:

$$
Y_{n}^{H}+Y_{n}^{F}=C_{n}^{H}+C_{n}^{F},
$$

$i v$. for recruitment vacancies:

$$
V^{i}=L^{i}\left(\phi^{i}\right)^{-1 / \eta}\left(\lambda^{i}\right)^{(1-\eta) / \eta}
$$


$v$. labour market:

$$
\begin{gathered}
L^{i}=\lambda^{i} N^{i}, \\
L^{i}=\int_{0}^{1} l^{i}(z) d z, \\
M^{i}=L^{i}+U^{i}+L_{n}^{i}+L_{r}^{i} .
\end{gathered}
$$

(e) and international trade is balanced.

\subsection{Resolution of the Model: Characterization of Equilibrium}

Using equation (3.5), notice that, if country $i$ produces variety $z$ in equilibrium, it is the case that

$$
p^{i}(z)=\frac{h^{i}}{(1-\sigma) a^{i}(z)}
$$

Replacing equation (3.21) into the worker's share of production, which is obtained after wage bargaining: $\sigma p^{i}(z) y^{i}(z)=w^{i} l^{i}(z)$, we obtain a relationship between hiring costs, $h^{i}$ and formal workers' wages, $w^{i}$ :

$$
(1-\sigma) w^{i}=\sigma h^{i}
$$

Combining equation (3.1) that relates to the probability of finding a job with equations (3.2), (3.10) and (3.22), we find the probability of finding a job as a function parameters:

$$
\lambda^{i}=\phi^{i}\left(A_{r}^{i}\right)^{\eta}\left(\frac{1-\sigma}{\sigma}\right)^{\eta}
$$

Observe that an increase in the productivity parameter of recruitment agencies, $A_{r}^{i}$, or an increase in the parameter of the matching function, $\phi^{i}$, causes lower labour market frictions, which in turn result in a higher probability of finding a job in the formal labour market. Moreover, using equation (3.22), we can write the hiring costs, $h^{i}$ as a function of parameters:

$$
h^{i}=\frac{A_{n}^{i}}{\phi^{i}\left(A_{r}^{i}\right)^{\eta}}\left(\frac{1-\sigma}{\sigma}\right)^{1-\eta} .
$$


Notice that lower labour market frictions imply lower hiring costs. The existence of hiring costs results in unemployment since not all individuals who search for jobs can find one. Using $L^{i}=\lambda^{i} N^{i}$, unemployment can be written as:

$$
U^{i}=N^{i}-L^{i}=\left(\frac{1-\lambda^{i}}{\lambda^{i}}\right) L^{i}
$$

which is proportional to the amount of people hired by formal producers.

For analytical convenience, we order formal varieties $z \in[0,1]$ in such a way that the Home country has relatively better technology in varieties $z$ closer to 0 , that is, the Home country has a comparative advantage in varieties $z$ with lower indices. In particular, we order formal varieties $z \in[0,1]$ in such a way that relative productivity of variety $z, A(z)=a^{H}(z) / a^{F}(z)$, is a decreasing function of $z$.

Denoting relative hiring costs as

$$
\theta=\frac{h^{H}}{h^{F}}
$$

the pattern of formal variety production in each country is determined as follows:

The Home country imports, and does not produce varieties, $z \in[0,1]$ for which $p^{H}(z)>(1+\tau) p^{F}(z)$, or

$$
\frac{h^{H}}{(1-\sigma) a^{H}(z)}>\frac{(1+\tau) h^{F}}{(1-\sigma) a^{F}(z)} \Longrightarrow \frac{\theta}{1+\tau}>A(z)
$$

If we define $\tilde{z}^{F}$ (the export threshold for the Foreign country) as the variety $z$ that satisfies

$$
A\left(\tilde{z}^{F}\right)=\frac{\theta}{1+\tau}
$$

the Home country produces varieties $z \in\left[0, \tilde{z}^{F}\right]$, and imports varieties $z \in\left[\tilde{z}^{F}, 1\right]$ from the Foreign country ${ }^{6}$.

When the export threshold, $\tilde{z}^{F}$ increases, the Home (Foreign) country imports (exports) a smaller set of varieties. Therefore, from equation (3.26), the Foreign country loses comparative advantage in the formal variety production if the trade cost, $\tau$ or its hiring costs, $h^{F}$ increase, and it gains comparative advantage when its hiring costs, $h^{H}$ increase:

$$
\frac{\partial \tilde{z}^{F}}{\partial \tau}>0 \text { and } \frac{\partial \tilde{z}^{F}}{\partial h^{F}}>0 \text { and } \frac{\partial \tilde{z}^{F}}{\partial h^{H}}<0
$$

Similarly, the Foreign country imports, and does not produce varieties, $z \in[0,1]$ from the Home country for which $p^{F}(z)>(1+\tau) p^{H}(z)$, or

$$
\frac{h^{F}}{(1-\sigma) a^{F}(z)}>\frac{(1+\tau) h^{H}}{(1-\sigma) a^{H}(z)} \Longrightarrow \frac{a^{H}(z)}{a^{F}(z)}>\theta(1+\tau)
$$

${ }^{6}$ Country $i$ is indifferent at threshold $\tilde{z}^{i}$ to export formal varieties to country $j$ or to produce formal varieties for domestic consumption 
If we define $\tilde{z}^{H}$ (the export threshold for the Home country) as the variety $z$ that satisfies

$$
A\left(\tilde{z}^{H}\right)=\theta(1+\tau)
$$

the Foreign country produces varieties $z \in\left[\tilde{z}^{H}, 1\right]$, and imports varieties $z \in\left[0, \tilde{z}^{H}\right]$ from the Home country.

The Home country exports a smaller set of varieties as the export threshold $\tilde{z}^{H}$ decreases. Therefore, according to equation (3.27), the Home country loses comparative advantage producing formal varieties as the trade cost, $\tau$ or its hiring costs, $h^{H}$ increase, and an increase in the Foreign country's hiring costs $h^{F}$ makes the Home country more competitive in formal variety production:

$$
\frac{\partial \tilde{z}^{H}}{\partial \tau}<0 \text { and } \frac{\partial \tilde{z}^{H}}{\partial h^{H}}<0 \text { and } \frac{\partial \tilde{z}^{H}}{\partial h^{F}}>0
$$

Figure 3.2 illustrates the pattern of production of formal varieties for a given trade cost, $\tau$ and relative hiring costs, $\theta$ :

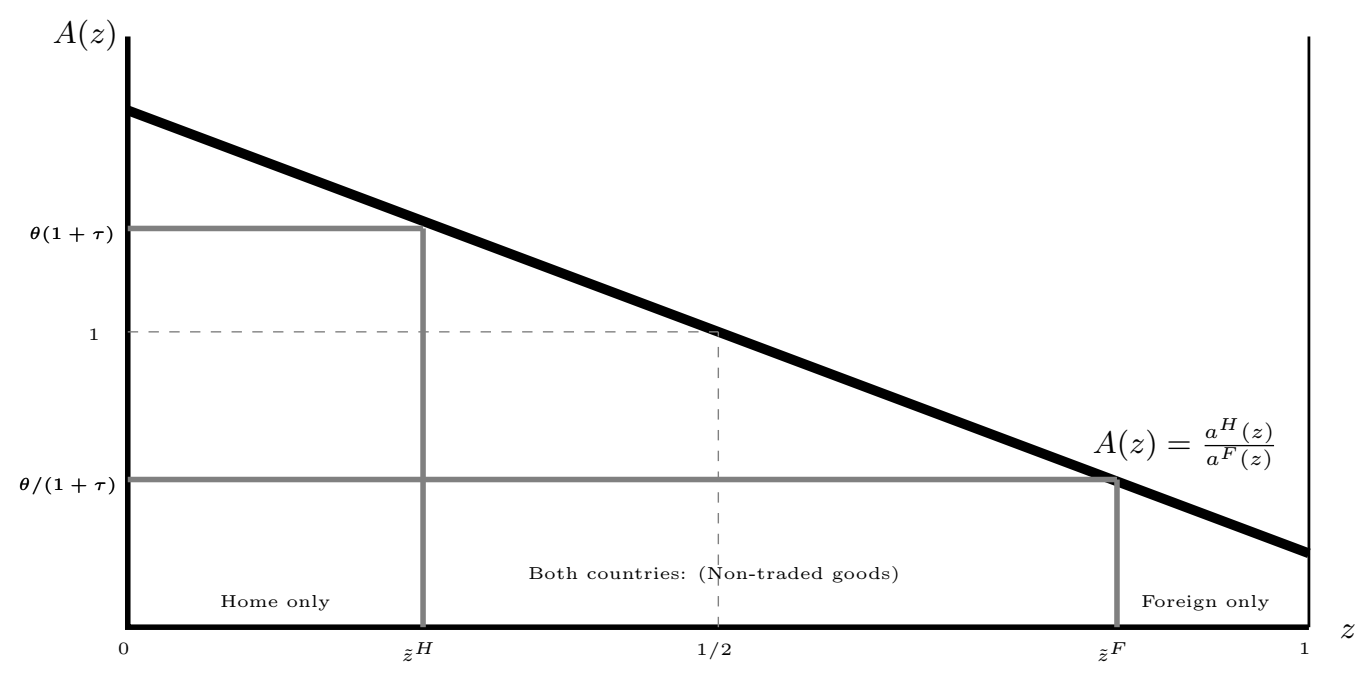

Figure 3.2: The export threshold and the pattern of production in formal varieties, $z$

Observe that the Home country produces varieties $z \in\left[0, \tilde{z}^{F}\right]$, and exports varieties $z \in\left[0, \tilde{z}^{H}\right]$ to the Foreign country. The Foreign country produces varieties $z \in\left[\tilde{z}^{H}, 1\right]$, and exports varieties $z \in\left[\tilde{z}^{F}, 1\right]$ to the Home country. Formal varieties $z \in\left[\tilde{z}^{H}, \tilde{z}^{F}\right]$ are produced by each country only for domestic consumption: these varieties are not traded. Notice that a decrease in the trade cost, $\tau$ reduces the size of the non-traded segment. 
Using equation (3.21), and the production pattern described above, the equilibrium price of the formal variety $z$ for each country is given by:

$$
\begin{gathered}
q^{H}(z)= \begin{cases}\frac{h^{H}}{(1-\sigma) a^{H}(z)} & \text { if } z \in\left[0, \tilde{z}^{F}\right] \\
\frac{h^{H}}{(1-\sigma) a^{H}(z)} & \text { if } z \in\left[\tilde{z}^{H}, \tilde{z}^{F}\right] \\
\frac{(1+\tau) h^{H}}{\theta(1-\sigma) a^{F}(z)} & \text { if } z \in\left[\tilde{z}^{F}, 1\right]\end{cases} \\
q^{F}(z)= \begin{cases}\frac{(1+\tau) h^{H}}{(1-\sigma) a^{H}(z)} & \text { if } z \in\left[0, \tilde{z}^{H}\right] \\
\frac{h^{H}}{\theta(1-\sigma) a^{F}(z)} & \text { if } z \in\left[\tilde{z}^{H}, \tilde{z}^{F}\right] \\
\frac{h^{H}}{\theta(1-\sigma) a^{F}(z)} & \text { if } z \in\left[\tilde{z}^{F}, 1\right]\end{cases}
\end{gathered}
$$

Furthermore, the composite good price for each country, using equations (3.28) and (3.29), is given by:

$$
\begin{aligned}
P^{H} & =\frac{h^{H}}{1-\sigma}\left[B_{0}^{H}\left(\tilde{z}^{F}\right)+\theta^{\alpha-1}(1+\tau)^{1-\alpha} B_{1}^{F}\left(\tilde{z}^{F}\right)\right]^{1 /(1-\alpha)} \\
P^{F} & =\frac{h^{H}}{1-\sigma}\left[\theta^{\alpha-1} B_{1}^{F}\left(\tilde{z}^{H}\right)+(1+\tau)^{1-\alpha} B_{0}^{H}\left(\tilde{z}^{H}\right)\right]^{1 /(1-\alpha)}
\end{aligned}
$$

where $B_{0}^{H}(\tilde{z})$ and $B_{1}^{F}(\tilde{z})$ are defined as

$$
B_{0}^{H}(\tilde{z})=\int_{0}^{\tilde{z}} a^{H}(z)^{\alpha-1} d z \text { and } B_{1}^{F}(\tilde{z})=\int_{\tilde{z}}^{1} a^{F}(z)^{\alpha-1} d z
$$

The following Lemma describes monotonicity properties of $B_{0}^{H}(\tilde{z})$ and $B_{1}^{F}(\tilde{z})$ which are used in the following sections.

Lemma 1: $B_{0}^{H}(\tilde{z})$ is increasing in $\tilde{z}$, and $B_{1}^{F}(\tilde{z})$ is decreasing in $\tilde{z}$.

Proof: Differentiating the expressions given in equation (3.32), we obtain:

$$
\begin{aligned}
& \frac{d B_{0}^{H}(\tilde{z})}{d \tilde{z}}=\tilde{z}^{\prime} a^{H}(\tilde{z})^{(\alpha-1)} a^{H}(\tilde{z})^{\prime}\left[a^{H}(\tilde{z})-a^{H}(0)\right]>0 \\
& \frac{d B_{1}^{F}(\tilde{z})}{d \tilde{z}}=-\tilde{z}^{\prime} a^{F}(\tilde{z})^{(\alpha-1)}-a^{F}(\tilde{z})^{\prime}\left[a^{F}(1)-a^{F}(\tilde{z})\right]<0
\end{aligned}
$$

which is true since these inequalities use our ordering assumption where $a^{H}(z)$ is increasing in $z$ and $a^{F}(z)$ is decreasing in $z$. 
The market clearing conditions for formal producers, given by equation (3.14), implies that for a given variety $z$, production in both countries is determined by:

$$
\begin{aligned}
y^{H}(z)= \begin{cases}x^{H}(z)+(1+\tau) x^{F}(z) & \text { if } z \in\left[0, \tilde{z}^{H}\right] \\
x^{H}(z) & \text { if } z \in\left[\tilde{z}^{H}, \tilde{z}^{F}\right] \\
0 & \text { if } z \in\left[\tilde{z}^{F}, 1\right]\end{cases} \\
y^{F}(z)= \begin{cases}0 & \text { if } z \in\left[0, \tilde{z}^{H}\right] \\
x^{F}(z) & \text { if } z \in\left[\tilde{z}^{H}, \tilde{z}^{F}\right] \\
x^{F}(z)+(1+\tau) x^{H}(z) & \text { if } z \in\left[\tilde{z}^{H}, 1\right]\end{cases}
\end{aligned}
$$

Replacing equations (3.8), (3.12), (3.15) into equations (3.33) and (3.34), the market clearing conditions can be written as:

$$
\begin{gathered}
y^{H}(z)= \begin{cases}(1-\mu)\left[\frac{(1-\sigma) a^{H}(z)}{h^{H}}\right]^{\alpha}\left[\frac{A_{n}^{H} M^{H}}{\left(P^{H}\right)^{1-\alpha}}+\frac{A_{n}^{F} M^{F}}{(1+\tau)^{\alpha}\left(P^{F}\right)^{1-\alpha}}\right] & \text { if } z \in\left[0, \tilde{z}^{H}\right] \\
(1-\mu)\left[\frac{(1-\sigma) a^{H}(z)}{h^{H}}\right]^{\alpha}\left[\frac{A_{n}^{H} M^{H}}{\left(P^{H}\right)^{1-\alpha}}\right] & \text { if } z \in\left[\tilde{z}^{H}, \tilde{z}^{F}\right]\end{cases} \\
y^{F}(z)= \begin{cases}0 & \text { if } z \in\left[\tilde{z}^{F}, 1\right] \\
(1-\mu) \theta^{\alpha}\left[\frac{(1-\sigma) a^{F}(z)}{h^{H}}\right]^{\alpha}\left[\frac{A_{n}^{F} M^{F}}{\left(P^{F}\right)^{1-\alpha}}\right] & \text { if } z \in\left[0, \tilde{z}^{H}\right] \\
(1-\mu) \theta^{\alpha}\left[\frac{(1-\sigma) a^{F}(z)}{h^{H}}\right]^{\alpha}\left[\frac{A_{n}^{F} M^{F}}{\left(P^{F}\right)^{1-\alpha}}+\frac{A_{n}^{H} M^{H}}{(1+\tau)^{\alpha}\left(P^{H}\right)^{1-\alpha}}\right] & \text { if } z \in\left[\tilde{z}^{H}, \tilde{z}^{F}\right]\end{cases}
\end{gathered}
$$

Using the production technology: $l^{i}(z)=y^{i}(z) / a^{i}(z)$ for $i=H, F$, we can compute the number of people working in each formal producer. Aggregating over all formal varieties $z$ produced in each country, we obtain aggregate formal employment for each country:

$$
\begin{aligned}
& L^{H}=\left[\frac{(1-\mu)(1-\sigma)^{\alpha}}{\left(h^{H}\right)^{\alpha}}\right]\left[\left(\frac{A_{n}^{H} M^{H}}{\left(P^{H}\right)^{1-\alpha}}\right) B_{0}^{H}\left(\tilde{z}^{F}\right)+\left(\frac{(1+\tau)^{1-\alpha} A_{n}^{F} M^{F}}{\left(P^{F}\right)^{1-\alpha}}\right) B_{0}^{H}\left(\tilde{z}^{H}\right)\right] \\
& L^{F}=\left[\frac{\theta^{\alpha}(1-\mu)(1-\sigma)^{\alpha}}{\left(h^{H}\right)^{\alpha}}\right]\left[\left(\frac{A_{n}^{F} M^{F}}{\left(P^{F}\right)^{1-\alpha}}\right) B_{1}^{F}\left(\tilde{z}^{H}\right)+\left(\frac{(1+\tau)^{1-\alpha} A_{n}^{H} M^{H}}{\left(P^{H}\right)^{1-\alpha}}\right) B_{1}^{F}\left(\tilde{z}^{F}\right)\right]
\end{aligned}
$$

Moreover, using the production technology of recruitment agencies, $V^{H}=A_{r}^{H} L_{r}^{H}$ and equations (3.17), (3.23) and (3.24), total employment of recruitment agencies in each country can be written as:

$$
\begin{aligned}
& L_{r}^{H}=L^{H}\left(\frac{h^{H}}{A_{n}^{H}}\right) \\
& L_{r}^{F}=L^{F}\left(\frac{h^{H}}{\theta A_{n}^{F}}\right) .
\end{aligned}
$$

Using equations (3.19), (3.23), (3.24), (3.25) and (3.39), (3.40), total informal employment in each country 
is given by:

$$
\begin{aligned}
& L_{n}^{H}=M^{H}-\left(\frac{h^{H}}{A_{n}^{H}(1-\sigma)}\right) L^{H} \\
& L_{n}^{F}=M^{F}-\left(\frac{h^{H}}{\theta A_{n}^{F}(1-\sigma)}\right) L^{F} .
\end{aligned}
$$

Replacing equations (3.39), (3.40), (3.41), (3.42) and (3.22) into equation (3.19), we find the total number of unemployed people in each country:

$$
\begin{aligned}
U^{H} & =L^{H}\left[\frac{h^{H}}{A_{n}^{H}}\left(\frac{\sigma}{1-\sigma}\right)-1\right] \\
U^{F} & =L^{F}\left[\frac{h^{H}}{\theta A_{n}^{F}}\left(\frac{\sigma}{1-\sigma}\right)-1\right] .
\end{aligned}
$$

Finally, using equations (3.8), (3.12), (3.15), and (3.28), (3.29), the value of imported formal varieties in each country is given by

$$
\begin{aligned}
\operatorname{Imp} p^{H} & =\int_{\tilde{z}^{F}}^{1} p^{F}(z) x^{H}(z) d z=(1+\tau)^{-\alpha}\left(\frac{h^{H}}{\theta(1-\sigma)}\right)^{1-\alpha}\left(\frac{(1-\mu) A_{n}^{H} M^{H}}{\left(P^{H}\right)^{1-\alpha}}\right) B_{1}^{F}\left(\tilde{z}^{F}\right) \\
\operatorname{Im} p^{F} & =\int_{0}^{\tilde{z}^{H}} p^{H}(z) x^{F}(z) d z=(1+\tau)^{-\alpha}\left(\frac{h^{H}}{1-\sigma}\right)^{1-\alpha}\left(\frac{(1-\mu) A_{n}^{F} M^{F}}{\left(P^{F}\right)^{1-\alpha}}\right) B_{0}^{H}\left(\tilde{z}^{H}\right) .
\end{aligned}
$$

Observe that both the price of the composite good and the employment level in the formal sector are functions not only of $\theta=h^{H} / h^{F}$ but also of the absolute level of $h^{H}$. This implies that the absolute value of the hiring costs, and not only their relative values, are important determining price levels and employment patterns.

In the following sections, we examine changes in equilibrium variables in different scenarios where countries implement trade liberalization, and/or change their labour market policies. To simplify the analysis, we make the following symmetry assumptions:

(i) households have the same amount of individuals in each country, $M^{H}=M^{F}=M$,

(ii) informal producers in each country have identical technology: $A_{n}^{H}=A_{n}^{F}=A_{n}$,

(iii) formal producer's productivities are symmetric after ordering, in the following way:

$$
a^{H}(z)=a^{F}(1-z) \text { for all } z \in[0,1]
$$

In what follows, we solve the equilibrium outcomes in different scenarios, and implement comparative statics using labour market and trade policy parameters. In section 4, we examine closed economies, and we analyse countries with symmetric and asymmetric hiring costs during trade liberalizations in section 5 and 6 respectively. 


\subsection{Closed economy}

Consider an autarkic equilibrium of a country with hiring costs, $h$. Since the relationship between hiring costs and price of the formal variety is given by equation (3.21):

$$
p(z)=\frac{h}{(1-\sigma) a(z)}
$$

it is the case that higher hiring costs, $h$ results in higher price of the formal variety $z$. From here, the composite good price, which is a function of the formal-variety prices, can be written as a function of parameters and hiring costs:

$$
P=\left(\frac{h}{1-\sigma}\right) B_{0}(1)^{1 /(1-\alpha)}
$$

where $B_{0}(1)$ is computed using equation (3.32).

Using equations (3.8), (3.12), (3.15) and (3.47), the aggregate formal employment can be written as a function of parameters and hiring costs:

$$
L=\frac{(1-\sigma)(1-\mu) A_{n} M}{h}
$$

Replacing equation (3.48) into (3.39), we obtain the aggregate employment for the recruitment agencies:

$$
L_{r}=(1-\sigma)(1-\mu) M
$$

and substituting equation (3.48) into (3.41), we find the aggregate informal employment:

$$
L_{n}=\mu M
$$

Finally, replacing equation (3.48) into (3.43), unemployment is given by

$$
U=(1-\mu) M\left(\sigma-\frac{A_{n}(1-\sigma)}{h}\right)
$$

The following propositions determine how the equilibrium of the closed economy changes with hiring costs. In particular, they show that hiring costs increase prices of the composite good and decrease production of differentiated goods s proportionally, leaving total expenditure on formal varieties unchanged. Moreover, hiring costs, $h$ do not influence informal producers and recruitment agencies, and therefore, do not affect the size of the informal sector. Higher hiring costs also lowers consumption of formal varieties which leads to lower welfare.

Proposition 1: Under autarky, $(i)$ the composite good price, $P$, is increasing in hiring costs, $(i i)$ the aggregate formal employment, $L$, is decreasing in hiring costs; (iii) the aggregate employment of 
recruitment agencies, $L_{r}$, does not depend on hiring costs; $(i v)$ hiring costs do not influence total informal employment, $L_{n},(v)$ and higher hiring costs result in higher unemployment, $U$.

\section{Proof:}

(i) Differentiating equation (3.47) with respect to hiring costs, we have:

$$
\frac{d P}{d h}=\left(\frac{1}{1-\sigma}\right) B_{0}(1)^{1 /(1-\alpha)}>0 .
$$

(ii) Differentiating equation (3.48) with respect to hiring costs, observe that:

$$
\frac{d L}{d h}=-\left(\frac{1}{h}\right)^{2}(1-\sigma)(1-\mu) A_{n} M<0 .
$$

(iii) From equation (3.49), observe that hiring costs do not affect employment of recruitment agencies, $L_{r}$.

(iv) From equation (3.50), notice that hiring costs do not affect total informal employment, $L_{n}$.

$(v)$ Moreover, differentiating equation (3.51) with respect to hiring costs, notice that:

$$
\frac{d U}{d h}=(1-\mu) M\left(\frac{A_{n}(1-\sigma)}{h^{2}}\right)>0
$$

Proposition 2: Under autarky, the size of the informal sector does not depend on hiring costs, $h$.

Proof: This follows directly from part $(i v)$ in Proposition 1.

Proposition 3: Under autarky, higher hiring costs, $h$ results in lower welfare, $W$.

Proof: Proposition 1 shows that the composite good price, $P$ increases in hiring costs. Since the welfare function of a country, which is given by equation (3.13), decreases with the composite good price, $P$, it is the case that higher hiring costs result in lower welfare, $W$.

In summary, higher hiring costs result in higher composite good price, lower production and consumption of formal varieties, higher unemployment and lower welfare. Furthermore, higher hiring costs do not affect the size of informal sector.

The next section examines the effect of changes in trade and labour market policies once countries with symmetric hiring costs implement trade liberalization. 


\subsection{Open economy with symmetric hiring costs}

Using equation (3.24), notice that for hiring costs are symmetric, $h^{H}=h^{F}=h$, only if:

$$
\phi^{H}\left(A_{r}^{H}\right)^{\eta}=\phi^{F}\left(A_{r}^{F}\right)^{\eta}
$$

Under the assumption of symmetric hiring costs, we also have $\theta=1$. Using equations (3.26) and (3.27), the export thresholds, $\tilde{z}^{H}$ and $\tilde{z}^{F}$ are determined as:

$$
A\left(\tilde{z}^{F}\right)=\frac{1}{1+\tau} \text { and } A\left(\tilde{z}^{H}\right)=1+\tau
$$

The properties of these thresholds are derived in the next proposition:

Proposition 4: Under our symmetry assumptions and $\theta=1$, the export thresholds satisfy:

$$
1-\tilde{z}^{F}=\tilde{z}^{H}<1 / 2
$$

Proof: From equation (3.52), notice that $A\left(\tilde{z}^{F}\right)=1 / A\left(\tilde{z}^{H}\right)$. Since the productivity parameter of formal producers in each country is assumed to be a mirror image of each other, it is the case that

$$
A\left(\tilde{z}^{F}\right)=\frac{a^{H}\left(\tilde{z}^{F}\right)}{a^{F}\left(\tilde{z}^{F}\right)}=\frac{a^{F}\left(1-\tilde{z}^{F}\right)}{a^{H}\left(1-\tilde{z}^{F}\right)}=\frac{1}{A\left(1-\tilde{z}^{F}\right)}=A\left(1-\tilde{z}^{H}\right) .
$$

Given that $A(z)$ is strictly decreasing in $z$, it is the case that $\tilde{z}^{F}=1-z^{\tilde{H}}$. Furthermore, if $\tau>0$,

$$
A\left(\tilde{z}^{F}\right)=\frac{1}{1+\tau}<1=A(1 / 2)
$$

which implies $\tilde{z}^{F}>1 / 2$ and $\tilde{z}^{H}=1-\tilde{z}^{F}<1 / 2$.

Lemma 2: Under our symmetry assumptions and $\theta=1$, we have

$$
B_{1}^{F}\left(\tilde{z}^{F}\right)=B_{0}^{H}\left(\tilde{z}^{H}\right) \text { and } B_{1}^{F}\left(\tilde{z}^{H}\right)=B_{0}^{H}\left(\tilde{z}^{F}\right)
$$

Proof: Using the symmetry condition on formal producers' productivity, which is $a^{H}(z)=a^{F}(1-z)$, notice that

$$
\begin{aligned}
& B_{1}^{F}\left(\tilde{z}^{F}\right)=\int_{\tilde{z}^{F}}^{1} a^{F}(z)^{(\alpha-1)} d z=\int_{\tilde{z}^{F}}^{1} a^{H}(1-z)^{(\alpha-1)} d z \\
& B_{1}^{F}\left(\tilde{z}^{H}\right)=\int_{\tilde{z}^{H}}^{1} a^{F}(z)^{(\alpha-1)} d z=\int_{\tilde{z}^{H}}^{1} a^{H}(1-z)^{(\alpha-1)} d z
\end{aligned}
$$

and using the change of variables, $z=1-s$ in the second integral in each expression, these equations 
can be written as:

$$
\begin{aligned}
& B_{1}^{F}\left(\tilde{z}^{F}\right)=-\int_{1-\tilde{z}^{F}}^{0} a^{H}(s)^{(\alpha-1)} d s=\int_{0}^{1-\tilde{z}^{F}} a^{H}(s)^{(\alpha-1)} d s=\int_{0}^{\tilde{z}^{H}} a^{H}(s)^{(\alpha-1)} d s=B_{0}^{H}\left(\tilde{z}^{H}\right) \\
& B_{1}^{F}\left(\tilde{z}^{H}\right)=-\int_{1-\tilde{z}^{F}}^{0} a^{H}(s)^{(\alpha-1)} d s=\int_{0}^{1-\tilde{z}^{H}} a^{F}(s)^{(\alpha-1)} d s=\int_{\tilde{z}^{H}}^{1} a^{F}(s)^{(\alpha-1)} d s=B_{1}^{H}\left(\tilde{z}^{F}\right) .
\end{aligned}
$$

Given these preliminary results, the next proposition derives symmetry properties of equilibrium variables.

Proposition 5: Under our symmetry assumptions and $\theta=1$, both countries experience $(i)$ the same composite good price: $P^{H}=P^{F}=P,(i i)$ the same aggregate formal employment: $L^{H}=L^{F}=L,(i i i)$ the same total employment of recruitment agencies: $L_{r}^{H}=L_{r}^{F}=L_{r},(i v)$ the same aggregate informal employment: $L_{n}^{H}=L_{n}^{F}=L_{n}$, (vi) the same unemployment $U^{H}=U^{F}=U$, and (vi) the same import value of formal varieties: $I m p^{H}=I m p^{F}=I m p$.

\section{Proof:}

(i) From equations (3.30) and (3.31), which determine the price of the composite good in each country with the common trade cost, and Lemma 2, we find:

$$
P^{H}=P^{F}=P=\left(\frac{h}{1-\sigma}\right)\left[B_{0}^{H}\left(\tilde{z}^{F}\right)+(1+\tau)^{1-\alpha} B_{1}^{F}\left(\tilde{z}^{F}\right)\right]^{1 /(1-\alpha)} .
$$

(ii) Replacing equation (3.53) into equations (3.37) and (3.38), notice that total formal employment of both countries is identical:

$$
L^{H}=L^{F}=L=\frac{(1-\mu)(1-\sigma) A_{n} M}{h}
$$

(iii) Substituting equation (3.54) into equations (3.39) and (3.40), total employment of the recruitment agencies in both countries is found as

$$
L_{r}^{H}=L_{r}^{F}=L_{r}=(1-\mu)(1-\sigma) M
$$

(iv) Replacing equation (3.54) into equations (3.41) and (3.42), total informal employment for both countries is given by

$$
L_{n}^{H}=L_{n}^{F}=L_{n}=\mu M
$$

(v) Substituting equation (3.54) into equations (3.43) and (3.44), unemployment for both countries is given by

$$
U^{H}=U^{F}=U=(1-\mu) M\left[\sigma-\frac{A_{n}(1-\sigma)}{h}\right]
$$


(vi) Furthermore, using Lemma 2 and equation (3.53), observe that the value of imported formal varieties given by equations (3.45) and (3.46) is identical in both countries:

$$
I m p^{H}=I m p^{F}=\operatorname{Imp}=(1+\tau)^{-\alpha}\left(\frac{h}{1-\sigma}\right)^{1-\alpha}\left(\frac{(1-\mu) A_{n} M}{P^{1-\alpha}}\right) B_{1}^{F}\left(\tilde{z}^{F}\right)
$$

The symmetry conditions in formal producers' productivity and symmetric hiring costs, $\theta=1$, result in identical equilibrium outcomes for aggregate variables in both countries. Therefore, both countries face the same composite good price, $P$; they employ the same amount of informal workers, $L_{n}$, and formal workers, $L$; they open the same amount of vacancies, $V$, and hire the same amount of workers of recruitment agencies, $L_{r}$. Trade in formal varieties is balanced in equilibrium, and informal goods are only produced for domestic consumption. Moreover, the size of the informal sector is the same in both countries. The only difference is in the set of formal varieties produced.

In what follows, we perform comparative statics on equilibrium of the model with respect to trade policy and labour market frictions.

\subsubsection{Trade liberalization}

This section examines how the equilibrium for the symmetric model changes with the trade cost.

The following proposition characterizes the effect on the export threshold.

Proposition 6: Under our symmetry assumptions and $\theta=1, \tilde{z}^{H}$ is decreasing in $\tau$ and $\tilde{z}^{F}$ is increasing in $\tau$.

Proof: Differentiating equations (3.26) and (3.27) with respect to $\tau$ respectively, we obtain:

$$
\begin{aligned}
& A^{\prime}\left(\tilde{z}^{F}\right) \frac{d \tilde{z}^{F}}{d \tau}+\frac{1}{(1+\tau)^{2}}=0 \text { or } \frac{d \tilde{z}^{F}}{d \tau}=-\frac{1}{A^{\prime}\left(\tilde{z}^{F}(1+\tau)^{2}\right.}>0 \\
& A^{\prime}\left(\tilde{z}^{H}\right) \frac{d \tilde{z}^{H}}{d \tau}-1=0 \text { or } \frac{d \tilde{z}^{H}}{d \tau}=\frac{1}{A^{\prime}\left(\tilde{z}^{H}\right)}<0
\end{aligned}
$$

where the last inequalities follow from the fact that $A(z)$ is strictly decreasing in $z$.

Proposition 7: Under our symmetry assumptions and $\theta=1$, the price of the composite good is increasing in trade cost, $\tau$.

Proof: Define

$$
\Omega=\left(\frac{(1-\sigma) P}{h}\right)^{1-\alpha}
$$

Observe that $\Omega$ is decreasing in $P$ since $\alpha>1$. Therefore, in order to prove $P$ is increasing in $\tau$, it is enough to show that $\Omega$ is decreasing in $\tau$. Using equation (53), we have:

$$
\Omega=B_{0}^{H}\left(\tilde{z}_{\tau}^{F}\right)+(1+\tau)^{1-\alpha} B_{1}^{F}\left(\tilde{z}_{\tau}^{F}\right)
$$


Differentiating equation $(3.59)$ with respect to $\tau$, we obtain:

$$
\frac{d \Omega}{d \tau}=\frac{1-\alpha}{(1+\tau)^{\alpha}} B_{1}^{F}\left(\tilde{z}_{\tau}^{F}\right)<0
$$

since $\alpha>1$. Therefore, the price of the composite good is higher with positive trade costs, $\tau$.

Trade liberalization improves aggregate productivity in the formal sector as varieties that were not traded before are now produced only in the country with lower costs. Under our assumption of symmetry, trade policy does not affect employment in any of the markets. That is, employment in the recruitment sector and vacancies posted remain the same, and so do employment in the formal sector. Moreover, the size of the informal sector remains constant. Trade policy only changes which varieties are produced domestically, and which are traded. There is no reallocation of labour across formal and informal sectors; however, there is labour reallocation across varieties within the formal sector. As trade liberalizes, countries specialize in the production of varieties where they have comparative advantage. This reduces the prices of the varieties consumed, and increases demand. As a result, the price index of formal sector varieties also decreases and quantities demanded increase proportionally to the decrease in price. Overall expenditure in formal varieties stays constant.

The following propositions formalize these results.

Proposition 8: Under our symmetry assumptions and $\theta=1$, employment in the formal sector, recruitment agencies and the informal sector do not depend on trade policy.

Proof: This derives directly from equations (3.54) - (3.56), which show that the equilibrium values of these variables do not depend on the trade cost, $\tau$.

Proposition 9: Under our symmetry assumptions and $\theta=1$, the size the informal sector does not depend on trade policy.

Proof: From the previous proposition, it is clear to observe that trade policy does not influence the size of the informal sector.

Proposition 10: Under our symmetry assumptions and $\theta=1$, informal goods are only consumed domestically.

Proof: Using equation (3.58), notice that the value of imported formal varieties are identical across countries: $I m p^{H}=I m p^{F}$. Given our balanced trade assumption, informal goods are only produced for domestic consumption, $C_{n}^{i}=Y_{n}^{i}$.

Proposition 11: Under our symmetry assumptions and $\theta=1$, welfare is a decreasing function of $\tau$.

Proof: Proposition 7 shows that the composite good price is increasing in $\tau$. Since the welfare function of each country, which is given by equation (3.13), is decreasing in the composite good price, welfare is decreasing in $\tau>0$.

Notice that the welfare effect is due only to the change in prices of the newly imported formal varieties. 


\subsubsection{Labour market policy}

In this subsection, we consider the equilibrium effect of labour market policy which results in an increase in hiring costs in the same proportion in both countries. Once countries increase their hiring costs, the representative households in each country experience higher prices for all formal varieties, and higher composite good price. This results in lower consumption of each formal variety, and thus, production of formal varieties and total employment in this sector decrease. The decrease in demand is proportional to the price; therefore, overall expenditure in each variety remains unchanged. The proportional increase in hiring costs does not influence employment of the recruitment agencies. The size of the informal sector is not affected by proportional increase in hiring costs, both countries produce informal goods only for domestic consumption. Furthermore, both countries face lower welfare since welfare is a decreasing function of the composite good price which is higher due to an increase in hiring costs.

Our analytical results related to statements above are structured in the following propositions:

Proposition 12: Under our symmetry assumptions and $\theta=1$, the export thresholds are not a function of hiring costs, $h$.

Proof: Using equations (3.26) and (3.27), observe that the export thresholds depend only on relative hiring costs, $\theta$, and this implies that proportional changes in hiring costs does not affect the export thresholds.

Proposition 13: Under our symmetry assumptions and $\theta=1,(i)$ the price of the composite good is increasing in hiring costs, $h,(i i)$ employment in the formal sector is decreasing in hiring costs, $h,($ iii $)$ employment in recruiting agencies and in the informal sector do not depend on hiring costs, $h,($ iii $)$ unemployment is increasing in hiring costs, $h$, and $(i v) N$ does not depend on $h$.

Proof: $(i)$ Equation (3.53) is given by

$$
P=\frac{h}{1-\sigma}\left[B_{0}^{H}\left(\tilde{z}^{F}\right)+(1+\tau)^{1-\alpha} B_{1}^{F}\left(\tilde{z}^{F}\right)\right]^{1 /(1-\alpha)}
$$

$B_{0}^{H}\left(\tilde{z}^{F}\right)$ and $B_{1}^{F}\left(\tilde{z}^{F}\right)$ are not affected by $h$ due to Proposition 13 . From here, we differentiate the composite good price with respect to $h$, and obtain:

$$
\frac{\partial P}{\partial h}=\frac{1}{1-\sigma}\left[B_{0}^{H}\left(\tilde{z}^{F}\right)+(1+\tau)^{1-\alpha} B_{1}^{F}\left(\tilde{z}^{F}\right)\right]^{1 /(1-\alpha)}>0
$$

(ii) We differentiate equation (3.54) with respect to hiring costs, $h$, and find:

$$
\frac{\partial L}{\partial h}=-\frac{(1-\mu)(1-\sigma) A_{n} M}{h^{2}}<0
$$


(iii) Notice from equations (3.55) and (3.56), $L_{r}$ and $L_{n}$ do not depend on $h$.

(iv) Moreover, differentiating equation (3.57) with respect to hiring costs $h$, we have:

$$
\frac{\partial U}{\partial h}=\frac{(1-\mu)(1-\sigma) A_{n} M}{h^{2}}>0
$$

Notice that $\frac{\partial U}{\partial h}=-\frac{\partial L}{\partial h}$. This implies that the loss in employment in the formal sector corresponds one-to-one the increase in unemployment. Therefore, the size of workers sent to the formal sector, $N=L+U$ do not depend on $h$.

Proposition 14: Under our symmetry assumptions and $\theta=1$, the size of the informal sector does not depend on $h$.

Proof: It follows directly from $(i i i)$ in the previous proposition.

Proposition 15: Under our symmetry assumptions and $\theta=1$, informal goods are only consumed domestically, and not subject to international trade.

Proof: Notice that the value of the imported formal varieties in both countries, which is given by equation (3.58), is the same: $I m p^{H}=\operatorname{Im} p^{F}$. Using our balanced trade assumption, it is the case that $C_{n}^{i}=Y_{n}^{i}$.

Proposition 16: Under our symmetry assumptions and $\theta=1$, higher hiring costs result in lower welfare in both countries.

Proof: From Proposition 13, which dictates that the composite good price is increasing in hiring costs, $h$, and the fact that the welfare function is decreasing in the composite good price, $P$, welfare in both countries is lower due to higher hiring costs.

In the symmetric model, we observe that an increase in hiring costs in the same proportion in both countries results in lower consumption of formal varieties. Lower demand for formal varieties causes lower formal production and employment. Moreover, both countries experience lower welfare since welfare decreases in the composite good price which is higher due to an increase in hiring costs. The proportional increase in hiring costs does not have any effect on employment of the recruitment agencies and the size of the informal sector.

\subsection{Asymmetric hiring costs}

In this section, we examine equilibrium outcomes of our symmetric model as countries have different hiring costs. In this case, asymmetric hiring costs create differences in the cost of production of the formal varieties relative to the informal good. Higher hiring costs make the production of formal varieties relatively more expensive, resulting in a comparative disadvantage on this sector in favour of the informal sector. Thus, in equilibrium, the country with the higher hiring costs produces a smaller set of formal varieties, and experiences lower formal employment. As a result, the informal sector in the country with the higher hiring costs is larger, and this country exports the informal good on net. 
In our analysis, we assume that the Home country has higher hiring costs than the Foreign country: $h^{H}>h^{F}=h$, which implies $\theta>1$.

\subsubsection{Free Trade: $\tau=0$}

To derive analytical intuition on how asymmetric hiring costs affect equilibrium, we first consider the special case in which countries are trading freely, $\tau=0$. In this case, the export threshold is the same for both countries, that is $\tilde{z}^{H}=\tilde{z}^{F}=\tilde{z}$.

The first propositions derive properties of this threshold:

Proposition 17: Under our symmetry assumptions with $h^{H}>h^{F}=h$ and $\tau=0$, the export threshold of formal varieties satisfies $\tilde{z}<1 / 2$.

Proof: From relative productivity of formal producers, the export threshold satisfies:

$$
A(\tilde{z})=\frac{a^{H}(\tilde{z})}{a^{F}(\tilde{z})}=\theta>1 \text {, or } a^{H}(\tilde{z})>a^{F}(\tilde{z}) .
$$

Moreover, using the symmetry condition of formal producers' productivity parameters, it is the case that:

$$
a^{H}(1-\tilde{z})=a^{F}(\tilde{z})<a^{H}(\tilde{z})
$$

which implies, given that $a^{H}(z)$ is decreasing,

$$
1-\tilde{z}>\tilde{z}, \text { or } \tilde{z}<1 / 2 \text {. }
$$

Lemma 3: Under our symmetry assumptions with $h^{H}>h^{F}=h$ and $\tau=0$, the following inequality is satisfied:

$$
B_{1}^{F}(\tilde{z})>B_{0}^{H}(\tilde{z})
$$

Proof: Using the symmetry condition of formal producers' productivity, observe that

$$
B_{0}^{H}(\tilde{z})=B_{1}^{F}(1-\tilde{z})
$$

From Proposition 17 which states $\tilde{z}<1 / 2$, and Lemma 1 which dictates that $B_{1}^{F}(\tilde{z})$ is decreasing in $\tilde{z}$, it is the case that

$$
B_{0}^{H}(\tilde{z})=B_{1}^{F}(1-\tilde{z})<B_{1}^{F}(\tilde{z})
$$

Under free trade with asymmetric hiring costs, both countries face the same composite good price since there is complete specialization in formal varieties.

Furthermore, the Home country with higher hiring costs has a comparative disadvantage in the production 
of formal varieties while the Foreign country produces and exports a larger set of formal varieties. Employment in the formal sector and the recruitment agencies is higher in the Foreign country than in the Home country. The informal sector in the Foreign country is smaller than the informal sector in Home country, and the Home country is a net exporter of informal goods.

The following propositions formally structure these results:

Proposition 18: Under our symmetry assumptions with $h^{H}>h^{F}=h$ and $\tau=0$, both countries have the same composite good price.

Proof: Using equations (3.30) and (3.31), the composite good price for both countries is given by

$$
P^{H}=P^{F}=P=\frac{h^{H}}{1-\sigma}\left[B_{0}^{H}(\tilde{z})+\theta^{\alpha-1} B_{1}^{F}(\tilde{z})\right]^{1 /(1-\alpha)}
$$

Proposition 19: Under our symmetry assumptions with $h^{H}>h^{F}=h$ and $\tau=0,(i)$ the aggregate employment of formal producers in the Home country is lower relative to the Foreign country: $L^{F}>L^{H}$, and $(i i)$ the Home country has lower employment of recruitment agencies relative to the Foreign country: $L_{r}^{F}>L_{r}^{H}$

Proof: $(i)$ Using equations (3.37) and (3.38), the aggregate employment of formal producers in each country is given by

$$
\begin{aligned}
L^{H} & =\left(\frac{(1-\mu)(1-\sigma)^{\alpha}}{\left(h^{H}\right)^{\alpha}}\right)\left(\frac{A_{n} M}{P^{1-\alpha}}\right) 2 B_{0}^{H}(\tilde{z}) \\
L^{F} & =\theta^{\alpha}\left(\frac{(1-\mu)(1-\sigma)^{\alpha}}{\left(h^{H}\right)^{\alpha}}\right)\left(\frac{A_{n} M}{P^{1-\alpha}}\right) 2 B_{1}^{F}(\tilde{z}) .
\end{aligned}
$$

From here, notice that $L^{F}>L^{H}$ if only if

$$
\theta^{\alpha} B_{1}^{F}(\tilde{z})>B_{0}^{H}(\tilde{z})
$$

This is true since $\theta>1, \alpha>1$ and $B_{0}^{H}(\tilde{z})<B_{1}^{F}(\tilde{z})$ which is given by Lemma 3 .

(ii) Similarly, using equations (3.39) and (3.40), $L_{r}^{F}>L_{r}^{H}$ if and only if

$$
\theta^{\alpha-1} B_{1}^{F}(\tilde{z})>B_{0}^{H}(\tilde{z})
$$

which is satisfied since $\theta>1, \alpha>1$ and $B_{0}^{H}(\tilde{z})<B_{1}^{F}(\tilde{z})$ based on Lemma 3 .

Proposition 20: Under our symmetry assumptions with $h^{H}>h^{F}=h$ and $\tau=0$, the Home country has higher informal employment relative to the Foreign country: $L_{n}^{H}>L_{n}^{F}$.

Proof: Using equations (3.41) and (3.42), $L_{n}^{H}>L_{n}^{F}$ if and only if

$$
\theta^{\alpha-1} B_{1}^{F}(\tilde{z})>B_{0}^{H}(\tilde{z})
$$

which is correct since $\theta>1, \alpha>1$ and from Lemma $3: B_{0}^{H}(\tilde{z})<B_{1}^{F}(\tilde{z})$. 
Proposition 21: Under our symmetry assumptions with $h^{H}>h^{F}=h$ and $\tau=0$, the Home country exports informal goods to the Foreign country on net.

Proof: Given our assumptions of balanced trade, this is equivalent to show that $\operatorname{Imp} p^{H}>\operatorname{Imp} p^{F}$. Using equations (3.45) and (3.46), we have:

$$
\theta^{\alpha-1} B_{1}^{F}\left(\tilde{z}^{F}\right)>B_{0}^{H}\left(\tilde{z}^{H}\right)
$$

since the result of Lemma 3 which dictates that $B_{0}^{H}(\tilde{z})<B_{1}^{F}(\tilde{z})$, and $\theta>1, \alpha>1$. This, together with balanced trade, change in hiring costs, $h^{H}$ imply that $Y_{n}^{H}>C_{n}^{H}$; therefore, the Home country exports informal goods on net.

The next propositions show the effect on equilibrium when the Home country, increases its hiring costs in the scenario with asymmetric hiring costs.

Proposition 22: Under our symmetry assumptions with $h^{H}>h^{F}=h$ and $\tau=0, \tilde{z}$ is decreasing in hiring costs in the Home country, $h^{H}$.

Proof: The export threshold, $\tilde{z}$ for both countries is defined as follows:

$$
A(\tilde{z})=\theta=\frac{h^{H}}{h^{F}}
$$

From here, we differentiate this expression with respect to $h^{H}$, and find:

$$
A^{\prime}(\tilde{z}) \frac{d \tilde{z}}{d h^{H}}-\frac{1}{h}=0 \Longrightarrow \frac{d \tilde{z}}{d h^{H}}=-\frac{1}{h A^{\prime}(\tilde{z})}<0
$$

since $A(z)$ is strictly decreasing in $z$.

Proposition 23: Under our symmetry assumptions with $h^{H}>h^{F}=h$ and $\tau=0$, the composite good price is an increasing function of $h^{H}$.

Proof: Using equation (3.60), we define

$$
\Omega=\left(\frac{(1-\sigma) P}{h}\right)^{1-\alpha}
$$

Notice that $\Omega$ is decreasing in the composite good price, $P$ since $\alpha>1$. To prove that the price index, $P$ is increasing in hiring costs in the Home country, it is enough to show that $\Omega$ is decreasing in $h^{H}$.

Using our definition, which is given in equation (3.59), we have:

$$
\Omega=\theta^{1-\alpha} B_{0}^{H}(\tilde{z})+B_{1}^{F}(\tilde{z})
$$

Differentiating this expression with respect to $h^{H}$, it is the case that

$$
\frac{d \Omega}{d h^{H}}=\left(\frac{1-\alpha}{h \theta^{\alpha}}\right) B_{0}^{H}(\tilde{z})+\frac{d \tilde{z}}{d h^{H}}\left[\left(\frac{a^{H}(\tilde{z})}{\theta}\right)^{\alpha-1}-a^{F}(\tilde{z})^{\alpha-1}\right]
$$


Observe that the term in the squared brackets is zero since $\tilde{z}$ satisfies $a^{H}(\tilde{z})=\theta a^{F}(\tilde{z})$. Therefore,

$$
\frac{d \Omega}{d h^{H}}=\left(\frac{1-\alpha}{h \theta^{\alpha}}\right) B_{0}^{H}(\tilde{z})<0
$$

since $\alpha>1$. This proves that the composite good price is increasing in hiring costs.

Therefore, higher hiring costs in the Home country, $h^{H}$ result in higher composite good price for both countries, and this results in lower consumption of this good in both countries. The welfare function given by equation (3.13) decreases in the composite good price. Higher hiring costs, which increases the composite good price, hurt both countries since both countries face the same composite good price.

Proposition 24: Under our symmetry assumptions with $h^{H}>h^{F}=h$ and $\tau=0$, an increase in hiring costs in the Home country, $h^{H}$ results in: $(i)$ a decrease (an increase) in employment in the formal sector and recruitment agencies in the Home country (in the Foreign country), and (ii) higher informal employment in the Home country, and lower informal employment in the Foreign country.

\section{Proof:}

(i) Using our definition, $\Omega=\left(\frac{(1-\sigma) P}{h}\right)^{1-\alpha}$, formal employment of the Home country can be written as

$$
L^{H}=\left(\frac{2 A_{n} M(1-\mu)(1-\sigma)}{h}\right)\left(\frac{B_{0}^{H}(\tilde{z})}{\theta^{\alpha} \Omega}\right)
$$

We differentiate this expression with respect to $h^{H}$, and obtain:

$$
\frac{d L^{H}}{d h^{H}}=\left(\frac{2 A_{n} M(1-\mu)(1-\sigma)}{h}\right)\left[\left(\frac{a^{H}(\tilde{z})^{\alpha-1}}{\theta^{\alpha} \Omega}\right)\left(\frac{d \tilde{z}}{d h^{H}}\right)-\frac{B_{0}^{H}(\tilde{z})\left(\alpha \theta^{\alpha-1} B_{1}^{F}(\tilde{z})+B_{0}^{H}(\tilde{z})\right)}{h\left(\theta^{\alpha} \Omega\right)^{2}}\right]<0 .
$$

This is satisfied since the first expression in the squared brackets of this equation is negative based on the result of Proposition 22, which dictates that $d \tilde{z} / d h^{H}<0$, and $\alpha>1$. This implies that an increase in hiring costs in the Home country results in lower formal employment in the Home country.

Similarly, we can write formal employment in the Foreign country in the following way:

$$
L^{F}=\left(\frac{2 A_{n} M(1-\mu)(1-\sigma)}{h}\right)\left(\frac{B_{1}^{F}(\tilde{z})}{\Omega}\right)
$$

Differentiating this expression with respect to $h^{H}$, we find:

$$
\frac{d L^{F}}{d h^{H}}=\left(\frac{2 A_{n} M(1-\mu)(1-\sigma)}{h}\right)\left[-a^{F}(\tilde{z}) \Omega\left(\frac{d \tilde{z}}{d h^{H}}\right)+\frac{(\alpha-1) B_{0}^{H}\left(\tilde{z} B_{1}^{F}(\tilde{z})\right.}{h \theta^{\alpha}}\right]>0
$$

which is satisfied since the expression in the bracket is positive due to the fact that $d \tilde{z} / d h^{H}<0$ given by Proposition 22 and $\theta>1, \alpha>1$. Therefore, formal employment in the Foreign country increases when hiring costs in the Home country increases. 
Using equation (3.39), employment of recruitment agencies in the Home country can be written as

$$
L_{r}^{H}=2(1-\mu)(1-\sigma) M\left(\frac{B_{0}^{H}(\tilde{z})}{\theta^{\alpha-1} \Omega}\right)
$$

From here, we differentiate this equations with respect to $h^{H}$, and find:

$$
\frac{d L_{r}^{H}}{d h^{H}}=\left[2(1-\mu)(1-\sigma) A_{n} M\right]\left[\left(\frac{a^{H}(\tilde{z})^{\alpha-1}}{\theta^{\alpha-1} \Omega}\right)\left(\frac{d \tilde{z}}{d h^{H}}\right)-\frac{(\alpha-1) \theta^{\alpha-2} B_{0}^{H}(\tilde{z}) B_{1}^{F}(\tilde{z})}{h\left(\theta^{\alpha-1} \Omega\right)^{2}}\right]<0 .
$$

This inequality follows since the first expression in the bracket is negative due to $\theta>1, \alpha>1$ and the result of Proposition 22 which states $d \tilde{z} / d h^{H}<0$. This proves that an increase in hiring costs in the Home country results in lower employment of recruitment agencies in the Home country.

Similarly, employment of recruitment agencies in the Foreign country, using equation (3.40), can be written as

$$
L_{r}^{F}=2(1-\mu)(1-\sigma) M\left(\frac{B_{1}^{F}(\tilde{z})}{\Omega}\right)
$$

We differentiate this equation with respect to $h^{H}$, and find:

$$
\frac{d L_{r}^{F}}{d h^{H}}=-\frac{a^{F}(\tilde{z})^{\alpha-1}}{\Omega}\left(\frac{d \tilde{z}}{d h^{H}}\right)-\left(\frac{(1-\alpha) B_{0}^{H}(\tilde{z}) B_{1}^{F}(\tilde{z})}{h \theta^{\alpha} \Omega^{2}}\right)>0
$$

which is satisfied since Proposition 22 states that $d \tilde{z} / d h^{H}<0$, and $\theta>1, \alpha>1$. Therefore, the Foreign country has higher employment of recruitment agencies when hiring costs in the Home country is higher.

(ii) Moreover, informal employment in the Home country, which is given by equation (3.41), can be written as

$$
L_{n}^{H}=M-2 M(1-\mu)\left(\frac{B_{0}^{H}(\tilde{z}}{\theta^{\alpha-1} \Omega}\right)
$$

From here, we differentiate this equation with respect to $h^{H}$, and find:

$$
\frac{d L_{n}^{H}}{d h^{H}}=-2(1-\mu)\left[\frac{a^{H}(\tilde{z})^{\alpha-1}}{\theta^{\alpha-1} \Omega}\left(\frac{d \tilde{z}}{d h^{H}}\right)-\frac{(\alpha-1) \theta^{\alpha-2} B_{0}^{H}(\tilde{z}) B_{1}^{F}(\tilde{z})}{h\left(\theta^{\alpha-1} \Omega\right)^{2}}\right]>0,
$$

since Proposition 22 states that $d \tilde{z} / d h^{H}<0$, and $\theta>1, \alpha>1$.

Moreover, informal employment in the Foreign country, which is given by equation (3.42), can be written as:

$$
L_{n}^{F}=M-2 M(1-\mu)\left(\frac{B_{1}^{F}(\tilde{z}}{\Omega}\right) .
$$


As we differentiate this equation with respect to $h^{H}$, it is the case that:

$$
\frac{d L_{n}^{F}}{d h^{H}}=-2 M(1-\mu)\left(-\frac{a^{F}(\tilde{z})^{\alpha-1}}{\Omega}\left(\frac{d z}{d h^{H}}\right)-\frac{(1-\alpha) B_{0}^{H}(\tilde{z}) B_{1}^{F}(\tilde{z})}{h \theta^{\alpha} \Omega^{2}}\right)
$$

since Proposition 22 dictates that $d \tilde{z} / d h^{H}<0$, and $\theta>1, \alpha>1$. Therefore, the Foreign country has lower informal employment when the Home country has higher hiring costs.

Proposition 25: Under our symmetry assumptions with $h^{H}>h^{F}=h$ and $\tau=0$, following an increase in $h^{H}$, the size of the informal sector expands in the Home country and it shrinks in the Foreign country.

Proof: It follows directly from the results of Proposition 24 which state that $d L_{n}^{F} / d h^{H}<0$ and $d L_{n}^{H} / d h^{H}>0$ and $Y_{n}^{H}=A_{n}^{H} L_{n}^{H}$.

Proposition 26: Under our symmetry assumptions with $h^{H}>h^{F}=h$ and $\tau=0$, if $h^{H}$ decreases, both countries experience higher welfare.

Proof: Using Proposition 23, which shows that the composite good price is increasing in hiring costs, and the fact that the welfare function, which is given by equation (13), decreases in the composite good price, a decreasing hiring costs in the Home country results in higher welfare in both countries

This result is different from Helpman and Itshoki (2010). In their paper, a country that unilaterally lowers its labour market frictions gains from trade while harming its trading partner. In their model, differentiated good producers engage in monopolistic competition. Lowering labour market frictions results in more competition in the differentiated sector (the formal sector) in both countries. However, the competition affects each country in a different way. The country that lowers its labour market frictions benefits from trade, because more firms enter into the differentiated sector, and produce more varieties at lower costs. In this country, both producer and consumer surplus increase. At the same time, there are less differentiated good producers (formal producers) in the trading partner of this country due to increased competition. These producers produce less varieties at higher costs. This results in lower producers surplus and lower welfare in this country. In our model, all producers operate in a perfectly competitive market; therefore, each producer makes zero profits. Once labour market frictions are decreased, lower prices and higher consumption in each country results, but there is no change in producers surplus. Therefore, both countries experience higher welfare.

The results in this section have important implications for the behaviour of the informal sector in trading economies. In particular, these results imply that the size of a country's informal sector depends on both its level of labour market rigidities and those of its trading partners. If a country's trading partners have relatively higher labour market frictions, then the country will have a smaller informal sector than if its trading partners have relatively lower labour market frictions. This outcome provides a rational for why empirical studies have obtained conflicting results as they studied the role of trade liberalization on the size of informal sector. 


\subsubsection{Restricted Trade: $\tau>0$}

In what follows, we investigate equilibrium outcomes of a more general case in which countries have different hiring costs: $\theta>1$ and have identical trade barriers, $\tau>0$. To do so, we compare equilibrium outcomes of the asymmetric hiring costs scenario, $h^{H}>h^{F}=h$ with the symmetric one, $h^{H}=h^{F}=h$. In this case, subindex $*$ indicates variables in the model with asymmetric hiring costs. Let $\tilde{z}_{*}^{i}$ to represent the thresholds of asymmetric model with $h^{H}>h^{F}=h$, and $\tilde{z}^{i}$ to denote the thresholds of a symmetric model with $h^{H}=h^{F}=h$.

Lemma 4: Under our symmetry assumptions with $h^{H}>h^{F}=h$ and $\tau>0$, it is the case that

$$
\tilde{z}_{*}^{H}<\tilde{z}^{H} \text { and } \tilde{z}_{*}^{F}<\tilde{z}^{F}
$$

which implies that both export thresholds move to the left. Furthermore, $\tilde{z}_{*}^{i}$ for $i=H, F$ must satisfy

$$
\tilde{z}_{*}^{F}>\tilde{z}_{*}^{H}
$$

with $\tilde{z}_{*}^{F}>1 / 2$ if $1+\tau>\theta$.

Proof: Given $\theta>1$, and the fact that $A(z)$ is strictly decreasing in formal varieties $z$, and using equations (3.26) and (3.27), observe that:

$$
\begin{aligned}
& A\left(\tilde{z}_{*}^{F}\right)=\frac{\theta}{1+\tau}>\frac{1}{1+\tau}=A\left(\tilde{z}^{F}\right) \Longrightarrow \tilde{z}^{F}>\tilde{z}_{*}^{F}, \\
& A\left(\tilde{z}_{*}^{H}\right)=\theta(1+\tau)>1+\tau=A\left(\tilde{z}^{H}\right) \Longrightarrow \tilde{z}^{H}>\tilde{z}_{*}^{H} .
\end{aligned}
$$

From here, it is the case that

$$
A\left(\tilde{z}_{*}^{H}\right)=\theta(1+\tau)>\frac{\theta}{1+\tau}=A\left(\tilde{z}_{*}^{F}\right)
$$

which implies $\tilde{z}_{*}^{F}>\tilde{z}_{*}^{H}$. Moreover, using the symmetry condition of formal producers, this can be written as $\tilde{z}_{*}^{F}>1-\tilde{z}_{*}^{F}$, or $\tilde{z}_{*}^{F}>1 / 2$ if $1+\tau>\theta$.

Lemma 5: Under our symmetry assumptions with $h^{H}>h^{F}=h$ and $\tau>0$, observe that

$$
B_{1}^{F}\left(\tilde{z}_{*}^{F}\right)>B_{0}^{H}\left(\tilde{z}_{*}^{H}\right)
$$

Proof: Using Lemma 1, which dictates that $B_{1}^{F}\left(\tilde{z}^{F}\right)$ is decreasing and $B_{0}^{H}\left(\tilde{z}^{H}\right)$ is increasing in the export thresholds, and Lemma 4, which shows $\tilde{z}_{*}^{H}<\tilde{z}^{H}$ and $\tilde{z}_{*}^{F}<\tilde{z}^{F}$, we obtain:

$$
B_{1}^{F}\left(\tilde{z}_{*}^{F}\right)>B_{1}^{F}\left(\tilde{z}^{F}\right) \text { and } B_{0}^{H}\left(\tilde{z}^{H}\right)>B_{0}^{H}\left(\tilde{z}_{*}^{H}\right)
$$

Combining these two results with Lemma 2, which states that in the symmetric case: $B_{1}^{F}\left(\tilde{z}^{F}\right)=B_{0}^{H}\left(\tilde{z}^{H}\right)$, 
notice that

$$
B_{1}^{F}\left(\tilde{z}_{*}^{F}\right)>B_{1}^{F}\left(\tilde{z}^{F}\right)=B_{0}^{H}\left(\tilde{z}^{H}\right)>B_{0}^{H}\left(\tilde{z}_{*}^{H}\right)
$$

The following proposition derives properties of the equilibrium composite good prices.

Proposition 27: Under our symmetry assumptions with $h^{H}>h^{F}=h$ and $\tau>0$, the households in the Home country experience higher composite good price relative to the Foreign country: $P_{*}^{H}>P_{*}^{F}$. Proof: Using equations (3.30) and (3.31), we define the following expressions when countries have asymmetric hiring costs,

$$
\begin{aligned}
& \Omega_{*}^{H}=\left(\frac{(1-\sigma) P_{*}^{H}}{h^{H}}\right)^{1-\alpha}=B_{0}^{H}\left(\tilde{z}_{*}^{F}\right)+\theta^{\alpha-1}(1+\tau)^{1-\alpha} B_{1}^{F}\left(\tilde{z}_{*}^{F}\right), \\
& \Omega_{*}^{F}=\left(\frac{(1-\sigma) P_{*}^{F}}{h^{F}}\right)^{1-\alpha}=(1+\tau)^{1-\alpha} B_{0}^{H}\left(\tilde{z}_{*}^{H}\right)+\theta^{\alpha-1} B_{1}^{F}\left(\tilde{z}_{*}^{H}\right)
\end{aligned}
$$

Moreover, we define $P$ as the equilibrium composite good price for the model with symmetric hiring costs, $h^{H}=h^{F}=h$ and $\tau>0$. Similarly, using equations (3.30) and (3.31), we define the following expressions when countries have identical hiring costs:

$$
\begin{aligned}
& \Omega^{H}=\left(\frac{(1-\sigma) P^{H}}{h}\right)^{1-\alpha}=B_{0}^{H}\left(\tilde{z}_{\tau}^{F}\right)+(1+\tau)^{1-\alpha} B_{1}^{F}\left(\tilde{z}_{\tau}^{F}\right) \\
& \Omega^{F}=\left(\frac{(1-\sigma) P^{F}}{h}\right)^{1-\alpha}=(1+\tau)^{1-\alpha} B_{0}^{H}\left(\tilde{z}_{\tau}^{F}\right)+B_{1}^{F}\left(\tilde{z}_{\tau}^{F}\right) .
\end{aligned}
$$

From here, we show that $\Omega_{*}^{F}-\Omega^{F}>\Omega_{*}^{H}-\Omega^{H}$ which implies $P_{*}^{H}>P_{*}^{F}$ since Proposition 5 states that $\Omega^{H}=\Omega^{F}$.

In this case, there are two scenarios to consider, which determine the relative position of the thresholds value on the y-axis in the following Figures.

Case-1: $\theta>1+\tau$. In this case, we have:

$$
a^{F}(z)^{\alpha-1}>\left(\frac{\theta a^{F}(z)}{1+\tau}\right)^{\alpha-1}
$$

The areas, $\Omega^{i}$ and $\Omega_{*}^{i}$ for $i=H, F$ are plotted in Figure 3.3. Observe that $\Omega_{*}^{F}-\Omega^{F}$ is given by the area $A+B+C$, and $\Omega_{*}^{H}-\Omega^{H}$ is the area $E$. 


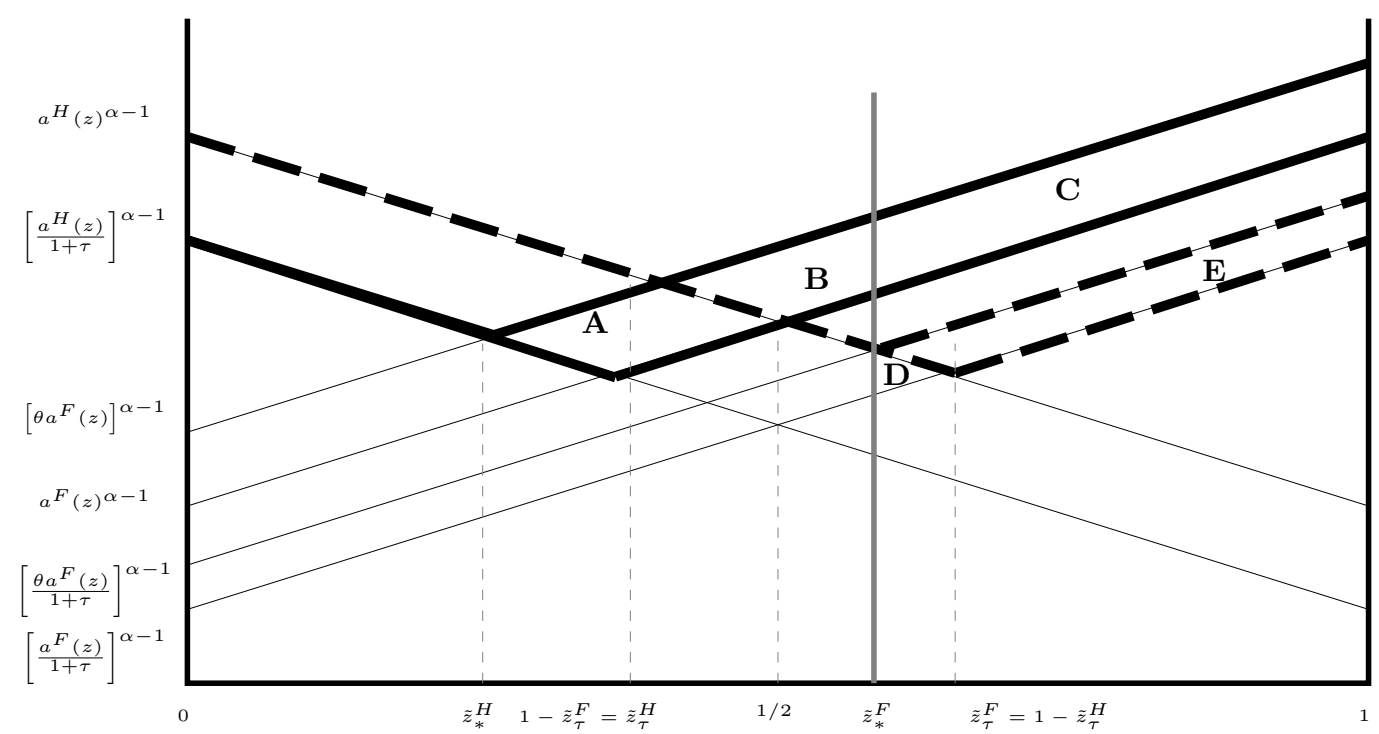

Figure 3.3: The export thresholds and the pattern of production with $\theta>1+\tau$

For any formal variety $z$, observe that

$$
\left[\frac{\theta a^{F}(z)}{1+\tau}\right]^{\alpha-1}-\left[\frac{a^{F}(z)}{1+\tau}\right]^{\alpha-1}=\left(\theta^{\alpha-1}-1\right)\left[\frac{a^{F}(z)}{1+\tau}\right]^{\alpha-1}>0
$$

and

$$
\theta^{\alpha-1} a^{F}(z)^{\alpha-1}-a^{F}(z)^{\alpha-1}=\left(\theta^{\alpha-1}-1\right) a^{F}(z)^{\alpha-1}>0
$$

since $\alpha>1$ and $\theta>1$.

Therefore, it is case that:

$$
\underbrace{\Omega^{F}-\Omega^{F}}_{A+B+C}>\underbrace{\int_{\tilde{z}_{*}^{F}}^{1}\left(\theta^{\alpha-1}-1\right) a^{F}(z)^{\alpha-1} d z}_{\mathrm{C}}>\underbrace{\int_{\tilde{z}_{*}^{F}}^{1}\left(\theta^{\alpha-1}-1\right)\left[\frac{a^{F}(z)}{1+\tau}\right]^{\alpha-1} d z}_{E+D}>\underbrace{\Omega^{H}-\Omega^{H}}_{E},
$$

which implies that the composite good price in the Home country is greater than that of the Foreign country, $P_{*}^{H}>P_{*}^{F}$.

Case-2: $\theta<1+\tau$. In this case, we have:

$$
a^{F}(z)^{\alpha-1}<\left(\frac{\theta a^{F}(z)}{1+\tau}\right)^{\alpha-1}
$$

Here, there are two possibilities to examine: $(i) \tilde{z}_{*}^{F}>\tilde{z}_{\tau}^{H}$, and $(i i) \tilde{z}_{*}^{F}<\tilde{z}_{\tau}^{H}$

(i) Figure 3.4 presents $\Omega_{*}^{i}$ and $\Omega^{i}$ for $i=H, F$ when the export thresholds satisfy $\tilde{z}_{*}^{F}>\tilde{z}^{H}$ : 


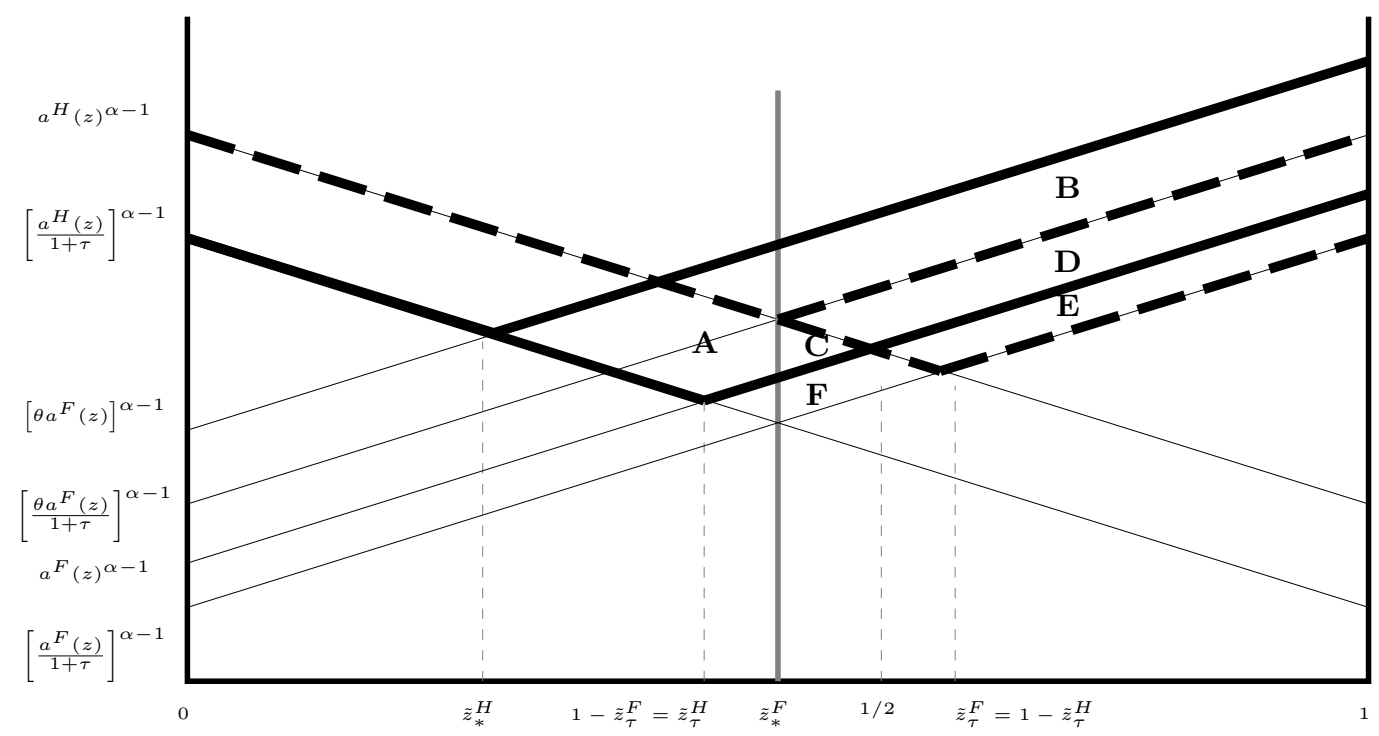

Figure 3.4: The export thresholds and the pattern of production with $\theta<1+\tau$ when $\tilde{z}_{*}^{F}>\tilde{z}^{H}$

For any formal variety $z$, observe that we have the same inequalities given in equations (3.64) and (3.65). The the area of $\Omega_{*}^{F}-\Omega^{F}$ is represented by $A+B+C+D$, and the area of $\Omega_{*}^{H}-\Omega^{H}$ is represented by $D+E$.

In Figure 3.4, notice that:

$$
\underbrace{\Omega_{*}^{F}-\Omega^{F}}_{A+B+C+D}>\underbrace{\int_{\tilde{z}_{*}^{F}}^{1}\left(\theta^{\alpha-1}-1\right) a^{F}(z)^{\alpha-1} d z}_{B+C+D}>\underbrace{\int_{\tilde{z}_{*}^{F}}^{1}\left(\theta^{\alpha-1}-1\right)\left[\frac{a^{F}(z)}{1+\tau}\right]^{\alpha-1} d z}_{C+D+E+F}>\underbrace{\Omega_{*}^{H}-\Omega^{H}}_{D+E},
$$

which implies that the Home country has higher composite-good price relative to the Foreign country: $P_{*}^{H}>P_{*}^{F}$.

(ii) Figure 3.5 plots $\Omega_{*}^{i}$ and $\Omega_{\tau}^{i}$ for $i=H, F$ when export thresholds satisfy $\tilde{z}_{*}^{F}<\tilde{z}^{H}$ :

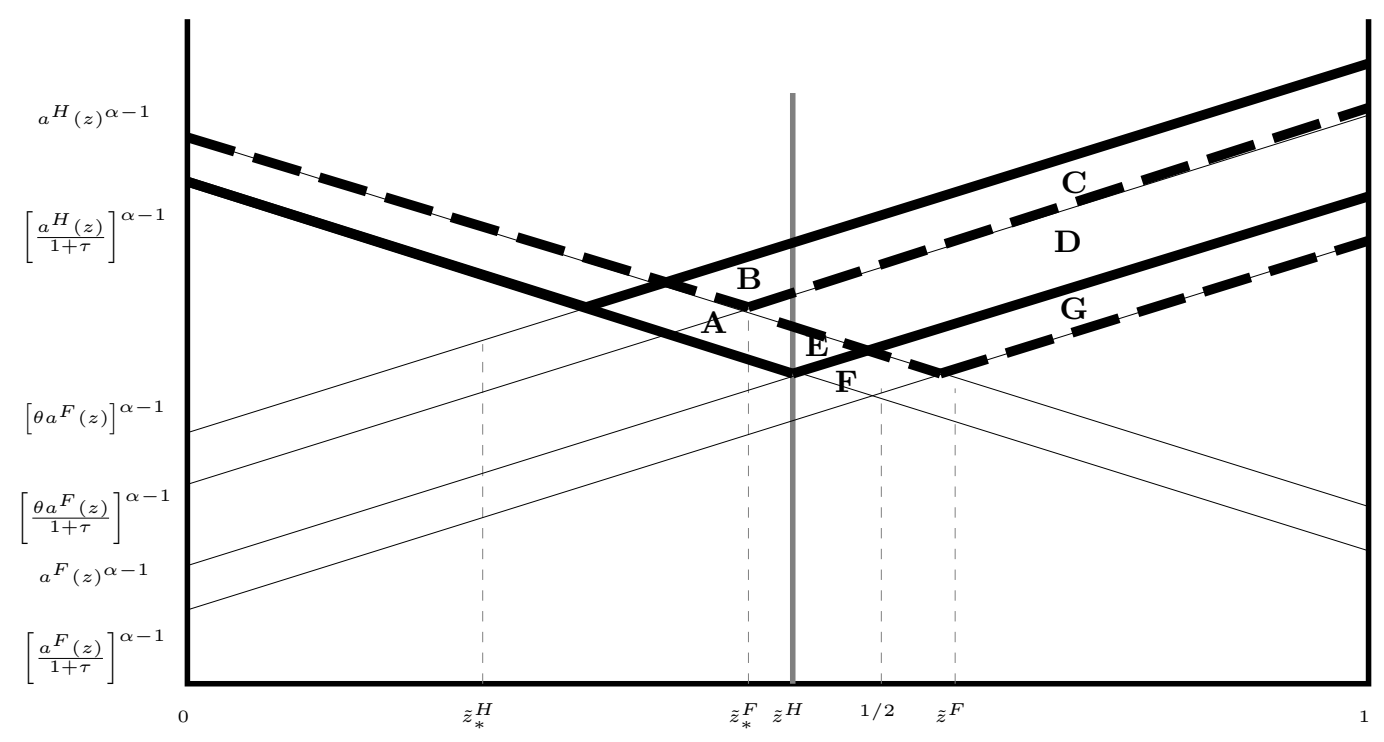

Figure 3.5: The export thresholds and the pattern of production with $\theta<1+\tau$ when $\tilde{z}_{*}^{F}<\tilde{z}^{H}$

Similarly, for any formal variety $z$, notice that we have the same inequalities given in equations (3.62) 
and (3.63). In Figure 3.5, $\Omega_{*}^{F}-\Omega^{F}$ represents the area $A+B+C+D$, and $\Omega_{*}^{H}-\Omega^{H}$ is the area $D+G$. From here, observe that

$$
\underbrace{\Omega_{*}^{F}-\Omega^{F}}_{A+B+C+D}>\underbrace{\int_{\tilde{z}^{H}}^{1}\left(\theta^{\alpha-1}-1\right) a^{F}(z)^{\alpha-1} d z}_{C+D+E}>\underbrace{\int_{\tilde{z}^{H}}^{1}\left(\theta^{\alpha-1}-1\right)\left[\frac{a^{F}(z)}{1+\tau}\right]^{\alpha-1} d z}_{D+E+F+G}>\underbrace{\Omega_{*}^{H}-\Omega^{H}}_{G+D},
$$

which implies that the Home country experiences higher composite-good price relative to the Foreign country, $P_{*}^{H}>P_{*}^{F}$.

The behaviour of of employments is similar to the case with free trade, and the next proposition states this formally:

Proposition 28: Under our symmetry assumptions with $h^{H}>h^{F}=h$ and $\tau>0,(i)$ the Foreign country has higher formal employment relative to the Home country: $L_{*}^{F}>L_{*}^{H}$, and the recruitment agencies in the Foreign country has higher employment than those in the Home country: $L_{r *}^{F}>L_{r *}^{H}$.

\section{Proof:}

(i) Comparing equations (3.37) and (3.38), which represent the aggregate formal employment in each country, we have that $L_{*}^{F}>L_{*}^{H}$ if and only if

$$
\theta^{\alpha}\left[\frac{B_{1}^{F}\left(\tilde{z}_{*}^{H}\right)}{\left(P_{*}^{F}\right)^{1-\alpha}}+\frac{B_{1}^{F}\left(\tilde{z}_{*}^{F}\right)}{(1+\tau)^{1-\alpha}\left(P_{*}^{H}\right)^{1-\alpha}}\right]>\left[\frac{B_{0}^{H}\left(\tilde{z}_{*}^{F}\right)}{\left(P^{H}\right)^{1-\alpha}}+\frac{B_{0}^{H}\left(\tilde{z}_{*}^{H}\right)}{(1+\tau)^{1-\alpha}\left(P^{F}\right)^{1-\alpha}}\right]
$$

or, operating:

$$
\left(P_{*}^{F}\right)^{1-\alpha}\left[\theta^{\alpha} B_{1}^{F}\left(\tilde{z}_{*}^{F}\right)-(1+\tau)^{\alpha} B_{0}^{H}\left(\tilde{z}_{*}^{F}\right)\right]>\left(P_{*}^{H}\right)^{1-\alpha}\left[B_{0}^{H}\left(\tilde{z}_{*}^{H}\right)-\theta^{\alpha}(1+\tau)^{\alpha} B_{1}^{F}\left(\tilde{z}_{*}^{H}\right)\right]
$$

Therefore, given that $P_{*}^{H}>P_{*}^{F}$ and $\alpha>1$, it is enough to show that

$$
\theta^{\alpha} B_{1}^{F}\left(\tilde{z}_{*}^{F}\right)-B_{0}^{H}\left(\tilde{z}_{*}^{H}\right)>(1+\tau)^{\alpha} B_{0}^{H}\left(\tilde{z}_{*}^{F}\right)-\theta^{\alpha}(1+\tau)^{\alpha} B_{1}^{F}\left(\tilde{z}_{*}^{H}\right)
$$

Here, we compare two expressions term by term.

First, using Lemma 5 which dictates that $B_{1}^{F}\left(\tilde{z}_{*}^{F}\right)>B_{0}^{H}\left(\tilde{z}_{*}^{H}\right)$, and $\theta>1$, it is the case that:

$$
\theta^{\alpha} B_{1}^{F}\left(\tilde{z}_{*}^{F}\right)>B_{0}^{H}\left(\tilde{z}_{*}^{H}\right)
$$

This implies that the left hand-side of the previous inequality is positive.

Moreover, using Lemma 4 which states $\tilde{z}_{*}^{F}>\tilde{z}_{*}^{H}$ and the fact that $B_{0}^{H}\left(\tilde{z}^{H}\right)$ is increasing and $B_{1}^{F}\left(\tilde{z}^{F}\right)$ is decreasing $\tilde{z}$ based on Lemma 1, observe that

$$
B_{1}^{F}\left(\tilde{z}_{*}^{H}\right)>B_{0}^{H}\left(\tilde{z}_{*}^{F}\right)
$$

and this implies that the right hand side of the previous inequality is negative. Therefore, we can conclude 
that $L_{*}^{F}>L_{*}^{H}$.

(ii) Similarly, comparing equations (3.39) and (3.40), which represent the aggregate formal employment in each country, we have that $L_{r *}^{F}>L_{r *}^{H}$ if and only if

$$
\left(P_{*}^{F}\right)^{1-\alpha}\left[\theta^{\alpha-1} B_{1}^{F}\left(\tilde{z}_{*}^{F}\right)-(1+\tau)^{\alpha} B_{0}^{H}\left(\tilde{z}_{*}^{F}\right)\right]>\left(P_{*}^{H}\right)^{1-\alpha}\left[B_{0}^{H}\left(\tilde{z}_{*}^{H}\right)-\theta^{\alpha-1}(1+\tau)^{\alpha} B_{1}^{F}\left(\tilde{z}_{*}^{H}\right)\right] .
$$

Given that $P_{*}^{H}>P_{*}^{F}$ and $\alpha>1$, it is enough to show that:

$$
\theta^{\alpha-1} B_{1}^{F}\left(\tilde{z}_{*}^{F}\right)-B_{0}^{H}\left(\tilde{z}_{*}^{H}\right)>(1+\tau)^{\alpha} B_{0}^{H}\left(\tilde{z}_{*}^{F}\right)-\theta^{\alpha-1}(1+\tau)^{\alpha} B_{1}^{F}\left(\tilde{z}_{*}^{H}\right)
$$

From the same arguments used in part $(i)$, it is clear to see that the Foreign country has higher employment of recruitment agencies than the Home country, $L_{r *}^{F}>L_{r *}^{H}$.

Proposition 29: Under our symmetry assumptions with $h^{H}>h^{F}=h$ and $\tau>0$, total informal employment is higher in the Home country relative to the Foreign country: $L_{n *}^{H}>L_{n *}^{F}$.

Proof: Comparing the aggregate employment of informal producers, given by equations (3.41) and (3.42), we have that $L_{*}^{F}>L_{*}^{H}$ if and only if

$$
M-\left(\frac{h^{H}}{A_{n}(1-\sigma)}\right) L_{*}^{H}>M-\left(\frac{h^{H}}{\theta A_{n}(1-\sigma)}\right) L_{*}^{F},
$$

or

$$
\theta^{\alpha} B_{1}^{F}\left(\tilde{z}_{*}^{F}\right)-\theta B_{0}^{H}\left(\tilde{z}_{*}^{H}\right)>(1+\tau)^{\alpha} B_{0}^{H}\left(\tilde{z}_{*}^{F}\right)-\theta^{\alpha+1}(1+\tau)^{\alpha} B_{1}^{F}\left(\tilde{z}_{*}^{H}\right)
$$

Applying the same argument used in Proposition (3.28), it is the case that the Home country has higher informal employment than the Foreign country: $L_{n *}^{H}>L_{n *}^{F}$ when hiring costs in the Home country increase.

Proposition 30: Under our symmetry assumptions with $h^{H}>h^{F}=h$ and $\tau>0$, the Home country has larger informal sector than the Foreign country.

Proof: This can be proved directly from the result of the previous propositions.

Proposition 31: Under our symmetry assumptions with $h^{H}>h^{F}=h$ and $\tau>0$, the Home country exports informal goods on net.

Proof: Using the value of imported formal varieties, which is given by equations (3.45) and (3.46), it is the case that $I m p_{*}^{H}>\operatorname{Im} p_{*}^{F}$ if and only if

$$
\theta^{\alpha-1}\left(P_{*}^{H}\right)^{\alpha-1} B_{1}^{F}\left(\tilde{z}_{*}^{F}\right)>\left(P_{*}^{F}\right)^{\alpha-1} B_{0}^{H}\left(\tilde{z}_{*}^{H}\right) .
$$

Using $\alpha>1$, Lemma 5 which dictates $B_{1}^{F}\left(\tilde{z}_{*}^{F}\right)>B_{0}^{H}\left(\tilde{z}_{*}^{H}\right)$, and the fact that $P_{*}^{H}>P_{*}^{F}$ given by Proposition 27, the Home country exports more informal goods to the Foreign country. 
Proposition 32: Under our symmetry assumptions with with $h^{H}>h^{F}=h$ and $\tau>0$, the Home country has lower welfare than the Foreign country.

Proof: Using Proposition 27, which shows that the Home country has higher composite good price relative to the Foreign country, the Home country has lower welfare since the welfare function, which is given by equation (3.13), is decreasing in the composite good price.

Similar to the previous section, which examines the effect of labour market policy under free trade, this section provides important conclusions for the case of restricted trade. Once countries with different hiring costs engage in trade with positive trade costs, a country with higher hiring costs faces higher composite good price relative to its trading partners since the prices of non-tradable goods are also affected, and this leads lower consumption and welfare in this country. The country with higher hiring costs has a larger informal and a smaller formal sector relative to its trading partners. As in the free trade case, in the presence of homogeneous trade cost, the size of the informal sector of a country is both determined by its own labour market characteristics and those of its trading partners

In the following section, we examine changes in trade outcomes when countries implement labour market and trade policy. We use numerical exercises for this study since analytical results cannot to obtain.

\subsubsection{Comparative Statics}

In this section, we use numerical simulation to examine the effect of changes in labour market and trade policies on the pattern of production, the trade structure and welfare of countries. In our simulations, we fix parameters from existing literature. In particular, the parameter of the bargaining power, $\sigma$ is given a value of 0.5 , and the share of the matching function, $\eta$ is set to 0.5 . We normalized the number of members in the household, $M$ to 10 . Moreover, we set the share of informal good consumption in the Cobb-Douglas utility function as $\mu=0.3$ since Schneider and Enste (2000) report that the two thirds of the income earned in the informal economy is later spent in the formal economy. Recall that hiring costs in country $i=H, F$, which is given by equation (3.24), are determined by productivity of recruitment agencies, $A_{r}^{i}$ and the productivity parameter of matching function, $\phi^{i}$. Assuming that the Home country has higher hiring costs relative to the Foreign country, we set the productivity parameter of matching function, $\phi^{i}=0.3$ for both countries, and set $A_{r}^{H}=4.9$ and $A_{r}^{F}=5$ to match with the empirical findings of Schneider et. al (2010) which state that the average size of the informal sector in developing countries is around $28 \%$. As it is used widely in literature, we set the elasticity of substitution, $\alpha$ to the value of 2 . 
We report the model parameters, their definitions and their sources in Table 3.1.

\begin{tabular}{lccc} 
Definitions of parameters & Symbols & Values & Sources \\
\hline The share parameter of the utility function & $\mu$ & 0.3 & Literature \\
Total individuals in the household & $M^{i}$ & 10 & Normalized \\
Productivity parameter of matching function & $\phi^{i}$ & 0.3 & Fixed \\
Bargaining power for workers & $\sigma$ & 0.5 & Literature \\
The share parameter in the matching function & $\eta$ & 0.5 & Literature \\
Elasticity parameter & $\alpha$ & 2 & Literature \\
Productivity parameters of recruitment agencies & $A_{r}^{H}$ & 4.8 & Fixed \\
Productivity parameters of recruitment agencies & $A_{r}^{F}$ & 5 & Fixed \\
Productivity parameters of informal producers & $A_{n}^{i}$ & 1 & Fixed \\
\hline
\end{tabular}

Table 3.1: Parameter Values

Furthermore, we order formal varieties, $z$ in the $[0,1]$ interval since we have continuum of goods in our model, and use the productivity values of formal producers following Eaton and Kortum (1999):

$$
a^{H}(z)=2-z \text { and } a^{F}(z)=1+z
$$

In what follows, we investigate changes in the key economic variables: $(i)$ once both countries implement trade liberalization by decreasing their common trade costs, $\tau$, and $(i i)$ when hiring costs increase in the Home country due to a gradual decrease in the productivity parameter of recruitment agencies in the Home country, $A_{r}^{H}$.

\section{Trade liberalization with $\theta>1$}

Assume that the value of the productivity parameter of the recruitment agencies in the Foreign country is $2 \%$ higher than that of the Home country. This results in higher hiring costs in the Home country relative to the Foreign country:

$$
h^{H}=1.3831>1.3552=h^{F} \text { with } \theta=1.0206 .
$$

As we report in the analytical part, countries with asymmetric hiring costs experience different export thresholds when $\tau>0$. Figure 3.6 plots export thresholds in each country at different levels of the trade costs: 


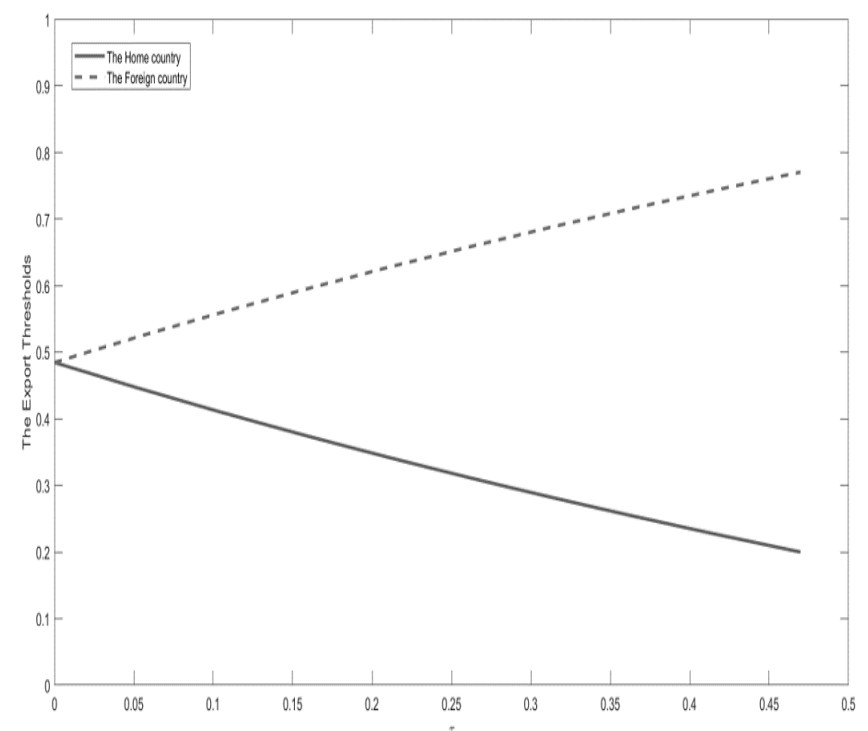

Figure 3.6: The export thresholds with $\tau>0$ and $\theta>1$

We observe that, as shown in Proposition 6, the export threshold of the Foreign country, $\tilde{z}^{F}$ increases and the export threshold of the Home country, $\tilde{z}^{H}$ decreases. Varieties in between in two thresholds are not traded. This implies that there are more formal varieties being traded with lower trade costs. Observe that the export thresholds of countries are equalized: $\tilde{z}^{F}=\tilde{z}^{H}=\tilde{z}$ at $\tau=0$, and all formal varieties are traded.

Figure 3.7 presents the effect of decreasing trade costs, $\tau$ on the composite good price in each country:

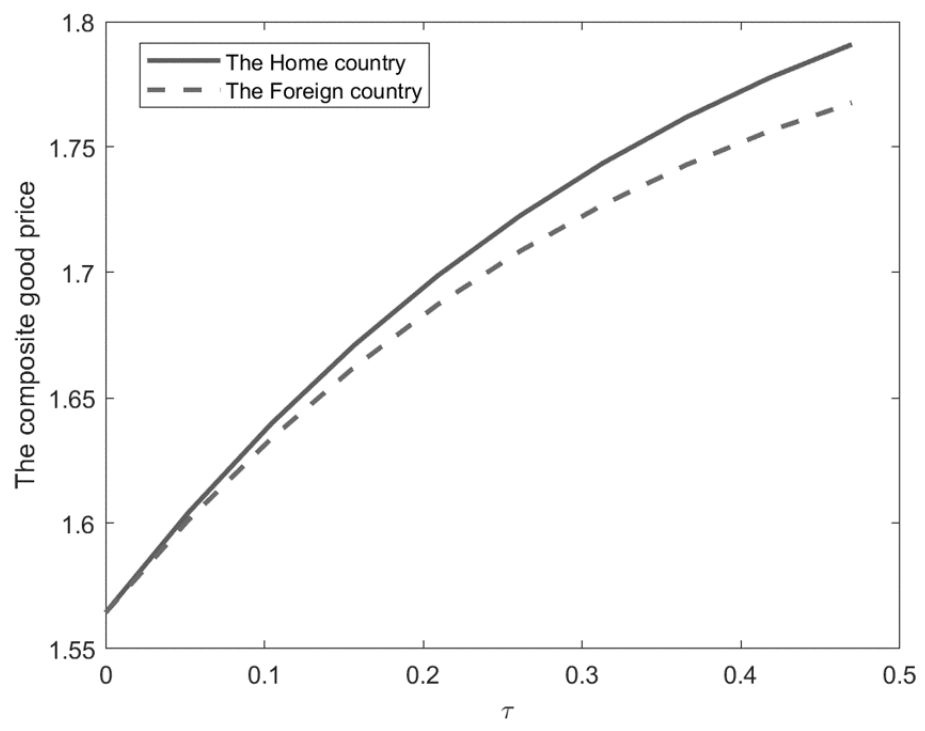

Figure 3.7: The composite good price with $\tau>0$ and $\theta>1$

As shown in Proposition 27, the Home country faces higher composite good price. Figure 3.7 shows that the differences in formal variety prices is higher for higher values of $\tau$. As the trade cost decreases, the difference in prices becomes smaller and prices are equal at free trade. All these effects are derived from the fact that each country exports more goods, trade liberalization leads formal varieties to be produced 
only in the lower cost country.

Figure 3.8 shows the corresponding welfare functions at different levels of trade costs, $\tau$. Notice that Figure 3.8 is consistent with Proposition 32: the Home country has lower welfare than the Foreign country in all different levels of trade costs, $\tau$ since the Home country has higher hiring costs.

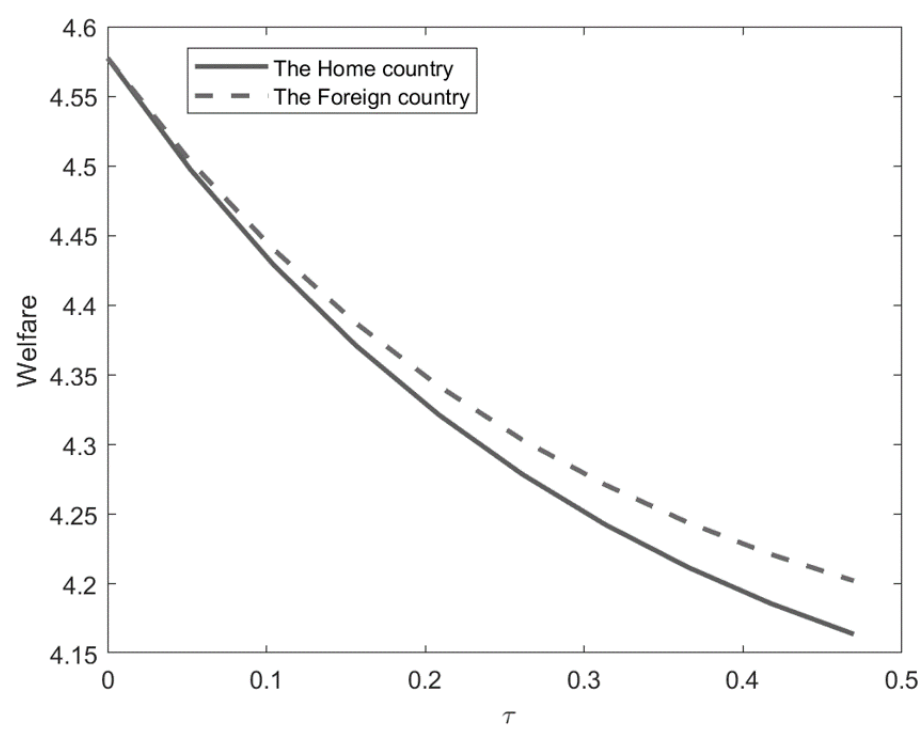

Figure 3.8: Welfare with $\theta>1$ and $\tau>0$

Once trade liberalization takes place, countries specialize in producing formal varieties in which they have a comparative advantage. This results in a lower cost of producing formal varieties which causes lower composite good price in the end. Since welfare function of each country, which is given in equation (3.13), decreases in the composite good price, trade liberalization results in mutual benefits for both countries, as shown in Figure 3.8. However, the Home country, which has higher hiring costs, benefits more from trade liberalization since the representative household in the Home country now accesses formal varieties imported from the Foreign country at much lower prices.

Figure 3.9 illustrates that the shares of total formal employment in both countries for different value of trade $\operatorname{cost} \tau$. We observe that the share decreases in the Home country and increases in the Foreign country as the trade cost $\tau$ is reduced. 


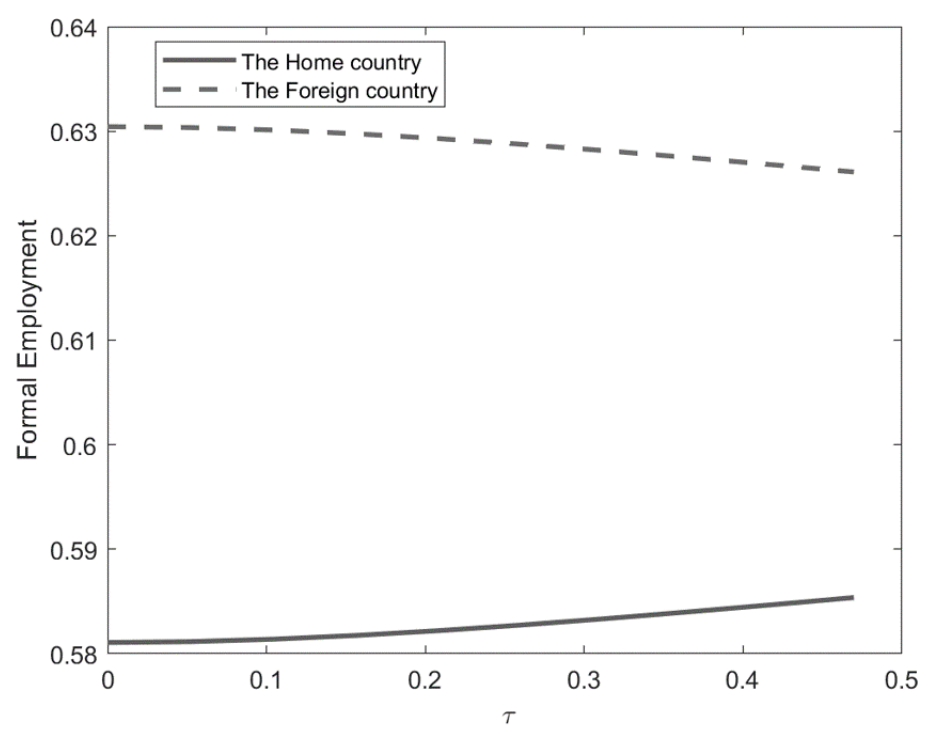

Figure 3.9: Total formal employment with $\tau>0$ and $\theta>1$

From Proposition 28, recall that the Foreign country has higher formal employment than the Home country due to lower frictions in its labour market. Lower trade costs result in more formal employment in the Foreign country. Moreover, formal employment decreases in the Home country.

Figure 3.10 reports that the Home country has higher the share of informal employment than the Foreign country at different levels of trade costs:

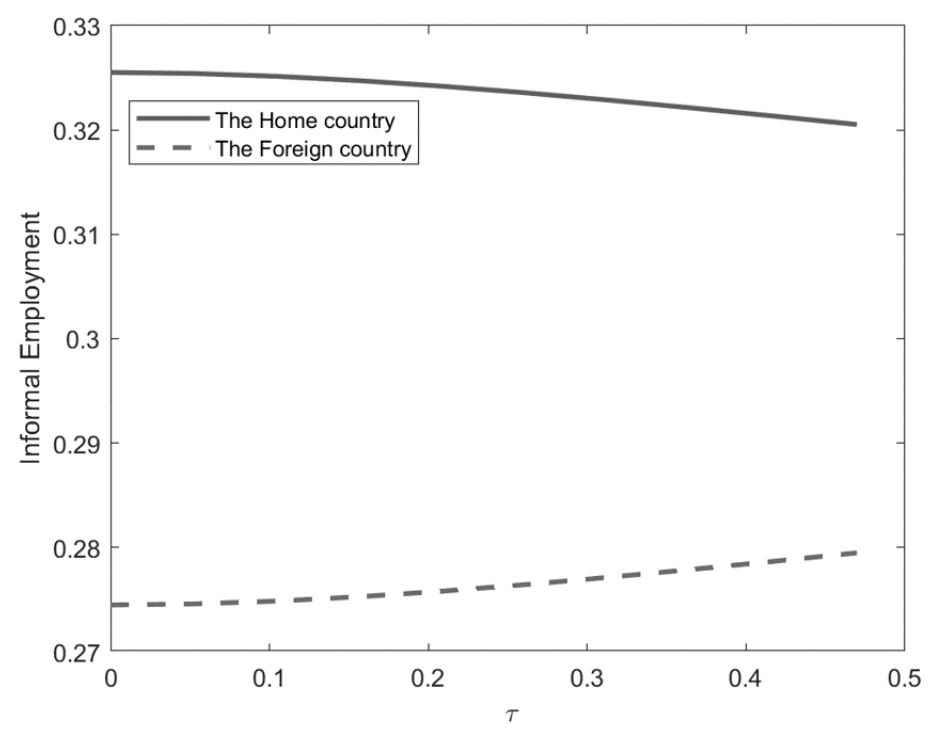

Figure 3.10: Total informal employment with $\tau>0$ and $\theta>1$

As stated in Presented in Proposition 29, informal employment in the Foreign country declines as trade $\operatorname{costs} \tau$ decreases since the Foreign country has comparative advantages in producing formal varieties. Furthermore, as in Proposition 30, the Home country, which has relatively higher labour market frictions, experiences the higher share of informal sector. The size of the informal sector expands in the Home country while it declines in the Foreign country. 
In Proposition 31, we show that the Foreign country exports more formal varieties to the Home country since it has lower hiring costs. Figure 3.11 plots the value of imports of formal varieties in each country at different levels of trade costs:

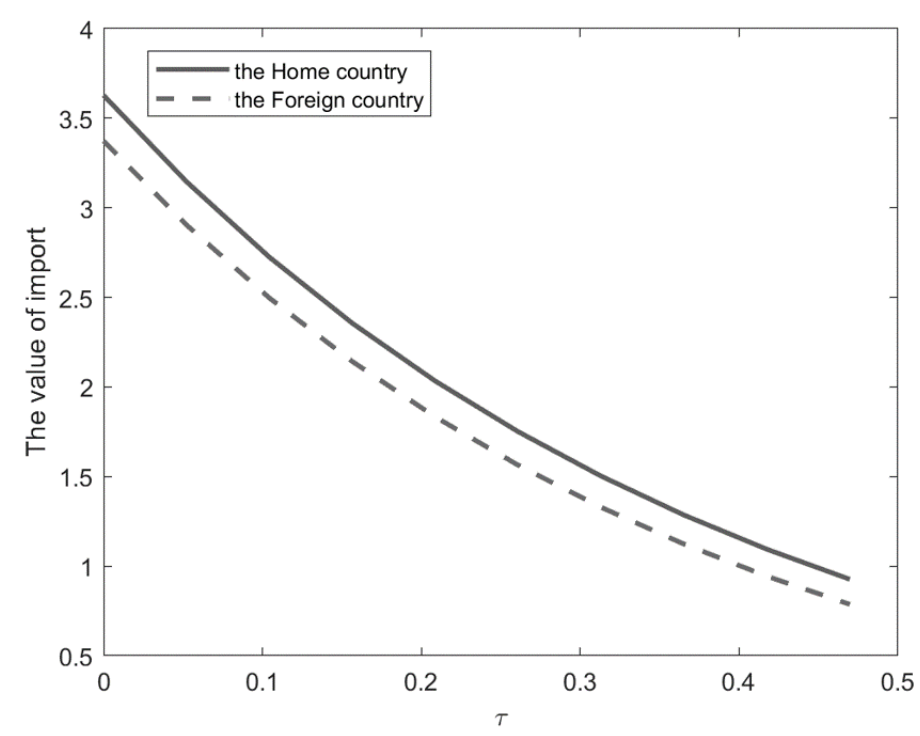

Figure 3.11: The value of import with $\tau>0$ and $\theta>1$

Notice that both countries have higher value of imports of formal varieties as trade barriers decrease. Moreover, the Home country has higher value of imports of formal varieties since the Foreign country has comparative advantages in formal good production.

As we proved in the theory section, countries have different export thresholds when they have asymmetric hiring costs. The Home country has comparative advantages in informal good production since it has larger informal sector. The reduction in trade costs makes the Home country even more competitive in informal good production, which leads the Home country to allocate more employment toward the informal sector. Once countries reduce trade costs, more formal varieties become traded. The reduction in trade costs reduce the price of informal varieties, and this causes a lower composite-good price in each country. Welfare of each country increases since the welfare function increases as the composite-good price decreases. However, the composite good price in the Home country remains higher than the one in the Foreign country since the Home country has relatively higher hiring costs, and therefore it faces relatively higher prices of varieties that are not traded. Furthermore, the Home country experiences lower welfare than the Foreign country.

\section{Labour market policy with $\tau>0$}

In this exercise, we keep trade costs, $\tau$ fixed and consider the effect of increasing hiring costs further in the Home country, while leaving the Foreign country' hiring costs fixed. We consider that hiring costs in the Home country increases through a decrease in the productivity of its recruitment agencies, $A_{r}^{H}$. 
Figure 3.12 presents changes in the export thresholds as hiring costs in the Home country increase:

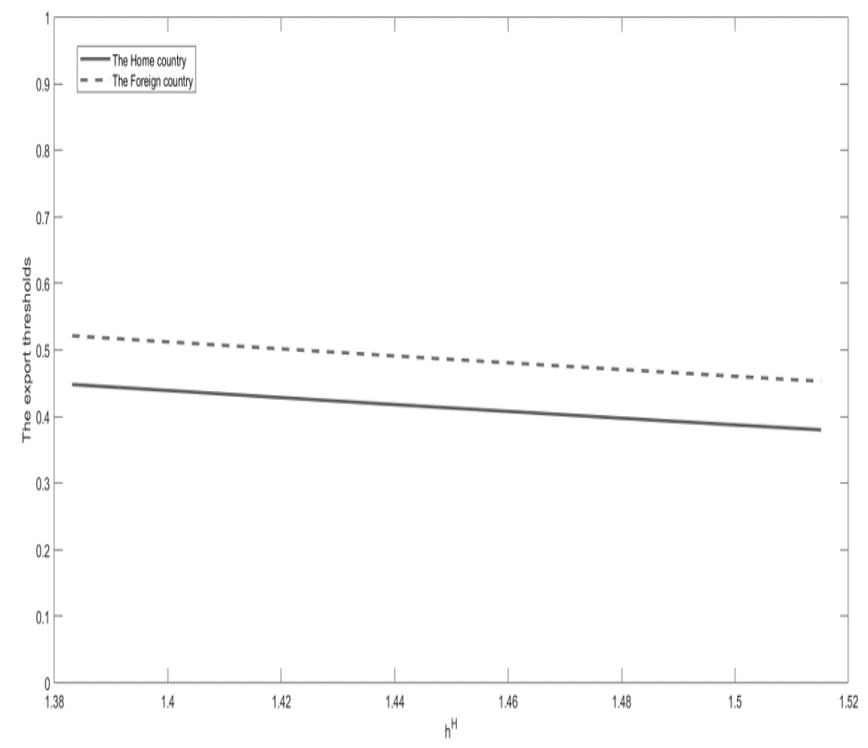

Figure 3.12: The export thresholds with $\tau>0$ and $\theta>1$

In the theory part, Lemma 4 states that higher hiring costs in the Home country result in movement of the export thresholds to the left which implies that the export threshold of each country decrease. This is reflected in Figure 3.12. Furthermore, notice that the difference between the solid line and the dashed line, which indicates non-traded goods, does not change as hiring costs in the Home country increase. Figure 3.13 shows how further increase of hiring costs in the Home country affects the composite good price in each country:

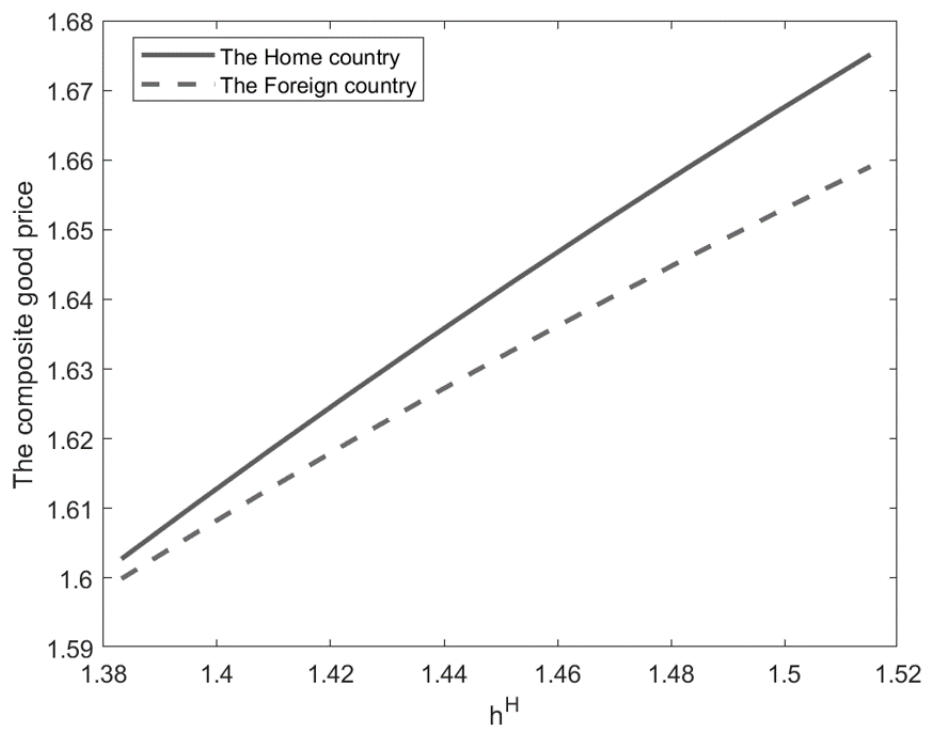

Figure 3.13: The composite good price with with $\tau>0$ and $\theta>1$

As stated in the theory section (Proposition 12), the households in each country experience higher composite good price due to higher hiring costs in the Home country. Moreover, from Proposition 27 , it is the case that consumers in the Home country face with higher composite good price since the 
prices of non-traded goods are also higher. Figure 3.13 presents that this difference in prices increases with increase in hiring costs in the Home country, $h^{H}$.

Figure 3.14 plots the welfare functions in both countries when hiring costs in the Home country increase:

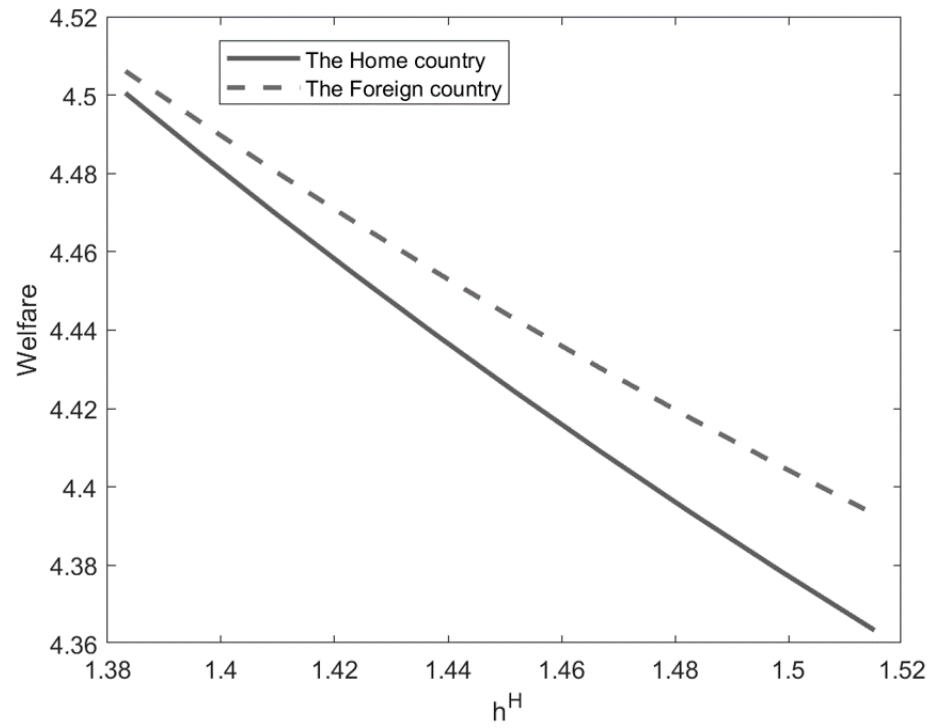

Figure 3.14: Welfare with $\theta>1$ and $\tau>0$

It shows that as hiring costs in the Home country, $h^{H}$ increase, welfare decreases as shown in the theory section (Equation (13)).

Figure 3.15 plots changes in the share of total formal employment in each country once the Home country increases its hiring costs:

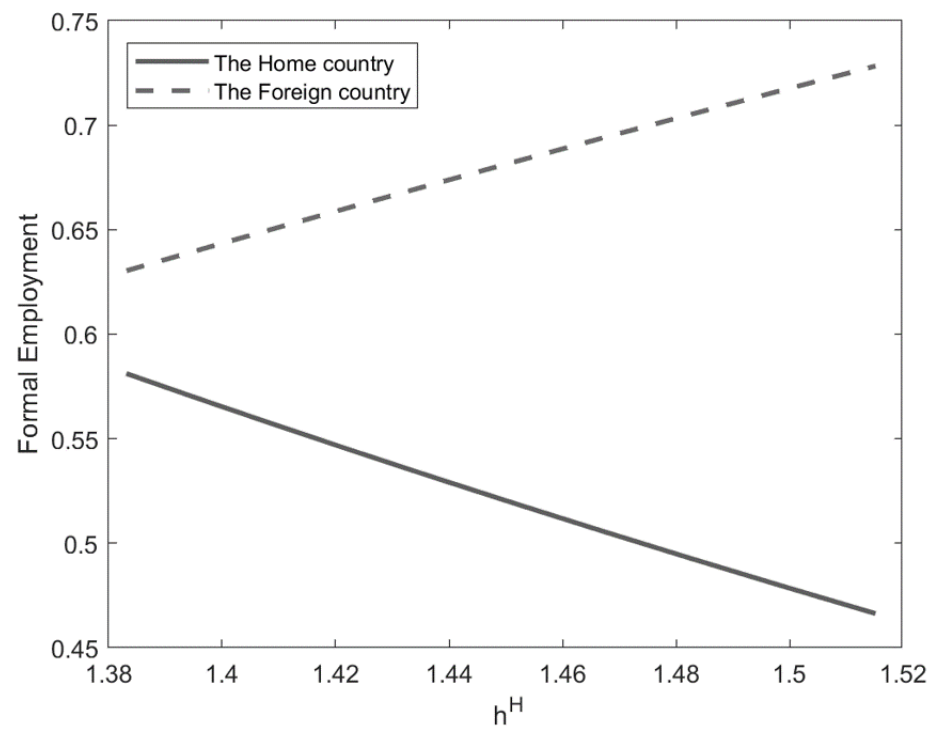

Figure 3.15: Total formal employment with $\theta>1$ and $\tau>0$

Notice that Figure 3.15 reflects the results in Proposition 28: higher hiring costs in the Home country result in higher formal employment in the Foreign country, and lower formal employment in the Home country. 
Moreover, Figure 3.16 plots the the effect of increasing hiring costs in the Home country on informal employment in each country:

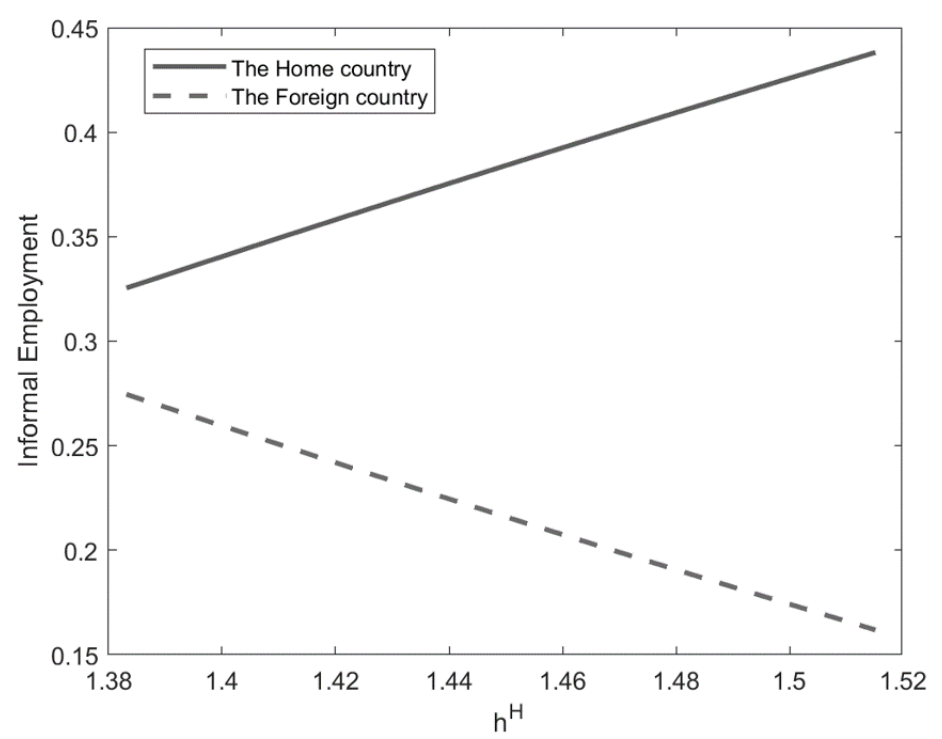

Figure 3.16: Total informal employment with $\theta>1$ and $\tau>0$

As shown in Proposition 29, higher hiring costs in the Home country imply higher informal employment in the Home country, and lower in the Foreign country. The Home country allocates more employment into the informal sector in which it has a comparative advantage.

Figure 3.17 presents the value of imports of formal varieties in each country as a function of the hiring costs in the Home country:

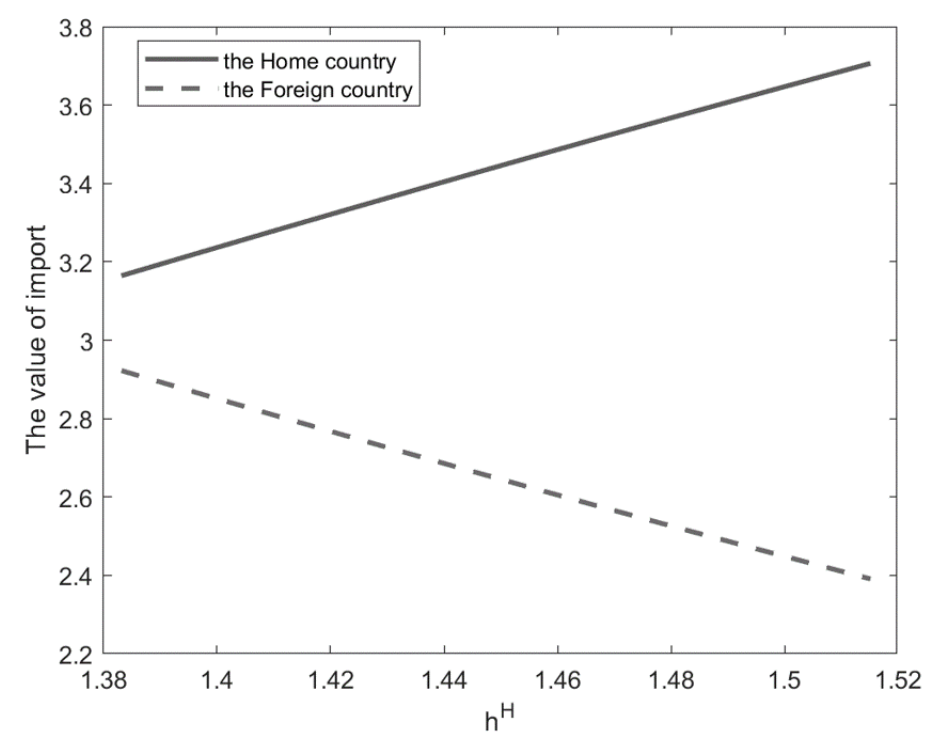

Figure 3.17: The value of imports with $\theta>1$ and $\tau>0$

In the theory section, as it reported in Proposition 31, higher hiring costs in the Home country make the Foreign country more competitive in the formal sector, the Foreign country exports more formal varieties to the Home country when hiring costs in the Home country is higher relative to those in the 
Foreign country. Figure 17 shows that the difference between the value of imports in formal varieties across countries become larger as hiring costs in the Home country, $h^{H}$ increase.

This exercise explores the outcomes of changes in labour market policy on the key economic variables in our model. Once the Home country further increases its hiring costs, the Foreign country becomes more competitive in formal variety production, and its share of formal employment increases. In the Home country, the share of formal employment declines, while the share of informal employment increases. The Home country allocates more workers into the informal sector, in which it has a comparative advantage. The value of imports in formal varieties is higher in the Home country since it imports more formal varieties from the Foreign country. Moreover, as hiring costs in the Home country gradually increase, the composite good price in each country increases, but the Home country experiences higher composite good price than the Foreign country since the prices of non-traded good are also affected. The difference between prices becomes larger as hiring costs in the Home country, $h^{H}$ increase further. Since the welfare function is a decreasing function of the composite good price, both countries experience lower welfare due to higher composite good price resulted from increasing hiring costs in the Home country. But, the Home country has relatively lower welfare than the Foreign country since consumers in the Home country face with higher composite good price relative to those in the Foreign country. The difference between prices increases when hiring costs in the Home country, $h^{H}$ increase.

\subsection{Conclusion}

This chapter adds a contribution to the trade literature, which highlights the importance of flexible labour markets in order to gain from international trade, by showing that developing countries with high labour market rigidities can still gain from international trade by using their informal economies. This chapter examines the role of informal producers in determining the pattern of production and the welfare of countries, and it investigates how informal producers can determine the trade structure of developing countries as informal producers directly produce for the world market.

In this chapter, we develop a Ricardian model of trade with labour market frictions. Labour market frictions result in segmented labour markets where formal and informal producers operate. Both informal and formal producers operate in separated markets and produce consumption goods for the domestic and foreign markets. Informal producers do not have labour market frictions and they operate in the perfectly competitive market in which they produce homogeneous informal goods (the second hand, low quality or counterfeit goods). Formal producers experience labour market frictions and produce differentiated formal varieties. As expected, we show that countries with different degrees of informal economies gain from international trade as trade costs are reduced. What makes this chapter different than the existing literature is that it shows that the size of the informal sector is affected by not only the country's own labour market frictions, but also its trading partners' labour market structure. Once a country with higher (lower) labour market frictions engages in trade with a country having relatively lower (higher) labour 
market frictions, its informal sector expands (shrinks), and the informal sector of its trading partner shrinks (expands). Furthermore, this chapter finds that a decrease in trade costs causes an increase in the size of the informal sector in the country with relatively higher labour market frictions, and a decrease in the informal sector in its trading partner. Another important contribution in this chapter is that once two countries with different degrees of labour market frictions implement trade liberalizations, changes in a countrys labour market policy impacts not only its own labour market and welfare, but also those of its trading partners. For example, a further increase in labour market frictions in the country that has initially higher labour market frictions, increases the size of its informal sector and decreases the size of the informal sector in its trading partner. Moreover, both countries face lower welfare, but the country having relatively higher labour market frictions experiences lower welfare than its trading partner. 


\section{Chapter 4}

\section{The Role of Informal Producers in the Global Supply Chain}

\subsection{Introduction}

This chapter, which is a joint work with Professor Claustre Bajona, explores a different role of informal producers in the supply side of the economy. It argues that informal producers are interlinked with formal producers in the production chain by supplying intermediate inputs to formal producers that compete in the global market. To the best of our knowledge, this is the first study to develop a theoretical framework to assess the role of informal producers in determining comparative advantages of developing countries through their participation in the global supply chain.

Our findings in the second chapter served to motivate this chapter. In the second chapter, we document that the Textile and Clothing sectors have high informality. Moreover, the textile and clothing production has stages of production. Therefore, we argue that it is worthwhile to explore the interlinkage between formal and informal producers in the global supply chain since informal producers provide low costs intermediate inputs to those competing in the world market.

In order to investigate the role of informal producers in the global supply chain, we add stages of production to a model in the spirit of the third chapter. In this model, informal and formal producers operate in the production chain. Countries produce a continuum of varieties and each variety is produced using labour and a first-stage intermediate input which is variety-specific, as in Yi (2003). This intermediate input can either be produced by formal or informal producers. All formal goods are traded, whereas intermediate inputs produced by informal producers are not traded. To examine the effect of the labour market and trade policies on the pattern of production and the welfare of countries, we calibrate our model economy to the Turkish and German economies in 2003. We choose Turkey in our study since Turkey has a very rigid labour market and a large informal economy, and it has been a participant in global trade since the 1980s. We select Germany since it has a small informal sector, and 
it is one of Turkeys top trading partners.

This chapter builds a theoretical framework to show that informal producers can determine comparative advantages of developing countries by supplying lower costs inputs to formal producers that engage in international trade. Moreover, as in the chapter two, this chapter documents that the size of the informal sector of a country is not only determined by its own labour market structure, but also the its trading partners' labour market characteristics.

In most developing countries, the informal economy is interlinked with the formal one, playing a crucial role in the production process by providing lower cost input alternatives to firms that experience price competition during trade liberalization (Willumsen et al. (2010), Marjit and Maiti (2005)). Bhme and Thiele (2012) examine the inter-linkage between formal and informal producers in six West African countries and show that informal firms supply intermediate inputs to formal firms in the chain of production, and the degree of informality influences formal firms performance indirectly. Based on the results of an empirical study of 193 companies operating in Poland, Mrozek and Mays (2011) suggest that integrating informal firms in the supply chain of large formal firms is an important determinant to increase profits. Moreover, Willumsen et al. (2010) argue that the interlinkage between the informal and the formal sector is complementary. That is, any policy change in international trade will affect the size of the formal and informal sector in the same direction. The authors state that trade barriers imposed on formal producers can reduce the size of the informal sector due to the interlinkage between the formal and informal sectors in the production chain. Furthermore, Marjit and Maiti (2005) find that any restriction on employment and production imposed on the formal sector limits the production ability and the size of the informal sector due to the relationship between formal and informal producers in the production chain. The studies, which investigate the role of informal producers in the production chain, are mainly empirical, and ignore the effects of this production structure on the global economy.

This chapter adds to the existing literature. It builds a theoretical framework to show the role of informal producers on the pattern of production and the trade structure of developing countries when informal producers operate in the global supply chain. This chapter shows that informal producers can affect comparative advantages of developing countries by supplying lower costs intermediate inputs to formal producers that compete in the global arena. Furthermore, as in the third chapter, this chapter shows that the size of the informal sector of a country is not only determined by its own labour market structure, but also the its trading partners' labour market characteristics. Another finding in this chapter is that the trade liberalization results in smaller informal sector in a country with higher labour market frictions relative to the its trading partners.

This chapter is structured as follows: In section 2, we develop the model economy. In section 3 , we provide the solution of the model. In section 4, we calibrate our model economy and report our results. In section 5, we perform policy experiments, and we conclude in section 6 . 


\subsection{The Model}

There are two countries in the model: Home and Foreign, indexed by $i=H, F$. Each country is populated by a measure one of identical households endowed with $M^{i}$ units of labour. A continuum of varieties of a differentiated consumption good, $z \in[0,1]$, are produced in the economy. Each of these varieties is produced in two stages: in the first stage producers use labour to produce a variety-specific intermediate input. This intermediate input is then combined with labour by second stage producers to produce the corresponding variety used in consumption. To rationalize the existence of an informal sector, we assume that there exist labour market regulations, which are modelled as search and matching frictions that are captured by a matching production function, and by costs of posting vacancies to search for available workers. There are three types of producers in the economy: formal producers, informal producers, and recruitment agencies. Formal producers are subject to labour market frictions whereas informal producers and (for simplicity) recruitment agencies are not. Also for simplicity, we assume that informal producers only participate in the first stage of production and all second stage production is done by formal producers. Finally, all inputs and varieties produced by formal producers are traded, whereas informal producers and recruitment agencies produce only for their domestic market.

There is only one type of labour in the economy. Given the job-finding probabilities and the wages paid by each type of producer, each household decides the proportion of labour that it sends to search for employment with each type of producer. Due to search frictions, some of the workers who search in the formal sector do not find jobs. These workers cannot search in other sectors and become unemployed. Workers that match with a formal producer engage in multilateral wage bargaining over total output. In the bargaining process, workers are offered a wage $w_{s}^{i}$ for $s=1,2$ which they can accept or reject. Workers who reject the wage offer become unemployed. In equilibrium, the household distributes labour across sectors until the expected wages among all production activities are equalized.

We assume that preferences are identical across countries, but countries differ in terms of their labour market structure and in their production technologies. We also assume that there is a common iceberg transportation cost $\tau$ on all imported goods. That is, the exporting country needs to ship $(1+\tau)$ units of any good to the importing country for the latter to receive 1 unit of the good.

We provide detailed explanations of labour market characteristics, wage determination, producers' technologies, and the consumer's preferences in the following sections.

\subsubsection{Labour Market}

We assume that the labour market is fragmented due to the existence of search and matching frictions in the formal sector. We model these frictions using the Diamond-Mortensen-Pissarides search model. The labour allocation in each stage of formal production is determined by the following matching function:

$$
L_{s}^{i}=\phi^{i}\left(V_{s}^{i}\right)^{\eta}\left(N_{s}^{i}\right)^{1-\eta} \text { for } s=1,2, i=H, F
$$


where $V_{s}^{i}$ denotes the number of vacancies posted to attract workers, $N_{s}^{i}$ indicates the number of people searching for a job in stage $s$, and $L_{s}^{i}$ shows formal employment in stage $s$. Moreover, $\eta \in(0,1)$ is the share parameter of opening vacancies, and $\phi^{i}>0$ is the technology parameter in the matching function. If we define the probability of finding a job in stage $s$ as:

$$
\lambda_{s}^{i}=\frac{L_{s}^{i}}{N_{s}^{i}} \text { for } s=1,2, i=H, F
$$

the number of vacancies in country $i$ can be written as:

$$
V_{s}^{i}\left(L^{i}, \lambda^{i}\right)=L_{s}^{i}\left(\phi^{i}\right)^{-1 / \eta}\left(\lambda_{s}^{i}\right)^{(1-\eta) / \eta}
$$

In addition, denoting the cost of posting a vacancy by $p_{r}^{i}>0$, the cost to a firm of hiring $L_{s}^{i}$ workers is given by $p_{r}^{i} V^{i}$. Therefore, the cost of hiring one worker in stages $h_{s}^{i}$ is obtained by

$$
h_{s}^{i}=\frac{p_{r}^{i} V_{s}^{i}}{L_{s}^{i}}=p_{r}^{i}\left(\phi^{i}\right)^{-1 / \eta}\left(\lambda_{s}^{i}\right)^{(1-\eta) / \eta}
$$

The cost of posting vacancies $p_{r}^{i}$, the matching parameter $\eta$ and the productivity parameter of the matching function $\phi^{i}$ determine the degree of labour market frictions. Observe that a higher cost of posting vacancies $p_{r}^{i}$, and/or lower productivity of the matching function $\phi^{i}$ imply greater labour market frictions in the formal sector.

\section{The recruitment agencies}

We assume that formal producers outsource their hiring process to recruitment agencies. Recruitment agencies in each country consist of infinitely many firms, operating a constant returns to scale technology in a perfectly competitive market which transforms one unit of labour into $A_{r}^{i}$ vacancies. The production function is: $V_{r}^{i}=A_{r}^{i} L_{r}^{i}$, where $L_{r}^{i}$ indicates the amount of labour hired by the recruitment agencies in country $i$ and $V_{r}^{i}$ indicates the number of vacancies posted. Given the price they receive for each vacancy, $p_{r}^{i}$, and wages $w_{r}^{i}$, recruitment agencies choose the number of workers to hire in order to maximize profits:

$$
\max _{L_{r}^{i}}\left\{p_{r}^{i} V^{i}-w_{r}^{i} L_{r}^{i}\right\}
$$

In equilibrium, the solution of the problem reflects that the unit cost of processing a vacancy equals the cost of opening a vacancy:

$$
p_{r}^{i}=\frac{w_{r}^{i}}{A_{r}^{i}}
$$

Therefore, the cost of posting a vacancy is determined by $A_{r}^{i}$ and the competitive wage $w_{r}^{i}$. Notice that, for any given wage, higher productivity parameters result in lower costs of posting vacancies and, 
therefore, lower hiring costs through equation (4.1).

\section{Multilateral wage bargaining}

Search and matching frictions introduce a positive cost of hiring workers for formal producers, which gives bargaining power to their workers, along with the costs of production. Once successful matching occurs in each stage, the firm and the workers engage in multilateral wage negotiation over total output. After bargaining, workers either accept the firm's offer or choose to be unemployed; however, they are not allowed to switch sectors. In each stage of production, we use strategic Nash wage bargaining to determine the share of total output that the workers and the firm obtain. A formal firm producing stage $s$ in country $i$ and its workers solve the following bargaining problem:

$$
\max _{w_{s}^{i}}\left\{\left(p_{s}^{i}(z) y_{s}^{i}(z)-w_{s}^{i} l_{s}^{i}(z)\right)^{1-\sigma}\left(w_{s}^{i} l_{s}^{i}(z)\right)^{\sigma}\right\}
$$

where $p_{s}^{i}(z) y_{s}^{i}(z)$ is the formal producer's revenue, $w_{s}^{i} l_{s}^{i}(z)$ is the wage bill that the formal producer pays to its workers, and $\sigma \in(0,1)$ is the worker's bargaining power parameter.

The solution of this problem provides the workers' share of total surplus: $\sigma p_{s}^{i}(z) y_{s}^{i}(z)$, and the firm's share of the total surplus: $(1-\sigma) p_{s}^{i}(z) y_{s}^{i}(z)$.

\subsubsection{Production Technologies and Producer's Maximization Problem}

We assume that all markets are perfectly competitive; therefore, all producers take prices as given. Moreover, labour is the only factor of production. Formal, informal, and imported variety-specific intermediate inputs are perfectly substitutable which implies that each first-stage variety $z$ is produced either by informal producers, by domestic formal producers, or it is imported. Second-stage producers choose a supplier of first-stage input, hire labour, and produce the second-stage varieties which are bought by consumers.

\section{Producers}

\section{Stage-1 Production: Formal Producers}

A potential formal producer for variety $z$ in country $i$ operates the technology:

$$
y_{1}^{i}(z)=a_{1}^{i}(z) l_{1}^{i}(z)
$$

where $l_{1}^{i}(z)$ is the amount of labour hired for production of variety $z$, and $a_{1}^{i}(z)$ is the productivity parameter, which differs across countries. 
After multilateral bargaining with the workers, the firm chooses its labour input to maximize profits given hiring costs per worker $h_{1}^{i}$ :

$$
\max _{l_{1}^{i}(z)}\left\{(1-\sigma) p_{1}^{i}(z) y_{1}^{i}(z)-h_{1}^{i} l_{1}^{i}(z)\right\},
$$

where $p_{1}^{i}(z)$ denotes the producer's price in the formal sector. In equilibrium, the producer's price if variety $z$ is given by:

$$
p_{1}^{i}(z)=\frac{h_{1}^{i}}{(1-\sigma) a_{1}^{i}(z)} .
$$

Notice that the producer's price increases with hiring costs, $h_{1}^{i}$, and are inversely proportional to the productivity parameter.

\section{Stage-1 Production: Informal Producers}

Informal producers produce an output $y_{n}^{i}(z)$ for the second-stage producers using the technology:

$$
y_{n}^{i}(z)=a_{n}^{i}(z) l_{n}^{i}(z) .
$$

where $a_{n}^{i}(z)$ is a productivity parameter and $l_{n}^{i}(z)$ is the amount of labour hired by an informal producer of intermediate input $z$ in country $i$.

Informal producers of intermediate variety $z$ solve the following profit maximization problem:

$$
\max _{l_{n}^{i}}\left\{p_{n}^{i}(z) a_{n}^{i}(z) l_{n}^{i}(z)-w_{n}^{i} l_{n}^{i}(z)\right\}
$$

where $p_{n}^{i}(z)$ is the producer's price of the informal input $z$ in country $i$.

In equilibrium, if the informal good is produced for the second-stage production, it is the case that:

$$
p_{n}^{i}(z)=\frac{w_{n}^{i}}{a_{n}^{i}(z)} .
$$

Observe that the producer's price is an increasing function of the wage paid to informal workers, $w_{n}^{i}$, and it is inversely proportional to the productivity parameter.

\section{Stage-2 Production}

In the second stage, a producer for variety $z$ has a Cobb-Douglas production function:

$$
y_{2}^{i}(z)=\left(x_{1}^{i}(z)\right)^{\theta}\left(a_{2}^{i}(z) l_{2}^{i}(z)\right)^{1-\theta},
$$

where $\theta \in(0,1)$ is the intermediate input share of income and $a_{2}^{i}(z)$ is a technology parameter that differs across countries. Moreover, $l_{2}^{i}(z)$ is the amount of labour hired in the second stage production and $x_{1}^{i}(z)$ 
is the amount of variety-specific intermediate input used in the second-stage production.

A second stage producer maximizes its profit by choosing the optimal amount of labour $l_{2}^{i}(z)$, and the first-stage input $x_{1}^{i}(z)$ :

$$
\max _{l_{2}^{i}(z), x_{1}^{i}(z)}\left\{(1-\sigma) p_{2}^{i}(z)\left(x_{1}^{i}(z)\right)^{\theta}\left(a_{2}^{i}(z) l_{2}^{i}(z)\right)^{1-\theta}-h_{2}^{i} l_{2}^{i}(z)-q_{1}^{i}(z) x_{1}^{i}(z)\right\}
$$

where $q_{1}^{i}(z)$ denotes the user's price of variety $z$ 's intermediate input and it is determined by the lowest cost's supplier:

$$
q_{1}^{i}(z)=\min \left\{p_{1 i}^{i}(z), p_{1 n}^{i}(z),(1+\tau) p_{1}^{j}(z)\right\}
$$

That is, the second-stage producer chooses the supplier that produces the intermediate input at the lowest cost. Furthermore, given our assumption of perfect substitutability, we have that

$$
x_{1}^{i}(z)=x_{1 i}^{i}(z)+x_{1 n}^{i}(z)+x_{1 j}^{i}(z) \text { for } i \neq j
$$

where $x_{1 i}^{i}(z)$ is the demand for domestic-formal input, $x_{1 n}^{i}(z)$ is the demand for domestic-informal input, and $x_{1 j}^{i}(z)$ is the imported-formal input. Notice that, in general, intermediate input demand is positive only for one type of supplier.

Taking first-order conditions, we obtain the second-stage producer's price if the variety is produced:

$$
p_{2}^{i}(z)=\theta^{-\theta}(1-\theta)^{\theta-1} \frac{q_{1}^{i}(z)^{\theta}\left(h_{2}^{i}\right)^{1-\theta}}{(1-\sigma) a_{2}^{i}(z)^{1-\theta}}
$$

This formula indicates that the unit cost of producing second-stage variety $z$ is increasing in the price of the intermediate input and in the hiring costs, and it is decreasing with respect to the labor productivity parameter. Therefore, everything else equal, access to cheaper intermediate inputs or lower hiring costs, provide a cost advantage to second stage producers. 


\section{The composite consumption good}

The representative household in each country purchases a composite of the varieties $z \in[0,1]$ that is produced domestically, and it is not traded. ${ }^{1}$ The aggregation technology is given by

$$
Y^{i}=\left(\int_{0}^{1} x_{2}^{i}(z)^{\frac{\alpha-1}{\alpha}} d z\right)^{\frac{\alpha}{\alpha-1}}
$$

where $\alpha>1$ is the elasticity of substitution among varieties and $x_{2}^{i}(z)$ denotes the demand of each second-stage good which is obtained by solving the following maximization problem:

$$
\max _{x_{2}^{i}(z)}\left\{P^{i} Y^{i}-\int_{0}^{1} q_{2}^{i}(z) x_{2}^{i}(z) d z\right\}
$$

where $q_{2}^{i}$ is the user's price of second stage variety $z$ and $P^{i}$ denotes the price index of the composite good. The user price of the second stage variety is equal to the price of the cheapest supplier, taking into account the iceberg transportation costs on imports:

$$
q_{2}^{i}(z)=\min \left\{p_{2}^{i}(z),(1+\tau) p_{2}^{j}(z)\right\}
$$

and the price index of the composite good is determined as:

$$
P^{i}=\left(\int_{0}^{1} q_{2}^{i}(z)^{(1-\alpha)} d z\right)^{1 /(1-\alpha)}
$$

The solution of this problem provides the demand for each second stage variety $x_{2}^{i}(z)$ as a function of prices:

$$
x_{2}^{i}(z)=Y^{i}\left(\frac{P^{i}}{q_{2}^{i}(z)}\right)^{\alpha}
$$

\subsubsection{Households}

Each country has an identical representative household which consists of a measure $M^{i}$ individuals that derive utility from consumption of the composite good, $u\left(C^{i}\right)=C^{i}$.

Each person in the household is endowed with one unit of time. The representative household chooses the share of its members to be sent to search for employment with each type of producer: recruitment agencies $L_{r}^{i}$, informal producers $L_{n}^{i}$, and formal producers in each stage $N_{s}^{i}$ for $s=1,2$. The difference between people searching for jobs in the formal sector, and people who actually find employment determines the amount of unemployed people in the economy, $U^{i}=U_{1}^{i}+U_{2}^{i}$ where $U_{s}^{i}=N_{s}^{i}-L_{s}^{i}$ for $s=1,2$.

\footnotetext{
${ }^{1}$ It is equivalent to say that the representative household purchases all the traded goods $z$ form the formal producers, and maximizes a utility $u^{i}\left(Y^{i}\right)$.
} 
The household's budget constraint is given by:

$$
P^{i} C^{i}=w_{n}^{i} L_{n}^{i}+w_{1}^{i} L_{1}^{i}+w_{2}^{i} L_{2}^{i}+w_{r}^{i} L_{r s}^{i}
$$

with the restrictions:

$$
\begin{aligned}
& M^{i} \geq L_{1}^{i}+L_{2}^{i}+L_{n}^{i}+L_{r}^{i} \geq 0 \\
& C^{i} \geq 0, L_{s}^{i}, L_{n}^{i}, L_{r}^{i} \geq 0
\end{aligned}
$$

Here $w_{n}^{i}$ and $w_{r}^{i}$ denote the wages paid by informal producers and recruitment agencies respectively, $w_{s}^{i}$ is the wage paid by formal producers of stages $s$.

Assuming that formal, informal producers and recruitment agencies are operative in the country, the household chooses the proportion of individuals searching for employment in each market in such a way that expected labour income of each worker in each sector is identical, that is:

$$
w_{n}^{i}=w_{r}^{i}=\lambda_{1}^{i} w_{1}^{i}=\lambda_{2}^{i} w_{2}^{i}
$$

The solution to the consumer's maximization problem provides the demand function for the composite good:

$$
C^{i}=\frac{w_{n}^{i} L_{n}^{i}+w_{1}^{i} L_{1}^{i}+w_{2}^{i} L_{2}^{i}+w_{r}^{i} L_{r}^{i}}{P^{i}}
$$

which, given our utility function, also represents welfare. That is, welfare in each country is inversely proportional to the composite-good price, and it is a linear function of the household's income.

\subsubsection{Definition of Equilibrium}

Given the trade cost $\tau$, a competitive equilibrium for this economy is a set of allocations for the representative household $\left\{C^{i}, N_{s}^{i}, L_{n}^{i}, L_{r}^{i}, c^{i}(z)\right\}$, for recruitment agencies $\left\{V_{r}^{i}, L_{r}^{i}\right\}$, for informal producers $\left\{y_{n}^{i}(z), l_{n}^{i}(z)\right\}$, for formal producers in the first stage $\left\{y_{1}^{i}(z), l_{1}^{i}(z)\right\}$, for formal producers in the second-stage $\left\{y_{2}^{i}(z), l_{2}^{i}(z), x_{1}^{i}(z), x_{1 i}^{i}(z), x_{n}^{i}(z), x_{1 j}^{i}(z)\right\}$, a set of prices $\left\{p_{1}^{i}(z), q_{1}^{i}(z), p_{2}^{i}(z), q_{2}^{i}(z), P^{i}, p_{n}^{i}, p_{r}^{i}, w_{s}^{i}, w_{n}^{i}, w_{r}^{i}\right\}$, hiring cost $h_{s}^{i}$, probability of employment $\lambda_{s}^{i}$ and unemployment level $U_{s}^{i}$, for $i, j=H, F$, ans $s=1,2$, such that:

(a) Given prices, the household's allocations solve the household's maximization problem.

(b) Given prices and hiring costs, the producer's allocations solve their respective producer's maximization problem.

(c) Given goods' prices, the wages $w_{s}^{i}$ solve the bargaining problem for formal producers

(d) The following market clearing conditions are satisfied: 
(i) in the first stage of production:

$$
x_{1 i}^{i}(z)+x_{1 i}^{j}(z)=y_{1}^{i}(z) \text { for all } z \in[0,1], i \neq j
$$

(ii) in the second stage of production:

$$
x_{2}^{H}(z)+x_{2}^{F}(z)=y_{2}^{H}(z)+y_{2}^{F}(z) \text { for all } z \in[0,1]
$$

(iii) in the second-stage for the composite good:

$$
Y^{i}=C^{i}
$$

(iv) in the informal sector:

$$
x_{n}^{i}(z)=y_{n}^{i}(z)
$$

$(v)$ in the labour market:

$$
\begin{gathered}
L_{s}^{i}=\lambda_{s}^{i} N_{s}^{i} \\
L_{n}^{i}=\int_{0}^{1} l_{n}^{i}(z) d z \\
L_{s}^{i}=\int_{0}^{1} l_{s}^{i}(z) d z \\
M^{i}=L_{1}^{i}+U_{1}^{i}+L_{2}^{i}+U_{2}^{i}+L_{n}^{i}+L_{r}^{i}
\end{gathered}
$$

(vi) the user's prices in stage 1 :

$$
q_{1}^{i}(z)=\min \left\{p_{1 i}^{i}(z), p_{1 n}^{i}(z),(1+\tau) p_{1}^{j}(z)\right\}
$$

(vii) the user's prices in stage 2 :

$$
q_{2}^{i}(z)=\min \left\{p_{2}^{i}(z),(1+\tau) p_{2}^{j}(z)\right\}
$$

(e) Trade is balanced. 


\subsection{Resolution of Model: Characterization of Equilibrium}

For simplicity, we assume that technologies in the model are such that the informal sector is not operative in the Foreign country.

\subsubsection{The first-stage formal production}

The second-stage producers of variety $z$ in country $i$ select the source of their input $x_{1}^{i}(z)$ from either domestic-formal producers, foreign-formal producers or domestic-informal producers. They choose the source that supplies the input at the lowest price, that is:

$$
q_{1}^{i}(z)=\min \left\{p_{1}^{i}(z), p_{n}^{i}(z),(1+\tau) p_{1}^{j}(z), i \neq j\right\}
$$

Or, using equations (4.4) and (4.5) :

$$
q_{1}^{i}(z)=\min \left\{, \frac{w_{1}^{i}}{\sigma a_{1}^{i}(z)}, \frac{w_{n}^{i}}{a_{n}^{i}(z)},(1+\tau) \frac{w_{1}^{j}}{\sigma a_{1}^{j}(z)}\right\}, i \neq j .
$$

Therefore, the demand for variety-specific intermediate input is zero for all suppliers except for the one that can supply the input at the lowest cost (in case of a tie, we give preference to domestic and to formal producers). That is:

$$
x_{1}^{i}(z)= \begin{cases}x_{1 i}^{i}(z) & \text { if } q_{1}^{i}(z)=p_{1}^{i}(z) \\ x_{n}^{i}(z) & \text { if } q_{1}^{i}(z)=p_{n}^{i}(z) \\ x_{1 j}^{i}(z) & \text { if } q_{1}^{i}(z)=(1+\tau) p_{1}^{j}(z)\end{cases}
$$

In the first stage, replacing equation (4.4) into the worker's share of production obtained after bargaining: $\sigma p_{1}^{i}(z) y_{1}^{i}(z)=w_{1}^{i} l_{1}^{i}(z)$, we find a relationship between hiring costs $h_{1}^{i}$ and wages $w_{1}^{i}$ :

$$
(1-\sigma) w_{1}^{i}=\sigma h_{1}^{i}
$$

Combining equation (4.1) that relates to the probability of finding a job with equations (4.5), (4.12) and (4.24), we determine the probability of finding a job, which is our measure of labour market frictions, as a function of model parameters:

$$
\lambda_{1}^{i}=\phi^{i}\left(A_{r}^{i}\right)^{\eta}\left(\frac{1-\sigma}{\sigma}\right)^{\eta}
$$


Observe that an increase in the productivity parameter of the recruitment producer $A_{r}^{i}$, and an increase in the productivity parameter of the matching function $\phi^{i}$ result in lower labour market frictions and lead to higher probability of formal employment. Using equation (4.1), we write the hiring costs $h_{1}^{i}$ as:

$$
h_{1}^{i}=\left(\frac{1-\sigma}{\sigma}\right)\left(\frac{w_{r}^{i}}{\lambda_{1}^{i}}\right)
$$

Notice that hiring costs are inversely proportional to labour market frictions.

\subsubsection{The second-stage production}

Recall from equation (4.9) that the unit cost of production for a second-stage producer of variety $z$ is given by:

$$
p_{2}^{i}(z)=\theta^{-\theta}(1-\theta)^{\theta-1} \frac{\left(h_{2}^{i}\right)^{1-\theta} q_{1}^{i}(z)^{\theta}}{(1-\sigma) a_{2}^{i}(z)^{1-\theta}} .
$$

Replacing equation (4.9) into the worker's share of production obtained after bargaining: $w_{2}^{i} l_{2}^{i}(z)=$ $\sigma p_{2}^{i}(z) y_{2}^{i}(z)$, we obtain a relationship between hiring costs $h_{2}^{i}$, and wages for the second-stage production:

$$
(1-\theta)(1-\sigma) w_{2}^{i}=\sigma h_{2}^{i}
$$

Combining equation (4.1) that relates to the probability of finding a job with equations (4.9),(4.12) and (4.27), and using equation (4.5), we obtain the probability of finding a job of the second stage as a function of the labour market frictions in the first stage and given parameters:

$$
\lambda_{2}^{i}=\phi^{i}\left(A_{r}^{i}\right)^{\eta}\left(\frac{(1-\theta)(1-\sigma)}{\sigma}\right)^{\eta}=(1-\theta)^{\eta} \lambda_{1}^{i}
$$

Notice that the higher the productivity parameter of the recruitment producer $A_{r}^{i}$, and the productivity parameter of the matching function $\phi^{i}$, the lower labour market frictions are. Lower labour market frictions cause a higher probability of formal employment. Furthermore, using equation (4.1), we obtain the hiring costs $h_{2}^{i}$ as

$$
h_{2}^{i}=\left(\frac{(1-\theta)(1-\sigma)}{\sigma}\right) \frac{w_{r}^{i}}{\lambda_{2}^{i}}=(1-\theta)^{1-\eta} h_{1}^{i} .
$$

Notice that the hiring costs in the second stage are lower than in the first stage, given that the labour share of income is lower in the second stage. Replacing equations (4.28) and (4.29) in (4.9), we derive the unit cost of producing the second stage variety $z$ as a function of wages, the price of intermediate inputs and parameters:

$$
p_{2}^{i}=q_{1}^{i}(z)^{\theta}\left(\frac{w_{r}^{i}}{\phi^{i}\left(A_{r}\right)^{\eta}}\right)\left(\frac{((1-\theta)(1-\sigma))^{\eta(1-\theta)}}{\sigma^{(1-\theta)(1-\eta)}(1-\sigma)^{\theta} a_{2}^{i}(z)^{1-\theta}}\right)
$$


The existence of hiring costs creates unemployment in each stage of production since not all individuals who search for jobs can find one. Using $L_{s}^{i}=\lambda_{s}^{i} N_{s}^{i}$, unemployment is written as:

$$
U_{s}^{i}=N_{s}^{i}-L_{s}^{i}=\left(\frac{1-\lambda_{s}^{i}}{\lambda_{s}^{i}}\right) L_{s}^{i}
$$

\subsubsection{Production pattern in the second stage}

The Home country purchases the second-stage varieties in its domestic market if and only if $p_{2}^{H}(z) \leq(1+\tau) p_{2}^{F}(z)$, or using equation (4.9) and defining $\omega=w_{r}^{H} / w_{r}^{F}$ :

$$
\left(\frac{q_{1}^{F}(z)}{q_{1}^{H}(z)}\right)^{\theta /(1-\theta)} \frac{a_{2}^{H}(z)}{a_{2}^{F}(z)} \geq\left(\frac{1}{1+\tau}\right)^{1 /(1-\theta)}\left(\frac{\lambda_{2}^{F}}{\lambda_{2}^{H}}\right) \omega
$$

The Foreign country purchases the second-stage varieties in its domestic market if and only if $p_{2}^{F}(z) \leq$ $(1+\tau) p_{2}^{H}(z)$, or using equation $(4.9)$ :

$$
\left(\frac{q_{1}^{F}(z)}{q_{1}^{H}(z)}\right)^{\theta /(1-\theta)} \frac{a_{2}^{H}(z)}{a_{2}^{F}(z)} \leq(1+\tau)^{1 /(1-\theta)}\left(\frac{\lambda_{2}^{F}}{\lambda_{2}^{H}}\right) \omega
$$

Let us define

$$
\begin{aligned}
B_{2}^{H} & =\left(\frac{1}{1+\tau}\right)^{1 /(1-\theta)}\left(\frac{\lambda_{2}^{F}}{\lambda_{2}^{H}}\right) \omega \\
B_{2}^{F} & =(1+\tau)^{1 /(1-\theta)}\left(\frac{\lambda_{2}^{F}}{\lambda_{2}^{H}}\right) \omega
\end{aligned}
$$

and

$$
B(z)=\left(\frac{q_{1}^{F}(z)}{q_{1}^{H}(z)}\right)^{\theta /(1-\theta)} \frac{a_{2}^{H}(z)}{a_{2}^{F}(z)}=\left(\frac{q_{1}^{F}(z)}{q_{1}^{H}(z)}\right)^{\theta /(1-\theta)} A_{2}(z)
$$

Then, the Home country buys domestically second stage varieties $z \in[0,1]$ for which $B(z) \geq B_{2}^{H}$ and imports varieties for which $B(z)<B_{2}^{H}$. The Foreign country buys domestically second stage varieties for which $B(z) \leq B_{2}^{F}$ and imports varieties for which $B(z)>B_{2}^{F}$. Notice that if $\tau>0, B_{2}^{F}>B_{2}^{H}$ and some second stage varieties are not traded in equilibrium, as long as both countries produce some second stage varieties.

\subsubsection{Production pattern in the first stage}

Consider a variety $z$ the second stage of which is produced in the Home country. The second stage producer purchases the variety-specific intermediate input from its lowest cost supplier. The second stage supplier would choose an informal domestic producer over a formal domestic producer if $p_{n}^{H}(z)<p_{1}^{H}(z)$ 
or, using equations (4.4) and (4.5):

$$
\frac{a_{n}^{H}(z)}{a_{1}^{H}(z)} \geq \sigma \lambda_{1}^{H}
$$

Notice that the right hand side of this inequality depends exclusively on parameters of the model and it is proportional to the probability of finding a job in the first stage. If the labour market frictions in the Home country increase $\left(\lambda_{1}^{H}\right.$ decreases $)$, the set of varieties $z$ for which this inequality is satisfied becomes larger.

Assume that equation (4.35) holds. The Home second stage producer imports the first stage input if $p_{n}^{H}(z)>(1+\tau) p_{1}^{F}(z)$ or, using equation (4.4) for the Foreign country and equation (4.5):

$$
\frac{a_{n}^{H}(z)}{a_{1}^{F}(z)}>\frac{\sigma \lambda_{1}^{F} \omega}{1+\tau}
$$

The right hand side of this equation depends on the labour market frictions in the Foreign country, the trade frictions, as well as on the relative wages in both countries (which are functions of the labour market rigidity of both countries). Therefore, the decision to import the first stage input is a function of the labour market rigidities of both Home and Foreign.

Assume that equation (4.35) does not hold. The Home second stage producer imports the first stage input if $p_{1}^{H}(z)>(1+\tau) p_{1}^{F}(z)$ or, using equation (4.4) for both countries:

$$
\frac{a_{1}^{H}(z)}{a_{1}^{F}(z)}>\frac{\lambda_{1}^{F} \omega}{(1+\tau) \lambda_{1}^{H}}
$$

The right hand side of this equation depends on the relative labour market frictions of the two countries, the trade frictions, as well as on their relative wages.

Unless we impose very restrictive assumptions on technology functions, the model in this chapter cannot be solved analytically. In the following sections we calibrate the technology functions to the manufacturing sectors of Turkey and Germany, and we use numerical simulations to show the role of the informal sector in determining the patterns of production and trade and to perform policy exercises. 


\subsection{Calibration}

In order to use our model to make predictions about how informal producers shape the comparative advantage of developing countries, we need to choose functional forms for the productivity parameters for formal and informal producers in the first and the second stage of production. We use Turkey and Germany in our calibration to determine functional forms of these productivity parameters. Turkey is an interesting example due to its geographic and demographic characteristics. An upper-middle-income country, Turkey has been integrated in the global economy since the 1980s, and its trade volume has been steadily increasing ever since. According to the European Commission, which is an organisation of EU, Turkey is the 4th largest export market and the 5th largest import market in the EU. Furthermore, Turkey has a very rigid labour market, and large informal economies relative to most countries in the Organisation for Economic Co-operation and Development (OECD). Furthermore, Germany, is one of Turkeys top trading partners with negligible informal economy in manufacturing sectors.

In this section, we regard Turkey as the Home country, and Germany as the Foreign country. To simplify the analysis, let us assume that informal producers are only operative in Turkey, and they are not part of the production chain in Germany. Moreover, we limit our analysis to manufacturing industries since they are one of the main driving forces in the Turkish economy, and their share of exports is the highest, particularly, in the Textile and Clothing industry (World Trade Organization (2016)).

There are two main challenges in the calibration $(i)$ to separate output and employment in each country's manufacturing industries into the two stages of production, and (ii) to determine the share of informal output and employment in the initial stage of manufacturing production in Turkey. We address the first challenge by collecting data on employment and output by industry from Turkish Statistics (TURKSTAT) and the Federal Statistical Office of Germany (Destatis) for 2003 at 2 and 4 digit level of aggregation. In these data sets, economic activities were defined by Classification of Economic Activities in the European Community (NACE Rev. 2). We use OECD input-output tables for Turkey and Germany, which are given at the 2 digit level, based on (NACE Rev. 2), to determine the intermediate and final output usage for each industry.

In the model, inputs are variety specific, but in the data, industries use intermediate inputs from all other industries. To adapt the model to the data, we follow Yi (2003) and construct a "first stage counterpart" for each industry which is a composite of intermediate goods from all other industries. We match domestic intermediate inputs shares in the input-output tables with first stage usage shares in our first stage counterpart. Once intermediate output is allocated, we compute employment by aggregating employment from the corresponding subsectors and using the usage weights.

We consider industries at 2-digit level to be the sectors in our model and use their corresponding 4-digit subsectors to determine first stage and second stage production and employment in each sector. In order to divide subsectors, we follow the methodology in Antras et al. (2013). The authors use input-output data for the United States in 2002 including 426 sectors and separate these sectors according 
to their upstreamness (i.e. the initial stages of production), and downstreamness (i.e. the final stages of production). The more upstream the sector, the more intermediate inputs these sectors supply. The authors also apply the same measure of upstreamness to industries in sampled OECD countries using OECD data and they document a high rank correlation of industries upstreamness across the United States and OECD countries.

In order to determine the share of informality in the first stage, we collect information about the share of informal employment in the Turkish manufacturing industries using Turkish Household Survey conducted by the Turkish Statistics (TURKSTAT) in 2003 which is based on (NACE Rev. 2) which is given at the 2 digit level. We use social security based definition of informality which regards workers as informal if they are not registered with any social security program. This definition is widely used, and it is considered a better metric than other measures used to define informal economic activities in Turkey (Aysit Tansel, 2014). This survey does not have information on output. To determine informal production by industry, we use the Micro and Small Enterprise Survey (MSE) conducted for Turkey by the Economic Research Forum (ERF) in 2003. The MSE survey was supervised by TURKSTAT, and the data sets are classified by NACE Rev. 2 and given at the 2 digit level. It contains data for 5000 small and medium size firms comprising registration status, employment and production levels among other firm characteristics. We use these data to determine the labour productivity of informal producers in each manufacturing industries. We multiply these productivities by the number of informal workers in the whole industry from the household survey to determine total informal output in the industry. Total first stage formal output and employment are obtained by subtracting the informal values from the first stage total obtained above. In the end, we obtain data on formal output and employment in both stages of production for Turkish and German manufacturing industries, and the share of informal employment and output for the Turkish manufacturing industries.

Due to data limitations resulted from insufficient observations from MSE, some sectors only include 2 or 3 informal firms, we use only the following four industries in our calibration: $(i)$ Food products, beverages and tobacco, (ii) Textiles, textile products, leather and footwear, (iii) Wood and products of wood and cork and (iv) Pulp, paper, paper products, printing and publishing.

In what follows, we use the production functions of informal and formal producers in our model economy to write the first stage productivity parameters of formal and informal producers. The productivity parameters for first stage producers in these four sectors are then calibrated as

$$
a_{1}^{i}(z)=\frac{y^{i}(z)}{l^{i}(z)} \text { for } \mathrm{i}=\mathrm{H}, \mathrm{F} \text { and } a_{n}^{H}(z)=\frac{y_{n}^{H}(z)}{l_{n}^{H}(z)}
$$

using output and employment for the first stage counterpart of each sector. Notice that we assume Germany does not have an informal sector due to data restrictions.

From the second stage production function in our model economy, the second stage productivity 
parameters of formal producers in each country is calibrated as:

$$
a_{2}^{i}(z)=\left(\frac{y_{2}^{i}(z)}{x_{1}^{i}(z)^{\theta} l_{2}^{i}(z)^{1-\theta}}\right)^{1 /(1-\theta)} \text { for } \mathrm{i}=\mathrm{H}, \mathrm{F}
$$

where $x_{1}^{i}(z)$ is output of first stage counterpart, and $\theta$ is the share of intermediate goods used in production , and it is calibrated to 0.68 using data from Turkey's input-output table.

Table 4.1 shows the calibrated productivity parameters of the first and the second stage producers in the Home country (Turkey) and the Foreign country (Germany):

Turkey

Germany

\begin{tabular}{lccccc}
\hline Manufacturing industries & $a_{1}^{H}(z)$ & $a_{n}^{H}(z)$ & $a_{2}^{H}(z)$ & $a_{1}^{F}(z)$ & $a_{2}^{F}(z)$ \\
\hline Pulp, paper, paper products, printing & 13.60 & 3.94 & 39.82 & 15.86 & 43.51 \\
Textiles, textile products, leather and footwear & 46.52 & 6.73 & 1.92 & 13.36 & 19.85 \\
Food products, beverages and tobacco & 31.48 & 3.09 & 7.31 & 25.05 & 46.06 \\
Wood and products of wood and cork & 6.17 & 5.49 & 36.30 & 18.96 & 59.89 \\
\hline
\end{tabular}

Table 4.1: Productivity Parameters

The model assumes a continuum of goods. To derive continuous productivity functions over the interval $[0,1]$, we follow the strategy in $\mathrm{Yi}(2003)$ and we use Piecewise Cubic Hermite Interpolating Polynomial (PCHIP) on the specified values of the productivity parameters to derive a smooth continuous functions. Figure 4.1 presents the calibrated productivity functions of the first stage producers. The data indicate the position of the four sectors. We place the two industries with the smallest shares in the extremes to minimize the freedom given to the algorithm on adjusting the borders.

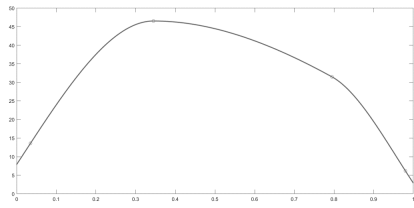

(a) Home formal

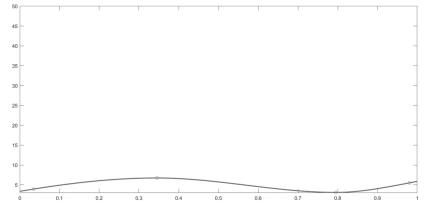

(b) Home informal

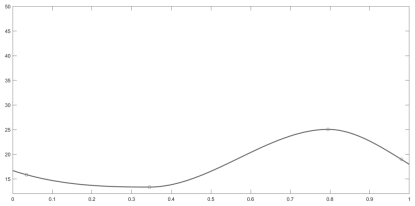

(c) Foreign formal

Figure 4.1: First stage productivity parameters

From Figure 4.1, notice that informal producers in Turkey have lower labour productivities than formal producers in any of the two countries. Also observe that stage 1 producers in Textile, textile products, leathers and footwear industries have higher labour productivity in Turkey. Finally, stage 2 producers have higher labour productivity in Germany for all industries. These properties translate to the continuum functions in Figures 4.1 and 4.2 . 


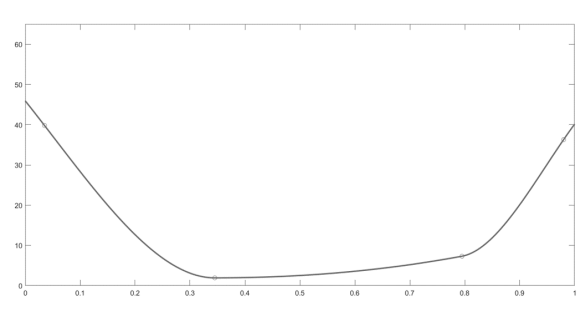

(a) Home formal

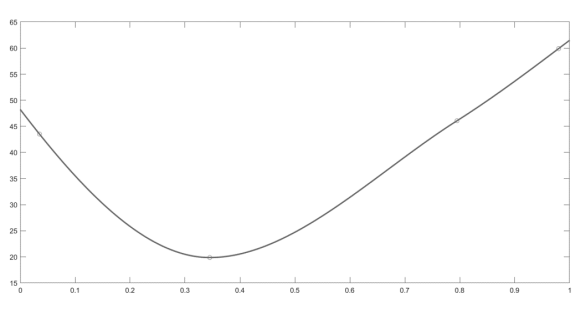

(b) Foreign formal

Figure 4.2: Second stage productivity parameters

Table 4.2 reports the values of the other calibrated parameters of the model. Following the existing literature, the share parameter of the bargaining power, $\sigma$ is given a value of 0.5 , and the share of the matching function, $\eta$ is set to 0.5 .

The productivity parameter of recruitment agencies, $A_{r}^{i}$ is one of the determinants of the labour market rigidities in our model. The higher it is, the lower the hiring costs of the country. Therefore, we set its value to 0.3 for the Foreign country (Germany), and set its value to .1 for the Home country (Turkey). Moreover, the productivity parameter of the matching function, $\phi$ is set to 0.5 . As it is used widely in literature, we set the elasticity of substitution, $\alpha$ to the value of 2 . We normalize the number of members in the household to ten. In order to study the effect of trade liberalization, we set the average tariff rates applied to all products, $\tau$ to 0.02 . Tariff rates were around $2.00 \%$ for Turkey and Germany in 2003 (The World Bank). Furthermore, we calibrate the share parameter of intermediate goods to $\theta=0.68$ using input and output tables.

\begin{tabular}{lcc} 
Definitions & Values & Source \\
\hline Matching productivity, $\phi$ & .50 & Literature \\
The share of vacancies in matching function, $\eta^{i}$ & 0.5 & Literature \\
Bargaining power for workers, $\sigma$ & 0.5 & Literature \\
The share of intermediate goods, $\theta$ & 0.68 & Input-output table \\
Elasticity parameter, $\alpha$ & 2 & Literature \\
Labour force, $M$ & 10 & Fixed \\
Tariff rate, $\tau$ & 0.02 & WTO \\
Productivity parameters of recruitment agencies, $A_{r}^{H}$ & 0.1 & fixed \\
Productivity parameters of recruitment agencies, $A_{r}^{F}$ & 0.3 & fixed \\
\hline
\end{tabular}

Table 4.2: Calibrated parameters

Since the productivity parameter of recruitment agencies, $A_{r}^{i}$ is one of the determinant of the labour market rigidities in our model, changing its value, allows us to explore the effect of labour market policies on the size of the informal sector, the pattern of production and other equilibrium characteristics in each country. 


\subsubsection{Informal producers and comparative advantages}

In what follows, we investigate how the existence of informal producers in the Home country affects the pattern of production in each country. We report our findings using tables and graphs. In all figures, the lower graph shows the cost of buying variety-specific intermediate inputs from all suppliers available to the country: the dashed line shows the domestic formal producers' price, the dotted line represents the foreign formal producers' price, and the solid line shows the price of informal producers. The thick solid line shows the lowest cost producers in each variety, $z \in[0,1]$. The upper graph plots the expressions, $B_{2}^{i}$ and $B(z)$ in equations (4.32), (4.33) and (4.34) that are used to determine the second stage production. $B(z)$ is represented by the solid line, the corresponding $B_{2}^{H}$ and $B_{2}^{F}$ are represented by the dashed and dotted line respectively. As we showed in section 3.3, the Home country produces the second stage formal varieties $z \in[0,1]$ when $B(z)$ is above $B_{2}^{H}$. The Foreign country produces formal varieties, $z \in[0,1]$ when $B_{2}^{F}$ is above $B(z)$. In the upper graph, $B(z)$ is shown by the solid line while $B_{2}^{H}$ is presented by the dashed line. The existence of trade costs, $\tau$ imposed by both countries results in some varieties, $z$, to be non-traded. At the non-traded varieties, it is the case that $B_{2}^{H} \leq B(z) \leq B_{2}^{F}$.

Table 4.3 reports the pattern of production in the Home country (Turkey) and the Foreign country (Germany). $z_{1 D} \in[0,1]$ represent the first stage intermediate inputs produced by domestic formal producers, and $z_{1 X} \in[0,1]$ indicate the imported inputs. Furthermore, $z_{1 n} \in[0,1]$ represent the intermediate goods produced by informal producers in the Home country. In the second stage, the Home and the Foreign country produce formal varieties, $z_{2} \in[0,1]$ using labour and the first stage intermediate goods, and export formal varieties, $z_{2 X} \in[0,1]$.

The Home country The Foreign country

\begin{tabular}{ccc}
\hline$z_{1 D}$ & {$[0,0]$} & {$[0.697,0.932]$} \\
$z_{1 X}$ & {$[0.232,0.697]$} & {$[0,0]$} \\
$z_{1 n}$ & {$[0,0.240] \cup[0.928,1]$} & {$[0,0]$} \\
$z_{2}$ & {$[0,0.240] \cup[0.928,1]$} & {$[0.232,0.932]$} \\
$z_{2 X}$ & {$[0,0.232] \cup[0.932,1]$} & {$[0.240,0.928]$} \\
\hline
\end{tabular}

Table 4.3: The pattern of production in the benchmark economy

Figure 4.3 illustrates the pattern of production in the Home country. Notice that the second stage formal varieties, $z_{2} \in[0,0.240] \cup[0.928,1]$ are produced in the Home country where the solid line is above the dashed line shown in the upper graph of Figure 4.3. All the second stage producers in the Home country use informal producers to obtain intermediate goods, $z_{1} \in[0,0.240] \cup[0.928,1]$ since these inputs are supplied at higher costs by domestic and foreign formal producers. This is shown in the lower graph of Figure 4.3 where the thin solid line is below the dashed and the dotted line. 


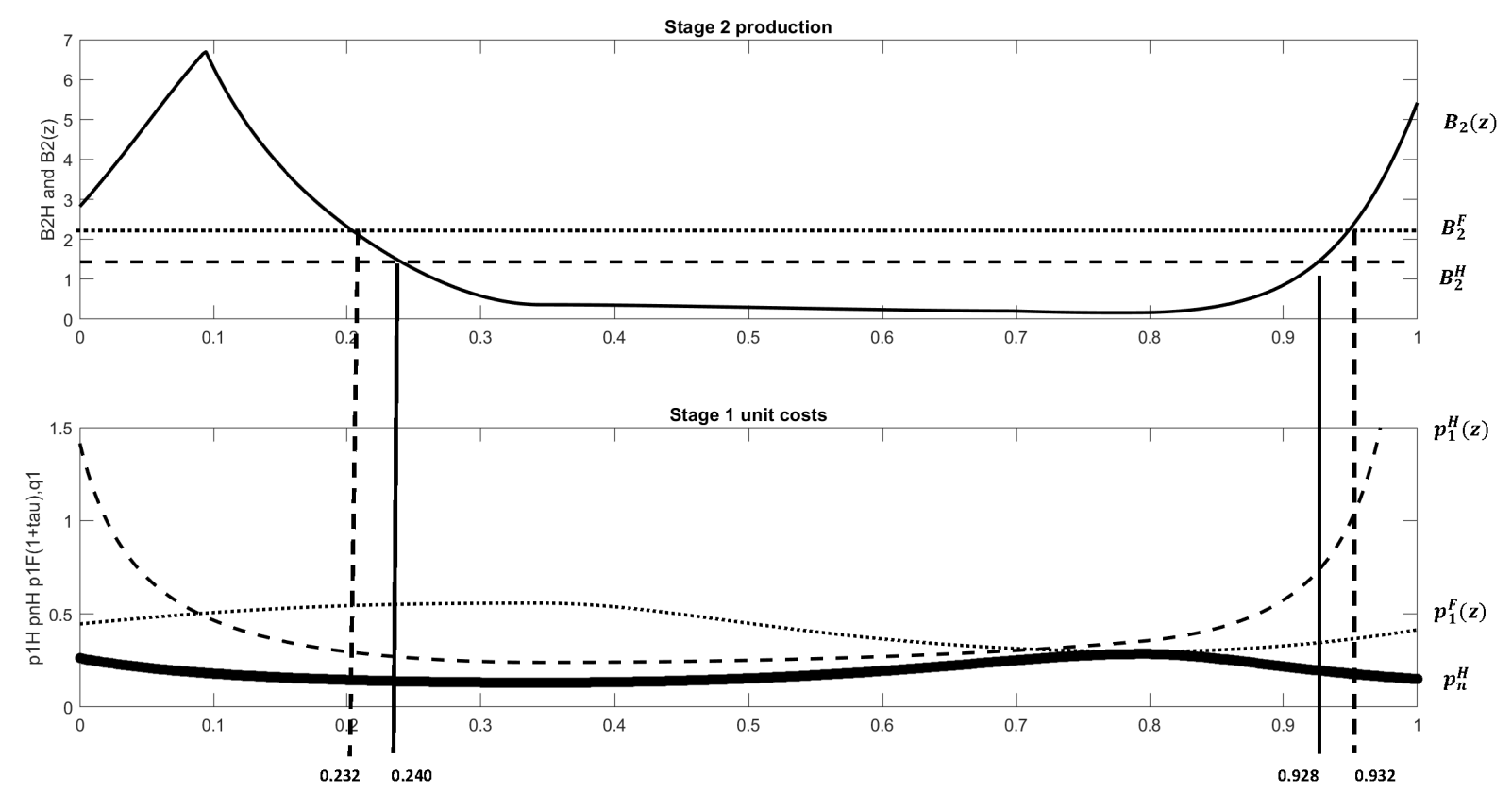

Figure 4.3: The pattern of production in the Home country

Furthermore, Figure 4.4 presents the pattern of production in the Foreign country. The second stage formal varieties, $z_{2} \in[0.232,0.932]$ are produced in the Foreign country where the dotted line is above the solid line in upper graph of Figure 4.4. Second stage producers import intermediate inputs, $z_{1} \in$ $[0.232,0.697]$ from first stage formal producers in the Home country, and obtain intermediate inputs, $z_{1} \in[0.697,0.932]$ from first stage domestic formal producers.

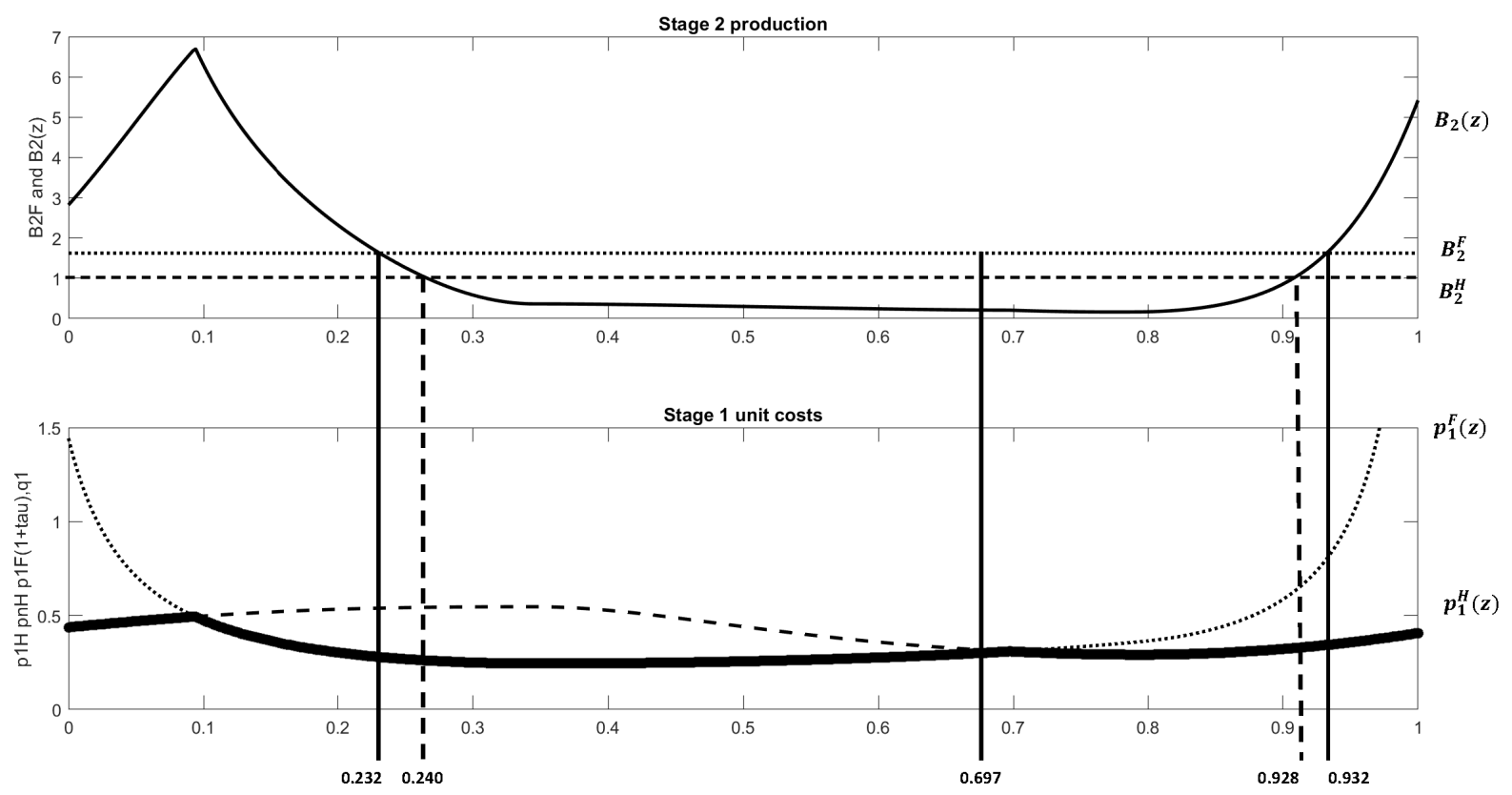

Figure 4.4: The pattern of production in the Foreign country

In this case, the second stage producers in the Foreign country obtain most of the intermediate inputs 
from formal Home producers to produce the final goods. Then, these final goods are exported to the Home country. This is a vertical specialization type of trade as defined in Yi et al.(2003). In vertical specialization, a country imports intermediate inputs from its trading partner to produce a final good which is exported to its trading partner in the end. Furthermore, the presence of trade costs, $\tau$ results in some second stage formal varieties not being traded: $z_{2} \in[0.232,0.240] \cup[0.928,0.932]$ in both countries. Non-traded formal varieties are shown by the line segments between the vertical dashed and the solid line in the upper graph of Figure 4.3 and 4.4. Therefore, the Home country exports second stage varieties, $z_{2} \in[0,0.232] \cup[0.932,1]$ to the Foreign country, while imports second stage varieties $z_{2} \in[0.240,0.928]$ from the Foreign country.

Table 4.4 reports the values of equilibrium aggregate variables for the Home and the Foreign country:

\section{The Home country The Foreign country}

\begin{tabular}{lll}
\hline First stage probability $\left(\lambda_{1}\right)$ & 0.15 & 0.27 \\
Second stage probability $\left(\lambda_{2}\right)$ & 0.08 & 0.15 \\
First stage formal wages $\left(w_{1}\right)$ & 5.57 & 3.65 \\
Second stage formal wages $\left(w_{2}\right)$ & 9.86 & 6.45 \\
First stage hiring costs $\left(h_{1}\right)$ & 5.57 & 3.65 \\
Second stage hiring costs $\left(h_{2}\right)$ & 3.15 & 2.06 \\
Wages in the recruitment agencies $\left(w_{r}\right)$ & 0.88 & 1.00 \\
The cost of posting vacancies $\left(p_{r}\right)$ & 8.81 & 3.33 \\
First stage formal employment $\left(L_{1}\right)$ & 0.24 & 0.20 \\
First stage informal employment $\left(L_{n}\right)$ & 2.37 & 0.00 \\
Second stage formal employment $\left(L_{2}\right)$ & 0.31 & 0.97 \\
First stage unemployment $\left(U_{1}\right)$ & 1.27 & 0.55 \\
Second stage unemployment $\left(U_{2}\right)$ & 3.17 & 5.68 \\
Consumption $(C)$ & 6886 & 5.27 \\
Value of first stage exports & 2.66 & 7862 \\
Values of second stage exports & 3.12 & 0.00 \\
\hline Value of total exports & 5.79 & 5.68 \\
\hline
\end{tabular}

Table 4.4: The key aggregate variables in the benchmark economy

In the theory section, equations (4.25) and (4.28) show that the probability of finding a job in each stage of production, $\lambda_{s}^{i}$ in country $i$ is increasing in its matching productivity parameter, $\phi^{i}$ and the productivity parameter of the recruitment agencies, $A_{r}^{i}$. The Home country has more frictions in its labour market since it has lower productivity parameter of recruitment agencies than the Foreign country. This results in lower $\lambda_{s}^{i}$ in the Home country relative to the Foreign country. Furthermore, from equations (4.26) and (4.29), observe that $h_{s}^{i}$ increase as $\lambda_{s}^{i}$ decreases. This implies that the Home country has higher hiring costs than the Foreign country in each stage of production. Moreover, the cost of posting vacancies, $p_{r}^{i}$, 
which is given in equation (4.2), increases in lower $A_{r}^{i}$. Therefore, the Home country experiences higher cost of posting vacancies relative to the Foreign country. Using equations (4.24) and (4.27), which show the relationship between hiring costs, $h_{s}^{i}$ and formal wages, $w_{s}^{i}$, it is clear to see that formal wages are higher in the Home country than in the Foreign country. Moreover, using equation (4.2), notice that wages in the recruitment agencies, $w_{r}$ are lower in the Home country relative to the Foreign country. From Table 4.3, observe that there is lower first stage employment in the Foreign country than in the Home country. The first stage formal producers in the Home country produce intermediate inputs exclusively for the Foreign market. This results in higher first stage formal employment in the Home country, $L_{1}^{H}$. Furthermore, the Foreign country produces a larger set of second stage formal varieties than the Home country. The Home country has also lower second stage employment, $L_{2}^{H}$ than the Foreign country. Notice that the first stage unemployment in the Home country, $U_{1}^{H}$ is higher than in the Foreign country, while the second stage unemployment, $U_{2}^{H}$ is lower relative to the Foreign country. This is due to the fact that the Foreign country is more competitive in the second stage of production than the Home country; therefore, there is more competition among more workers to find a formal job, and this results in higher unemployment in the second stage in the Foreign country. Since the Foreign country produces a smaller set of intermediate inputs only for its domestic market, and does not export any intermediate inputs to the Home country, it has a lower unemployment relative to the Home country. Moreover, observe that the Foreign country has higher consumption, $C^{F}$, and accordingly higher welfare relative to the Home country. In the Foreign country, the first stage producers do not export any formal varieties to the Home country. Moreover, the first stage formal producers in the Home country exclusively produce intermediate inputs to export to the Foreign country. As a result, the value of exports in the first stage is higher in the Home country than the Foreign country. Second stage formal producers in the Foreign country use intermediate inputs to produce final goods, and some of which are exported to the Home country. In the second stage, the value of exports is higher in the Foreign country relative to the Home country since the Foreign country exports a larger set of varieties to the Home country.

In order to examine the role of informal producers in the production chain, assume that the Home country eliminates its informal sector. We keep all the productivity parameters the same, and have the same degree of labour market rigidity across countries, but we shut down the informal sector in the Home country ${ }^{2}$.

\footnotetext{
${ }^{2}$ Suppose government takes a strict action to eliminate informal economy in the Home country.
} 
Table 4.5 reports the pattern of production in the Home country comparing two economies: the Home country with informal producers and without informal producers. Under this new specification, second stage formal varieties, $z_{2} \in[0,0.112]$ are produced in the Home country, of which varieties, $z_{2} \in[0,0.012] \cup$ $[0.032,0.068]$ are exported to the Foreign country. In this case, the Home country produces less second stage varieties relative to the benchmark economy in which informal producers are operative. Relative to the benchmark economy, where all second stage Home producers used domestic informal suppliers, second stage producers in the Home country imports intermediate inputs, $z_{1} \in[0,0.032]$ from the Foreign country and purchase first stage varieties, $z_{1} \in[0.032,0.112]$ from its domestic formal producers when informal producers are not operative.

\begin{tabular}{ccc} 
& Operative & Non-operative \\
\hline$z_{1 D}$ & {$[0,0]$} & {$[0.032,0.112]$} \\
$z_{1 X}$ & {$[0.232,0.697]$} & {$[0.068,0.898]$} \\
$z_{1 n}$ & {$[0,0.240] \cup[0.928,1]$} & {$[0,0]$} \\
$z_{2}$ & {$[0,0.240] \cup[0.928,1]$} & {$[0,0.112]$} \\
$z_{2 X}$ & {$[0,0.232] \cup[0.932,1]$} & {$[0,0.012] \cup[0.032,0.068]$} \\
\hline
\end{tabular}

Table 4.5: The pattern of production in the Home country without informal producers

Moreover, Table 4.6 reports the pattern of production in the Foreign country. Observe that the Foreign country produces more second stage formal varieties, $z_{2} \in[0.012,0.032] \cup[0.068,1]$ than it does when informal producers are operative in the Home country. Furthermore, the Foreign country has a larger comparative advantage at the second stage relative to the benchmark economy, as it exports more second stage varieties, $z_{2} \in[0.012,0.032] \cup[0.112,1]$ to the Home country. Some first stage formal producers in the Foreign country also become competitive, and export $z_{2} \in[0,0.032]$ to the Home country in this economy.

\begin{tabular}{ccc} 
& Operative & Non-operative \\
\hline$z_{1 D}$ & {$[0.697,0.932]$} & {$[0.012,0.032] \cup[0.899,1]$} \\
$z_{1 X}$ & {$[0,0]$} & {$[0,0.032]$} \\
$z_{1 n}$ & {$[0,0]$} & {$[0,0]$} \\
$z_{2}$ & {$[0.232,0.932]$} & {$[0.012,0.032] \cup[0.068,1]$} \\
$z_{2 X}$ & {$[0.232,0.240]$} & {$[0.112,1]$} \\
\hline
\end{tabular}

Table 4.6: The pattern of production in the Foreign country without informal producers 
The pattern of production in each country, which is reported in Table 4.5 and 4.6, is illustrated in Figure 4.5, which only focuses on the Home country:

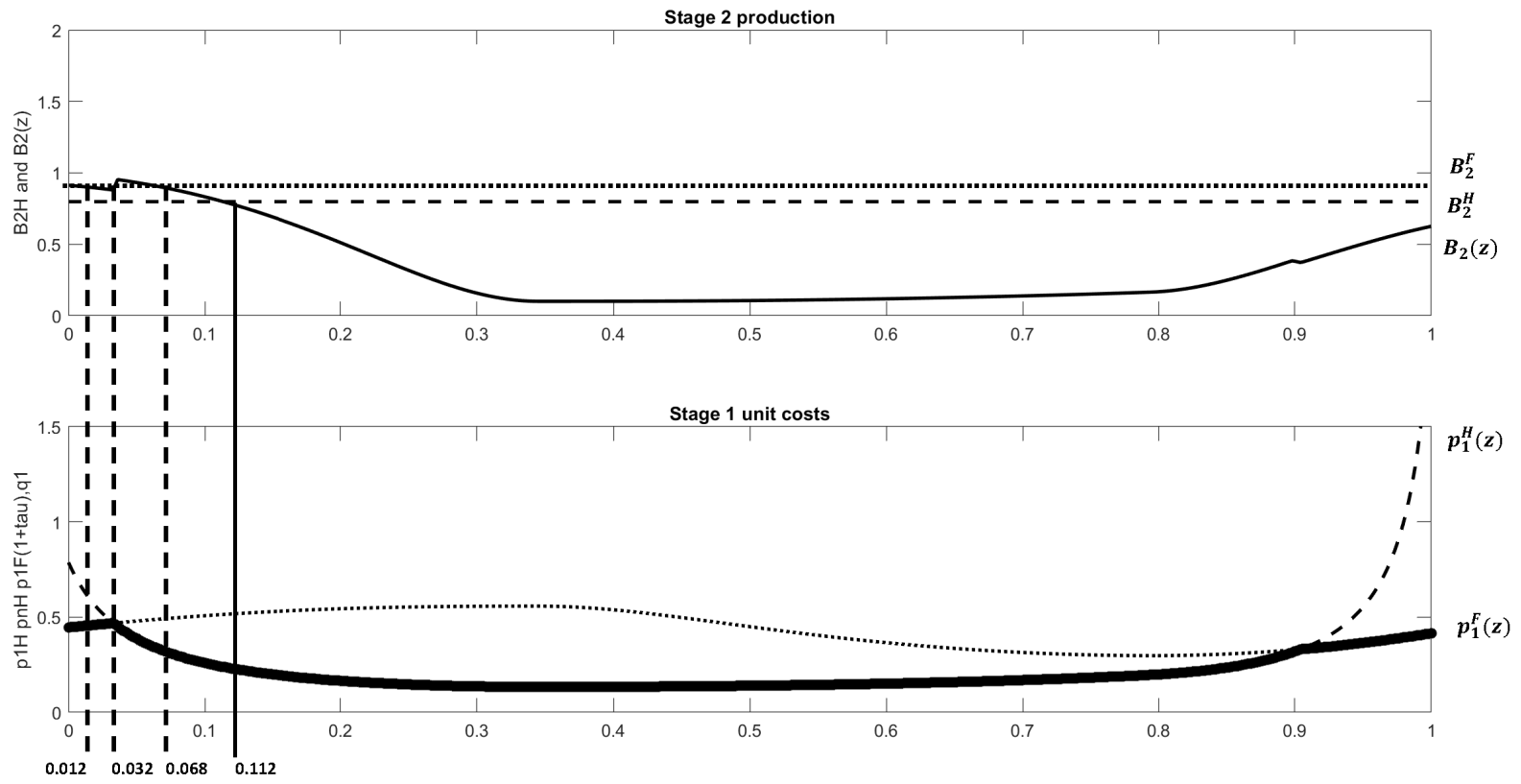

Figure 4.5: The pattern of production in the Home country

On the top of graph, notice that the Home country produces less varieties in the second stage, $z_{2} \in$ $[0,0.112]$ (where the solid line is above the dashed line in the upper graph), and a smaller set of these varieties are exported to the Foreign country, $z_{2} \in[0,0.112] \cup[0.032,0.068]$. Observe from the lower graph that some second stage producers in the Home country obtain some of their inputs, $z_{1} \in[0.032,0.112]$ from domestic formal producers (where the dashed line is lower than the dotted line), and others import their intermediate inputs, $z_{1} \in[0,0.012]$ from the Foreign country (where the dotted line is below the dashed line). Therefore, the presence of informal producers can determine comparative advantages of a country in both stages of production. Without informal producers in the Home country, the Foreign formal producers become more competitive in the first stage of production, they export intermediates inputs in varieties which are produced by informal producers in the benchmark economy. Furthermore, the Home country loses competitiveness in the second stage of production since they do not have access to low costs informal intermediate inputs. 
Table 4.7 reports the key aggregate variables comparing this particular experiment and the benchmark economy:

\section{The Home Country The Foreign country}

Operative, Non-operative Operative, Non-operative

\begin{tabular}{lcc}
\hline First stage probability $\left(\lambda_{1}\right)$ & $0.15, \mathbf{0 . 1 5}$ & $0.27, \mathbf{0 . 2 7}$ \\
Second stage probability $\left(\lambda_{2}\right)$ & $0.08, \mathbf{0 . 0 8}$ & $0.15, \mathbf{0 . 1 5}$ \\
First stage formal wages $\left(w_{1}\right)$ & $5.57, \mathbf{3 . 1 0}$ & $3.65, \mathbf{3 . 6 5}$ \\
Second stage formal wages $\left(w_{2}\right)$ & $9.86, \mathbf{5 . 4 8}$ & $6.45, \mathbf{6 . 4 5}$ \\
First stage hiring costs $\left(h_{1}\right)$ & $5.57, \mathbf{3 . 1 0}$ & $3.65, \mathbf{3 . 6 5}$ \\
Second stage hiring costs $\left(h_{2}\right)$ & $3.15, \mathbf{1 . 7 5}$ & $2.06, \mathbf{2 . 0 6}$ \\
Wages in the recruitment agencies $\left(w_{r}\right)$ & $0.88, \mathbf{0 . 4 9}$ & $1.00, \mathbf{1 . 0 0}$ \\
The cost of posting vacancies $\left(p_{r}\right)$ & $8.81, \mathbf{4 . 9 0}$ & $3.33, \mathbf{3 . 3 3}$ \\
First stage formal employment $\left(L_{1}\right)$ & $0.24, \mathbf{0 . 7 1}$ & $0.20, \mathbf{0 . 0 7}$ \\
First stage informal employment $\left(L_{n}\right)$ & $2.37, \mathbf{0 . 0 0}$ & $0.00, \mathbf{0 . 0 0}$ \\
Second stage formal employment $\left(L_{2}\right)$ & $0.31, \mathbf{0 . 0 6}$ & $0.97, \mathbf{1 . 0 9}$ \\
First stage unemployment $\left(U_{1}\right)$ & $1.27, \mathbf{3 . 8 1}$ & $0.55, \mathbf{0 . 1 8}$ \\
Second stage unemployment $\left(U_{2}\right)$ & $3.17, \mathbf{0 . 6 5}$ & $5.27, \mathbf{5 . 9 6}$ \\
Consumption $\left(C^{i}\right)$ & $6886, \mathbf{4 7 8 5}$ & $7862, \mathbf{9 9 2 8}$ \\
Value of first stage exports & $2.66, \mathbf{4 . 2 6}$ & $0.00, \mathbf{0 . 0 6}$ \\
Value of second stage exports & $3.12, \mathbf{0 . 2 9}$ & $5.68, \mathbf{4 . 0 9}$ \\
Value of total export & $5.79, \mathbf{4 . 5 6}$ & $5.68, \mathbf{4 . 4 7}$ \\
\hline
\end{tabular}

Table 4.7: The key aggregate variables without informal producers

Observe that the probability of finding a formal job in each stage of production, $\lambda_{s}^{i}$ in country $i$ remains the same, since all the productivity parameters affecting $\lambda_{s}^{i}$, which is given in equations (4.25) and (4.29), are fixed. Informal producers are very unproductive if they operate in the Home country due to the strict labour market policy. In this case, Home formal producers supply intermediate inputs to the domestic and foreign market. Table 4.7 reports that formal wages in the Home country are lower than those in the Foreign country. Using producers' price in each stage of production, which are given in equations (4.4), (4.9), observe that formal variety prices increase in hiring costs, $h_{s}^{i}$ (and formal wages, $w_{s}^{i}$ ), and decrease in productivity parameters of formal producers, $a_{s}^{i}(z)$ and the bargaining power of workers, $\sigma$, which is fixed. Since the Foreign country is more productive in producing any sets of formal varieties relative to the Home country as reported in Table 4.1, formal wages in the Home country are lower in each stage of production to export some formal varieties to the Foreign country. Moreover, wages in the recruitment agencies, $w_{r}^{i}$ are lower in the Home country since it is assumed that the expected labour income of each worker in each sector is the same in equilibrium which is shown equation (4.12). This leads lower cost of posting vacancies in the Home country since $p_{r}^{i}$ decreases in $w_{r}^{i}$. When informal producers are not operative, the 
Home country has higher first stage formal employment, $L_{1}^{H}$ and higher first stage unemployment, $U_{1}^{H}$. In this example, eliminating the informal sector may result in reallocation of producers into the formal sector. Moreover, some people, who were engaging in informal economic activities in the benchmark economy, may not find a formal job, and become unemployed. In the new economy, the Foreign country has lower first stage formal employment, $L_{1}^{F}$ and unemployment, $U_{1}^{F}$ relative to the benchmark economy where informal producers are operative. Since the Foreign country obtains a larger sets of intermediate inputs from the first stage Home producers, it has lower first stage production which leads to lower employment and unemployment. In the second stage, the Home country produces a smaller set of formal varieties relative to the benchmark economy, where informal producers are operative, and this results in lower second stage employment, $L_{2}^{H}$ and unemployment $U_{2}^{H}$. In this example, eliminating informal producers in the new economy causes a lower second stage production since informal producers are the ones supplying intermediated inputs the second stage Home producers. The Home country imports a larger set of second stage varieties from the Foreign country, and this results in lower second stage employment and unemployment in the Home country. The Foreign country is more competitive in the second stage of production in the new economy, it produces more formal varieties. This implies more second stage employment, $L_{2}^{F}$ and higher unemployment, $U_{2}^{F}$. Furthermore, without informal producers, the Home country experiences lower consumption, $C^{H}$ which implies lower welfare. In this new economy, the value of the first stage exports is higher, whereas the value of the second stage exports is lower in each country relative to the benchmark economy. However, a decrease in the value of exports in the second stage is more pronounced in the Home country. Therefore, removing informal producers in the Home country causes higher production in intermediate inputs that are exclusively exported to the Foreign country, and lower second stage Home production. This exercise has an important implication about the role of informal producers determining the pattern of production and comparative advantages of a country. Observe that the pattern of production in each stage is altered as informal producers are removed in the Home country. Moreover, the trade structure is changed: the Home country starts importing intermediate inputs from the Foreign country. It loses comparative advantage in a large set of formal varieties in the second stage, that is, the Home country produces and exports a smaller set of second stage varieties relative to the Foreign country once informal producers are not operative in the production chain. Therefore, policy makers whose goal is to reduce or eliminate the informal sector should take into account the interlinkage between formal and informal producers in the production chain since informal producers may have contributions to trade outcome of a country. Our findings in this exercise suggest that informal producers play a crucial role in shaping developing countries comparative advantage in the global market. 


\subsection{Policy Experiments}

In this section, we examine the changes in the pattern of production and the trade structure of countries when countries change their labour market and trade policies. We assume that informal producers are only operative in the Home country. We perform three experiments: (i) the Home country trades with a country having higher labour frictions, (ii) the Home country with higher labour market frictions and the Foreign country impose higher trade costs and (iii) the Home country trades with a country with higher labour market frictions in a protectionist economy.

\subsubsection{Experiment-I: Labour market policy}

In this subsection, we modify the model above by assuming that the Home country trades with a country which has higher labour market frictions. We assume that the differences in labour market frictions comes from differences in the productivity of the recruitment agencies. Suppose the recruitment agencies in the Home country to be more productive than those of its trading partner: $A_{r}^{H}=0.1$ and $A_{r}^{F}=0.05$. In Table 4.8, we compare the pattern of production in the benchmark economy and the economy in Experiment-I for the Home country:

\begin{tabular}{ccc} 
& Benchmark & Experiment-I \\
\hline$z_{1 D}$ & {$[0,0]$} & {$[0,0]$} \\
$z_{1 X}$ & {$[0.232,0.697]$} & {$[0.256,0.840]$} \\
$z_{1 n}$ & {$[0,0.240] \cup[0.928,1]$} & {$[0,0.262] \cup[0.875,1]$} \\
$z_{2}$ & {$[0,0.240] \cup[0.928,1]$} & {$[0,0.262] \cup[0.875,1]$} \\
$z_{2 X}$ & {$[0,0.232] \cup[0.932,1]$} & {$[0,0.256] \cup[0.879,1]$} \\
\hline
\end{tabular}

Table 4.8: Experiment-I: The pattern of production in the Home country

Observe that trading with the country having higher labour market frictions, the Home country now produces a different set of second stage varieties, $[0.262,0.883] \cup[0.875,1]$ and exports a larger set of formal varieties, $[0,0.256] \cup[0.8879,1]$ to the Foreign country. As in the benchmark economy, the second stage Home producers obtain their intermediate inputs from domestic informal producers. 
Table 4.9 reports the pattern of production in the Foreign country comparing the benchmark economy with the Experiment-I where the Foreign country has more rigid labour markets relative to the Home country.

\begin{tabular}{ccc} 
& Benchmark & Experiment-I \\
\hline$z_{1 D}$ & {$[0.697,0.932]$} & {$[0.840,0.879]$} \\
$z_{1 X}$ & {$[0,0]$} & {$[0,0]$} \\
$z_{1 n}$ & {$[0,0]$} & {$[0,0]$} \\
$z_{2}$ & {$[0.232,0.932]$} & {$[0.256,0.879]$} \\
$z_{2 X}$ & {$[0.240,0.928]$} & {$[0.262,0.875]$} \\
\hline
\end{tabular}

Table 4.9: Experiment-I: The pattern of production in the Foreign country

Notice that the Foreign country produces second stage varieties, [0.256,0.875], and exports a smaller set of formal varieties, $z_{2} \in[0.262,0.875]$ to the Home country. Second stage producers in the Foreign country import their intermediate input, $[0.256,0.840]$ from formal Home producers and they obtain intermediate input, [0.840,0.879] from their domestic producers.

Furthermore, the pattern of production in each country is presented using Figure 4.6:

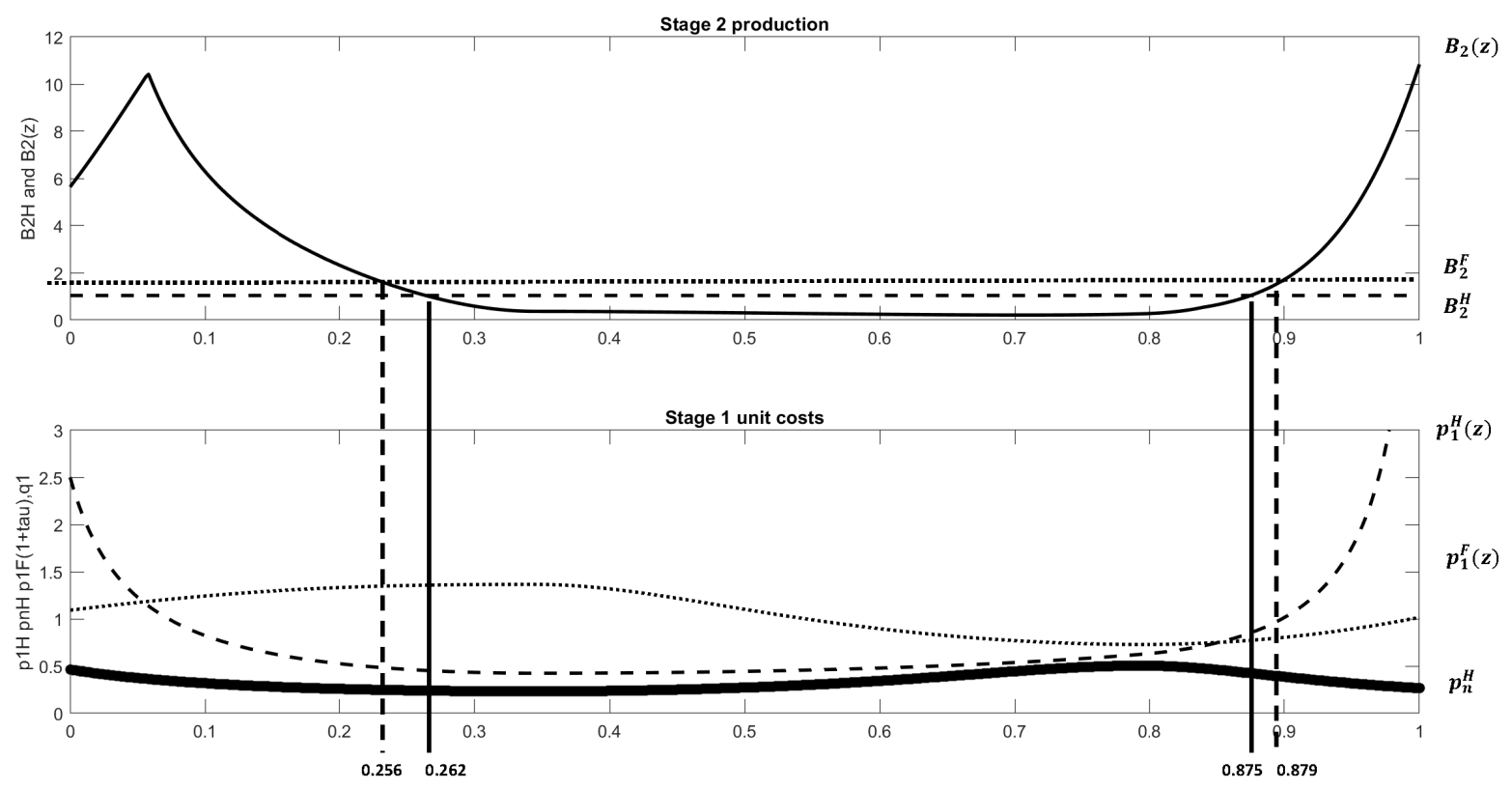

Figure 4.6: The pattern of production in Experiment-I

The upper graph of Figure 4.6 shows that the Home country produces the second stage varieties for which the solid line is greater than the dashed line, and the Foreign country produces the second stage varieties for which the dotted line is above the the solid line. The line segments between the dashed and solid vertical line show second-stage varieties, $z_{2} \in[0.256,0.262] \cup[0.875,0.879]$ that are not traded. The lower graph of Figure 4.6 presents that all seconds stage producers in the Home country buy their intermediate 
input from domestic informal producers for which the solid line is below the the dotted and the dashed line.

Table 4.10 reports key aggregate variables for the benchmark economy and the economy in Experiment-I:

The Home Country

The Foreign country

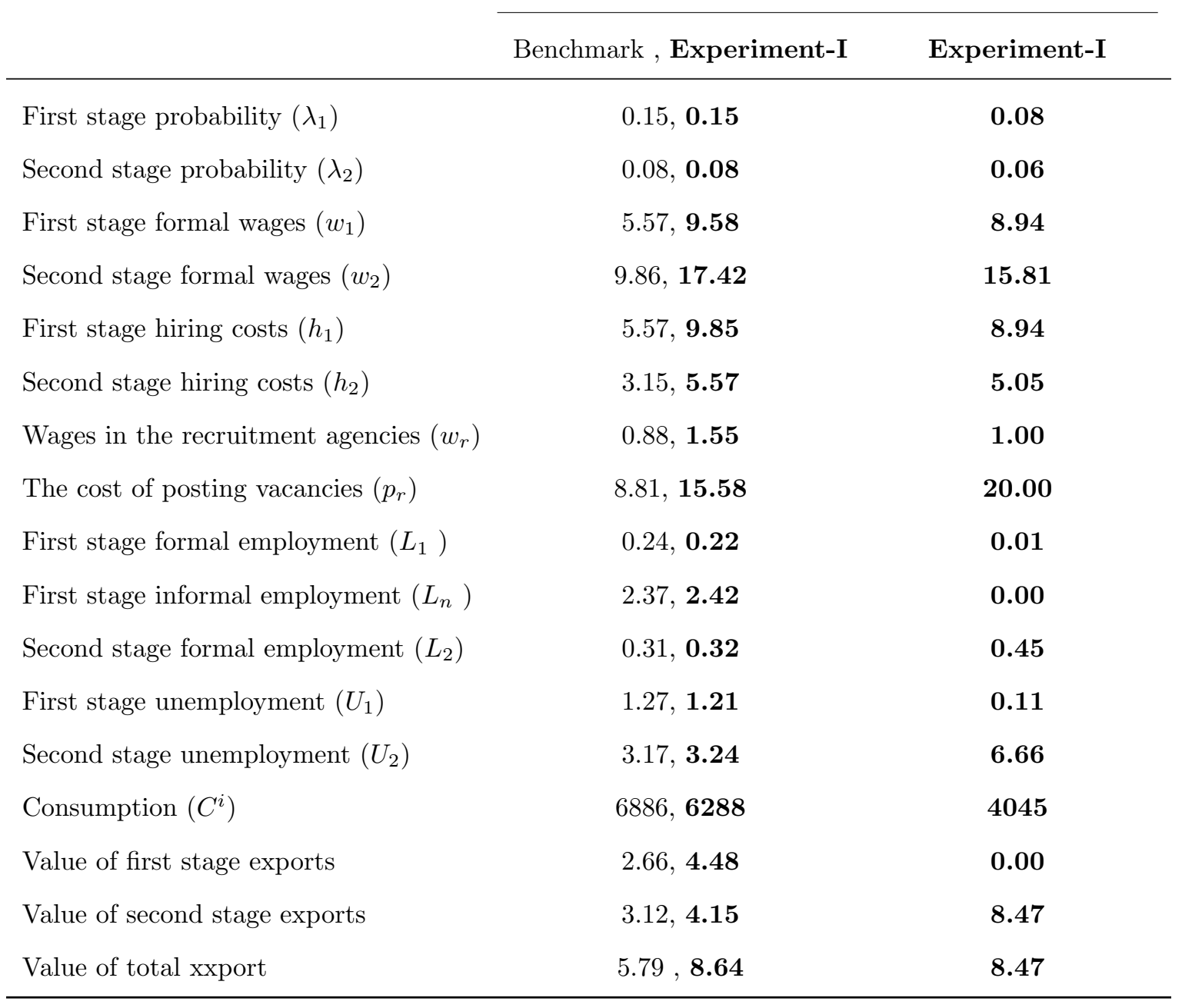

Table 4.10: The key aggregate variables in Experiment-I

The probability of finding a job in each stage of production, $\lambda_{s}^{i}$ is higher in the Home country relative to the Foreign country since the productivity parameter of the recruitment agencies, $A_{r}^{i}$ is higher in the Home country (Notice from equations (4.25) and (4.28) that $\lambda_{s}^{i}$ decreases in $A_{r}^{i}$ ). Formal wages in the Home country, $w_{s}^{H}$ are higher in the new economy relative to the benchmark economy. In this example, formal wages do not need to be lower as in the benchmark economy since the trading partner of the Home country less competitive than the one in the benchmark economy. Moreover, using equations (4.24) and (4.27), observe that higher $w_{s}^{i}$ imply higher hiring costs, $h_{s}^{i}$ in the Home country. Furthermore, wages in the recruitment agencies, $w_{r}^{i}$ are higher in the Home country due to the fact that the expected labour income is the same in equilibrium which is given in equation (4.12). From equation (4.2), notice that higher $w_{r}^{i}$ causes higher cost of posting vacancies, $p_{r}^{i}$ in the Home country. Relative to the benchmark economy, the Home country has lower first stage formal employment and unemployment. Moreover, the second stage producers in the Home country produce a larger set of formal varieties; therefore, the second stage formal employment is higher. The second stage Home producers obtain all their intermediate 
inputs from domestic informal producers; therefore, informal employment in the Home country is higher to satisfy the demand of the second stage production. This may imply that lower first stage formal employment and unemployment in the Home country are resulted from the fact that people move into the informal sector. In the new economy, consumption, $C^{i}$, which represents welfare in our model, is higher in the Home country relative to the Foreign country. since the Foreign country has higher labour market frictions than the Home country. Furthermore, the Home country has lower welfare in the new economy than the one in the benchmark economy since the price of each formal varieties higher due to higher wages. This results in lower consumption of the final goods. In the new economy, the Home country has higher value of exports in the first stage and lower value of exports in the second stage relative to the Foreign country.

In this experiment, we show that the size of the informal sector in a country is influenced not only by its own labour market structure but also by its trading partner's labour market rigidity. Furthermore, we find that the size of informal sector in the Home country expands as it trades with a country having more labour market frictions. This is due to the fact that the second stage producers in the Home country produces a larger set of formal varieties. This results in higher informal employment since, the second stage Home producers obtain all their intermediate inputs from domestic informal producers.

\subsubsection{Experiment-II: Trade policy-the Home country with higher labour market frictions}

In this experiment, we compare the size of the informal sector and the pattern of production under different trade policies. We keep all characteristics of the benchmark economy to be the same, and change only the value of trade cost to $\tau=0.2$.

In Table 4.11, we compare the pattern of production in the Home country between the benchmark economy with lower trade costs and the new protectionist scenario:

\begin{tabular}{ccc} 
& Benchmark & Experiment-II \\
\hline$z_{1 D}$ & {$[0,0]$} & {$[0,0]$} \\
$z_{1 X}$ & {$[0.232,0.695]$} & {$[0.224,0.665]$} \\
$z_{1 n}$ & {$[0,0.240] \cup[0.928,1]$} & {$[0,0.300] \cup[0.889,1]$} \\
$z_{2}$ & {$[0,0.240] \cup[0.928,1]$} & {$[0,0.300] \cup[0.889,1]$} \\
$z_{2 X}$ & {$[0,0.232] \cup[0.932,1]$} & {$[0,0.224] \cup[0.946,1]$} \\
\hline
\end{tabular}

Table 4.11: Experiment-II: The pattern of production in the Home country 
The Home country produces a larger set of second stage varieties, $z_{2} \in[0,0.300] \cup[0.889,1]$ in the protectionist scenario, and exports a smaller set of varieties, $z_{2} \in[0,0.224] \cup[0.946,1]$ to the Foreign country. The second stage producers in the Home country purchase all intermediate inputs from domestic informal producers.

Furthermore, Table 4.12 illustrates the pattern of production in the Foreign country comparing the benchmark economy with the economy having higher trade barriers:

\begin{tabular}{ccc} 
& Benchmark & Experiment-II \\
\hline$z_{1 D}$ & {$[0.697,0.932]$} & {$[0.665,0.945]$} \\
$z_{1 X}$ & {$[0,0]$} & {$[0,0]$} \\
$z_{1 n}$ & {$[0,0]$} & {$[0,0]$} \\
$z_{2}$ & {$[0.232,0.932]$} & {$[0.224,0.946]$} \\
$z_{2 X}$ & {$[0.240,0.928]$} & {$[0.300,0.889]$} \\
\hline
\end{tabular}

Table 4.12: Experiment-II: The pattern of production in the Foreign country

Similar to the Home country, the Foreign country produces a larger set of second stage varieties, $z_{2} \in[0.224,0.946]$, and exports a smaller set of formal varieties, $z_{2} \in[0.300,0.889]$ to the Home country. Moreover, second stage producers in the Foreign country obtain intermediate inputs, $z_{1} \in[0.665,0.945]$ from domestic formal producers, and import intermediate inputs, $z_{1} \in[0.224,0.665]$ from formal producers in the Home country.

Using the Home country's pattern of production, Figure 4.7 illustrates changes in trade structure in each country:

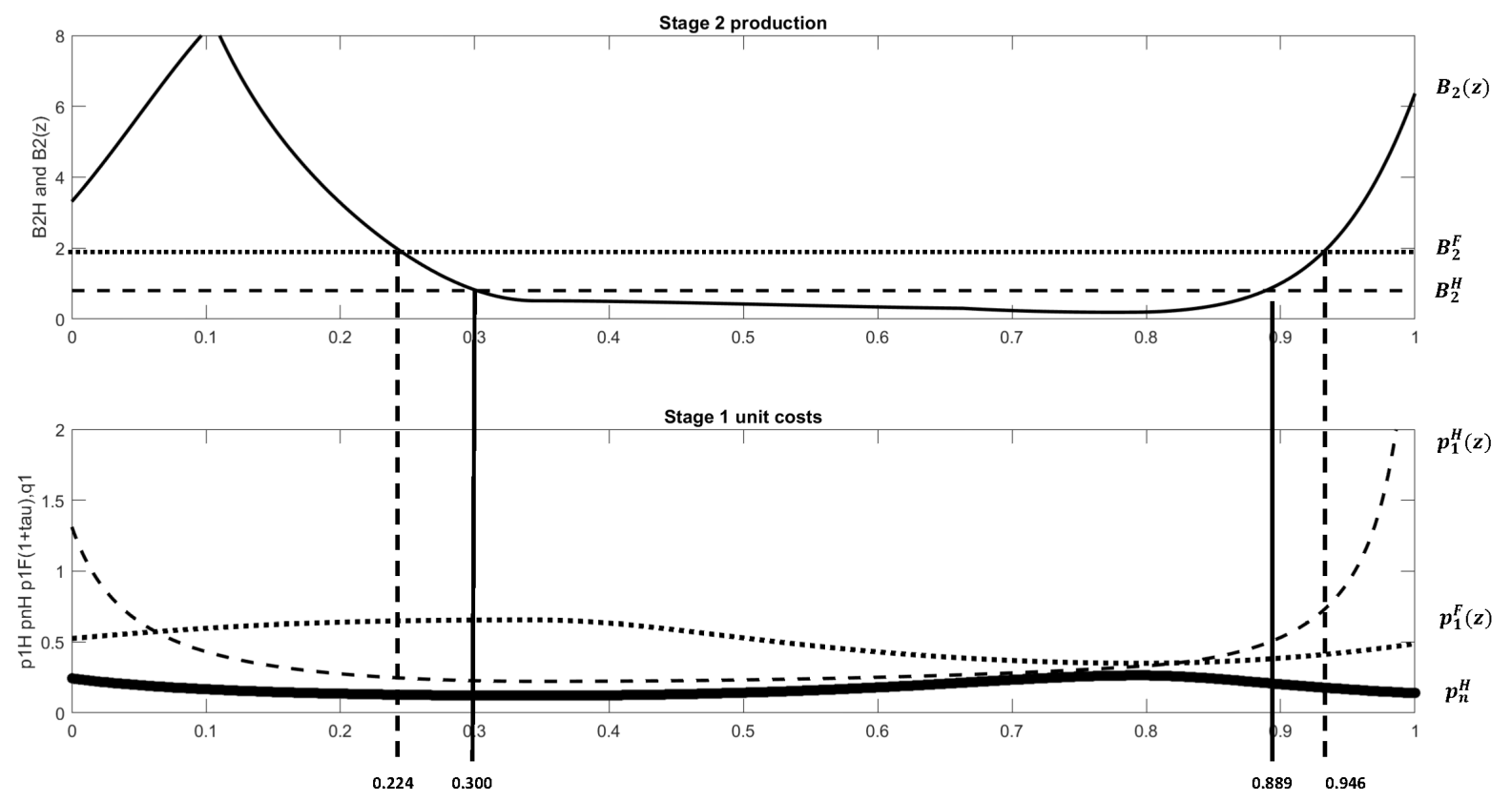

Figure 4.7: The pattern of production in Experiment-II 
Observe that the Home country produces a larger set of second stage formal varieties for which the solid line in above the dashed line in the upper graph of Figure 4.7. This implies that a larger set of intermediate inputs are produced by informal producers since the second stage Home producers only purchase their inputs from domestic informal producers. Furthermore, the first stage formal producers in the Home country export a lower set of formal varieties to the Foreign country due to higher trade costs. In the new economy, higher trade costs results in more varieties, $z_{2} \in[0.224,0.300] \cup[0.889,0.900]$ that are non-traded which this is illustrated in the line segments between the vertical dashed and solid line in Figure 4.7.

Table 4.13 reports key aggregate variables comparing the benchmark economy and the Experiment-II in which both countries have higher trade costs:

The Home Country The Foreign country

Benchmark, Experiment-II Benchmark, Experiment-II

\begin{tabular}{|c|c|c|}
\hline First stage probability $\left(\lambda_{1}\right)$ & $0.15, \mathbf{0 . 1 5}$ & $0.27, \mathbf{0 . 2 7}$ \\
\hline Second stage probability $\left(\lambda_{2}\right)$ & $0.08, \mathbf{0 . 0 8}$ & $0.15, \mathbf{0 . 1 5}$ \\
\hline First stage formal wages $\left(w_{1}\right)$ & $5.57,5.17$ & $3.65, \mathbf{3 . 6 5}$ \\
\hline Second stage formal wages $\left(w_{2}\right)$ & $9.86, \mathbf{9 . 1 4}$ & $6.45,6.45$ \\
\hline First stage hiring costs $\left(h_{1}\right)$ & $5.57,5.17$ & $3.65, \mathbf{3 . 6 5}$ \\
\hline Second stage hiring costs $\left(h_{2}\right)$ & $3.15,2.92$ & $2.06, \mathbf{2 . 0 6}$ \\
\hline Wages in the recruitment agencies $\left(w_{r}^{i}\right)$ & $0.88, \mathbf{0 . 8 1}$ & $1.00, \mathbf{1 . 0 0}$ \\
\hline The cost of posting vacancies $\left(p_{r}\right)$ & $8.81,8.17$ & $3.33, \mathbf{3 . 3 3}$ \\
\hline First stage formal employment $\left(L_{1}\right)$ & $0.24, \mathbf{0 . 1 6}$ & $0.20, \mathbf{0 . 2 0}$ \\
\hline First stage informal employment $\left(L_{n}\right)$ & $2.37, \mathbf{2 . 6 8}$ & $0.00, \mathbf{0 . 0 0}$ \\
\hline Second stage formal employment $\left(L_{2}\right)$ & $0.31, \mathbf{0 . 3 5}$ & $0.97, \mathbf{0 . 8 1}$ \\
\hline First stage unemployment $\left(U_{1}\right)$ & $1.27, \mathbf{0 . 8 8}$ & $0.55, \mathbf{0 . 5 5}$ \\
\hline Second stage unemployment $\left(U_{2}\right)$ & $3.17, \mathbf{3 . 5 9}$ & $5.27,4.46$ \\
\hline Consumption $\left(C^{i}\right)$ & $6886, \mathbf{5 8 7 4}$ & $7862, \mathbf{7 4 6 9}$ \\
\hline Value of second first exports & $2.66, \mathbf{1 . 7 2}$ & $0.00, \mathbf{0 . 0 0}$ \\
\hline Value of second stage exports & $3.12, \mathbf{2 . 3 9}$ & $5.68, \mathbf{3 . 4 2}$ \\
\hline Value of total export & $5.79, \mathbf{4 . 1 1}$ & $5.68,3.42$ \\
\hline
\end{tabular}

Table 4.13: The key aggregate variables in Experiment-II

Table 4.13 shows that the probability of finding a formal job, $\lambda_{s}^{i}$ in each country is not affected by higher trade costs, $\tau$. Furthermore, higher $\tau$ do not alter hiring costs, $h_{s}^{i}$, the cost of posting vacancies, $p_{r}^{i}$ and wages: $w_{r}^{i}, w_{s}^{i}$ in the Foreign country. However, all these costs are lower in the Home country when trade is more restricted. From Table 4.11, notice that the first stage formal producers in the Home country produce intermediate inputs exclusively for the second stage Foreign producers. An increase in trade costs 
results in higher price of each intermediate input. In the theory section, we shows that the producer' price increases in hiring costs, and decreases in the productivity parameters of formal producers. Since the bargaining power of workers, $\sigma$ is fixed and the Home country is less productive in producing any set of formal varieties than the Foreign country, which is shown in Table 4.1, the Home country has lower formal wages to export intermediate inputs to the Foreign country in the new economy. Using equations (4.24) and (4.27), which shows the relationship between formal wages and hiring costs, it is the case that the Home country has lower hiring costs in each stage of production. Furthermore, lower formal wages result in lower wages in the recruitment agencies, $w_{r}^{i}$ since equation (4.12) dictates that the expected income of each worker in each sector is same in the equilibrium. From equation (4.2), it is observable that the cost posting vacancies in the Home country, $p_{r}^{H}$ is lower since it decreases in $w_{r}^{H}$. Notice that the first stage Home formal producers export a smaller set of intermediate inputs to the Foreign country due to higher trade costs. This implies lower first stage formal employment in the Home country. The Home country has a larger size of the informal sector in the protectionist economy. Observe from Table 4.11 that the second stage Home producers obtain all their intermediate inputs from domestic informal producers; therefore, the size of the informal sector expands. This may result in lower first stage unemployment in the new economy. Furthermore, the second stage employment and unemployment are higher in the Home country. It may be the case that there is more second stage formal employment since there is more production for the domestic consumption, and more unemployment due to a low probability of finding a second stage formal job. Consumption, $C^{i}$, which is welfare in our model, is lower in each country under the protectionist scenario. Relative to the benchmark economy, welfare is $14 \%$ lower in the Home country and $5 \%$ lower in the Foreign country. In both countries, consumers pay higher prices for the consumption good. However, a decrease in welfare is more pronounced in the Home country due to the fact that the Home country has higher labour market frictions relative to the Foreign country. Furthermore, both countries experience lower value of exports due to higher trade costs. The value of exports is $40 \%$ and $66 \%$ lower in the Home and the Foreign country respectively in the protectionist economy.

In this experiment, we allow countries to have higher trade costs to examine changes in the pattern of production, the size of the informal sector and trade structure of countries. Our result shows that the size of the informal sector is larger in a country with higher labour market frictions under the protectionist scenario. It may be the case that there are more labour allocation toward the informal sector to supply intermediate inputs to the second stage producers that serve a larger set of non-traded goods. 


\subsubsection{Experiment-III Restricted trade with a country having higher labour market frictions}

In this experiment, we allow the Foreign country to have higher labour market frictions than the Home country as in Experiment-I, and explore changes in the pattern of production, the size of the informal sector and trade structure of countries when the value of trade costs is higher, $\tau=0.2$.

In Table 4.14, we compare the pattern of production of the Home country comparing the Experiment-I and Experiment-III:

\begin{tabular}{ccc} 
& Experiment-I & Experiment-III \\
\hline$z_{1 D}$ & {$[0,0]$} & {$[0,0]$} \\
$z_{1 X}$ & {$[0.256,0.840]$} & {$[0.248,0.793]$} \\
$z_{1 n}$ & {$[0,0.262] \cup[0.875,1]$} & {$[0,0.322] \cup[0.839,1]$} \\
$z_{2}$ & {$[0,0.262] \cup[0.875,1]$} & {$[0,0.322] \cup[0.839,1]$} \\
$z_{2 X}$ & {$[0,0.256] \cup[0.879,1]$} & {$[0,0.248] \cup[0.897,1]$} \\
\hline
\end{tabular}

Table 4.14: Experiment-III: The pattern of production in the Home country

Observe that once both countries impose higher trade costs, the Home country produces a larger set of formal varieties, $z_{2} \in[0,0.322] \cup[0.839,1]$, and exports a smaller set of second stage varieties, $z_{2} \in$ $[0,0.248] \cup[0.897,1]$. The second stage producers in the Home country obtain all intermediate inputs from domestic informal producers as before.

Furthermore, Table 4.15 presents the pattern of production in the Foreign country comparing with Experiment-I and the Experiment-III where both countries have higher trade barriers:

Experiment-I Experiment-III

\begin{tabular}{ccc}
\hline$z_{1 D}$ & {$[0.840,0.879]$} & {$[0.793,0.897]$} \\
$z_{1 X}$ & {$[0,0]$} & {$[0,0]$} \\
$z_{1 n}$ & {$[0,0]$} & {$[0,0]$} \\
$z_{2}$ & {$[0.256,0.879]$} & {$[0.248,0.897]$} \\
$z_{2 X}$ & {$[0.262,0.875]$} & {$[0.322,0.839]$} \\
\hline
\end{tabular}

Table 4.15: Experiment-III: The pattern of production in the Foreign country

The Foreign country produces a larger set of formal varieties, $z_{2} \in[0.248,0.897]$ while exports a smaller set of second stage varieties, and $z_{2} \in[0.322,0.839]$. Moreover, second stage producers in the Foreign country purchase intermediate inputs, $z_{1 D} \in[0.793,0.897]$ from domestic formal producers, and import a larger set of intermediate inputs, $z_{1 X} \in[0.248,0.793]$ from formal producers in the Home country. 
Using the Home country's pattern of production, Figure 4.8 illustrates changes in the trade structure and the pattern of production in each country:

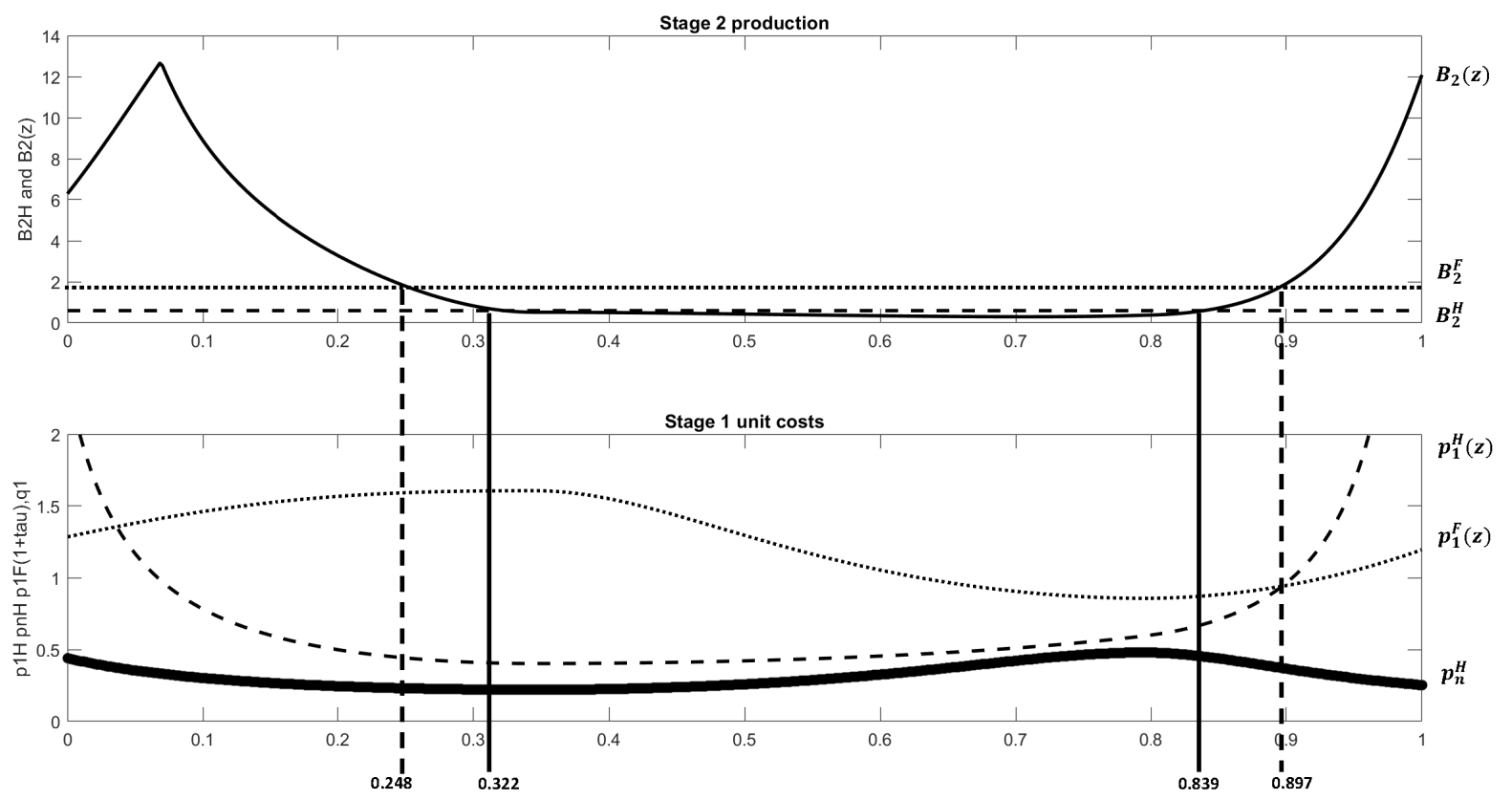

Figure 4.8: The pattern of production in Experiment-III

Similar to the previous figures, in the upper graph, when the solid line in above the dashed line, the Home country produces second stage varieties. Observe that the set of intermediate inputs supplied by informal producers are larger under the protectionist scenario. Moreover, the first stage formal producers in the Home country export a smaller set of formal varieties to the Foreign country due to higher trade costs. Relative to the Experiment-I where trade is liberalized, notice that higher trade costs results in more non-traded varieties, $z_{2} \in[0.248,0.322] \cup[0.839,0.897]$. The set of non-traded goods is shown in the line segments between the vertical dashed and solid line in Figure 4.8. 
Table 4.10 reports key aggregate variables comparing the Experiment-I and the Experiment-III in which both countries face with more restrictions in trade:

The Home Country Experiment-I , Experiment-III
The Foreign country

Experiment-III

\begin{tabular}{lcc}
\hline First stage probability $\left(\lambda_{1}\right)$ & $0.15, \mathbf{0 . 1 5}$ & $\mathbf{0 . 1 1}$ \\
Second stage probability $\left(\lambda_{2}\right)$ & $0.08, \mathbf{0 . 0 8}$ & $\mathbf{0 . 0 6}$ \\
First stage formal wages $\left(w_{1}\right)$ & $9.58, \mathbf{9 . 3 6}$ & $\mathbf{8 . 9 4}$ \\
Second stage formal wages $\left(w_{2}\right)$ & $17.42, \mathbf{1 6 . 5 5}$ & $\mathbf{1 5 . 8 1}$ \\
First stage hiring costs $\left(h_{1}\right)$ & $9.85, \mathbf{9 . 3 6}$ & $\mathbf{8 . 9 4}$ \\
Second stage hiring costs $\left(h_{2}\right)$ & $5.57, \mathbf{5 . 2 9}$ & $\mathbf{5 . 0 5}$ \\
Wages in the recruitment agencies $\left(w_{r}\right)$ & $1.55, \mathbf{1 . 4 8}$ & $\mathbf{1 . 0 0}$ \\
The cost of posting vacancies $\left(p_{r}\right)$ & $15.58, \mathbf{1 4 . 8}$ & $\mathbf{2 0 . 0 0}$ \\
First stage formal employment $\left(L_{1}\right)$ & $0.22, \mathbf{0 . 1 4}$ & $\mathbf{0 . 0 2}$ \\
First stage informal employment $\left(L_{n}\right)$ & $2.42, \mathbf{2 . 7 6}$ & $\mathbf{0 . 0 0}$ \\
Second stage formal employment $\left(L_{2}\right)$ & $0.32, \mathbf{0 . 3 6}$ & $\mathbf{0 . 3 5}$ \\
First stage unemployment $\left(U_{1}\right)$ & $1.21, \mathbf{0 . 7 8}$ & $\mathbf{0 . 2 0}$ \\
Second stage unemployment $\left(U_{2}\right)$ & $3.24, \mathbf{3 . 7 0}$ & $\mathbf{5 . 2 0}$ \\
Consumption $\left(C^{i}\right)$ & $6288, \mathbf{5 4 8 4}$ & $\mathbf{3 7 1 4}$ \\
Value of second first exports & $4.48, \mathbf{2 . 7 5}$ & $\mathbf{0 . 0 0}$ \\
Value of second stage exports & $4.15, \mathbf{3 . 2 5}$ & $\mathbf{5 . 0 0}$ \\
Value of total export & $8.64, \mathbf{6 . 0 1}$ & $\mathbf{5 . 0 0}$ \\
\hline
\end{tabular}

Table 4.16: The key aggregate variables in Experiment-III

As it is shown in equation (4.25), the probability of finding a formal job, $\lambda_{s}^{i}$ increases in the productivity parameter of the recruitment agencies, $A_{r}^{i}$. In the economy, which is presented by the Experiment-III, $\lambda_{s}^{i}$ in the Home country is higher than the Foreign country since the recruitment agencies in the Foreign country has lower productivities relative to those in the Home country. Moreover, all wages are higher in the Home country relative to the Foreign country in the Experiment-III. In this example, the Foreign country is less competitive than the one in the Experiment-I. Therefore, the Home country does not need to have lower wages to remain competitive like in the economy which is represented by the Experiment-III. Furthermore, higher formal wages result in higher hiring costs in the Home country since hiring costs and formal wages change in the same direction, which is given in equations (4.24) and (4.27). Relative to the Experiment-I, formal wages in the Home country are lower under the protectionist scenario. As we mention earlier, formal producers in the Home country produce intermediate inputs exclusively for the second stage Foreign producers. From equation (4.4), observe that the producer' price increases in hiring costs, $h_{1}^{i}$ and decreases in the productivity parameters of formal producers, $A_{r}^{i}$. Since the 
bargaining power of workers, $\sigma$ is fixed and the Home country is less productive in producing any set of formal varieties which is shown in Table 4.1, the Home country has lower wages and hiring costs in the Experiment-III to remain competitive. Moreover, lower formal wages results in lower wages in the recruitment agencies, $w_{r}^{H}$ because of equation (4.12) which shows that the expected income of each worker in each sector is identical in the equilibrium. From here, notice that the cost posting vacancies in the Home country, $p_{r}^{H}$ is lower since $p_{r}^{i}$ decreases in lower $w_{r}^{i}$ (equation (4.2)). Relative to the Experiment-I, where trade is liberalized, the Home country exports less intermediate inputs to the Foreign country in the economy which is represented in Experiment-III. This implies that the Home country has lower first stage formal employment, $L_{1}^{H}$. Furthermore, the second stage Home producers have more employment in the protectionist scenario. It may be the case that the second stage Home producers produce a large set of formal varieties goods that not traded, along with a smaller set of varieties that are exported to to the Foreign country. Moreover, higher production in the second stage in the Home country leads to higher employment in the informal sector since the second stage producers purchase their intermediate inputs only from domestic informal producers. In the Experiment-III, the Home country has lower unemployment in the first stage relative to the economy in the Experiment-I. Lower first stage unemployment may be resulted from higher informal employment, and higher second stage unemployment may be derived from the fact that the probability of finding a formal job is low. Consumption, $C^{i}$, which also represents welfare, is higher in the Home country relative to the Foreign country in the economy presented in the Experiment-III. Lower labour market frictions in the Home country cause this outcome. However, the Home country experiences lower welfare in the economy where trade is restricted than the economy in the Experiment-I. Relative to the liberalize trade, the representative households pay higher prices for the consumption goods in the protectionist scenario, and this results in lower welfare in the Home country. Moreover, as expected, both countries experience lower value of exports in the economy when trade costs are higher.

In this experiment, we keep all the characteristics of the economy in the Experiment-I, and allow countries to impose higher trade costs. In the protectionist economy, which is studied in the Experiment-III, we find that the size of the informal sector expands in the country in which informal producers are operative. In the protectionist scenario, informal producers supply a larger set of intermediate inputs to the second stage Home producers which mostly produce their final products for the domestic consumption. This implies that the size of the informal sector may shrink as countries liberalize trade. 


\subsection{Conclusion}

This chapter, which is a joint work with Professor Claustre Bajona, shows that informal producers have a relationship with formal producers in the production chain by providing intermediate inputs to formal producers that serve in the world market. This chapter is unique since it builds a theoretical framework to investigate the role of informal producers influencing the trade structure of developing countries through their participation in the global supply chain..

In this chapter, we add the stages of production to a model in the spirit of the third chapter. In this model, informal and formal are interlinked in the production chain. Countries produce a continuum of varieties and each variety is produced using labour and a first-stage intermediate input which is variety-specific. This intermediate input can either be produced by formal or informal producers. All formal goods are traded, whereas intermediate inputs produced by informal producers are not traded. To examine the effect of the labour market and trade policies on the pattern of production and the welfare of countries, we calibrate our model economy to the Turkish and German economies in 2003. We choose Turkey in our study since Turkey has a very rigid labour market and a large informal economy, and it has been a participant in global trade since the 1980s. We selected Germany since it has a small informal sector, and it is one of Turkeys top trading partners.

Using a theoretical framework, this chapter shows that informal producers can influence the trade structure and the welfare of developing countries as they operate in the production chain. They supply lower cost intermediate inputs to formal producers that engage in trade. Moreover, similar to the finding in the third chapter, this chapter finds that the size of the informal sector of a country is not only determined by its own labour market structure, but also by its trading partners' labour market structure. Another contribution of this chapter is that trade liberalization causes smaller informal economies in a country with higher labour market frictions relative to its trading partners. 


\section{Chapter 5}

\section{Conclusion}

In this dissertation, we examine the role of informal producers in shaping the trade structure, and the welfare of developing countries, and study the mechanisms through which informal producers affect the trade outcome of developing countries.

This dissertation aims to complete the traditional trade theories, which regard the flexible labour market as the driving force to gain from trade. It shows that a country with rigid labour markets can still benefit from international trade through its informal producers. Different than the existing literature, which investigates the effect of international trade on the size of the informal sector, this dissertation has a goal is to examine the effect of informal producers on the trade outcome of developing countries. Building theoretical frameworks, another goal of this dissertation is to investigate the channels through which informal producers affect the trade structure and welfare of developing countries.

This dissertation contains three chapters, and each one provides unique contributions to the existing literature. The second chapter is different from the existing literature, which investigates the size of the informal sector in Turkey or advises labour market policies to reduce the informal sector Turkey. The second chapter, which uses descriptive statistic and econometric analysis, documents the main employment and demographic characteristics of informal workers in the Turkish manufacturing industries that compete in the global arena. We find that informality is highest among female workers with lower education. Furthermore, we investigate the employment characteristics of these informal workers and report that these workers are mainly home producers employed in in the textile and clothing industries. Since Turkey is one of the leading exporters of textile and clothing products, informal producers can be part of the textile and clothing trade. Our findings from the second chapter motivate the third and fourth chapters which develop theoretical frameworks to explore the channels through which informal producers influence the pattern of trade and the welfare of developing countries. In the third chapter, informal producers directly engage in international trade by exporting their products, which can be low quality, second-hand or counterfeit goods, in the world market. Therefore, informal and formal producers serve in different markets. The third chapter builds a Ricardian model of trade with labour market frictions. Labour market frictions cause segmented labour markets in which formal and informal producers operate. 
This chapter completes the existing literature by showing that the size of the informal sector is affected by not only the country's own labour market structure, but also by its trading partners' labour market frictions. Moreover, this chapter finds that a decrease in trade costs causes an increase in the size of the informal sector in countries with relatively higher labour market rigidities, and a reduction of informality in their trading partners. In this regard, the country with high labour market rigidities becomes a net exporter of informal goods and a net importer of formal goods during trade liberalization. Another important contribution in this chapter is that when two countries with different labour market frictions implement trade liberalizations, changes in labour market policy in a country with higher labour market frictions affect both its own labour market and welfare, as well as those of its trading partner. As an example, if the country with higher labour market frictions experiences a further increase in its labour market frictions, its informal sector expands and its trading partners informal sector shrinks. In addition, welfare in each country decreases, but the country with higher labour market frictions faces lower welfare than its trading partner. In the fourth chapter,which is a joint work with Professor Claustre Bajona, we study the interlinkage between formal and informal producers in the global supply chain. We build a two-country model of trade with stages of production and labour market frictions. As in the third chapter, labour market frictions result in a dual economy where informal and formal producers operate. Countries produce a differentiated good which has a continuum of varieties, and each variety is produced using labour and a first-stage intermediate input which is variety-specific. This intermediate input can either be supplied by formal or informal producers. All formal goods are traded, whereas intermediate inputs produced by informal producers are not traded. To quantify the changes in the labour market and trade policies on the trade structure and the welfare of countries, we calibrate our model to the Turkish and German economies in 2003. This fourth chapter is different than the existing literature since it develops a theoretical framework to investigate the role of informal producers in the global supply chain. The important contribution of the fourth chapter is that informal producers can influence the comparative advantage of developing countries by supplying lower cost intermediate inputs to formal producers that compete in the global arena. Furthermore, as in the third chapter, we find that the size of the informal sector of a country is not only altered by its own labour market structure, but also by its trading partners' labour market characteristics. Furthermore, the fourth chapter shows that a country with higher labour market frictions has a larger informal sector under a protectionist economy relative to the liberalized trade. 


\section{Chapter 6}

\section{References}

Adams, V., Johansson de, S. and Setareh, R. (2013), "Improving Skills Development in the Informal Sector", The World Bank.

Afrika, K. and Ajumbo, G. (2012) Informal Cross Border Trade in Africa: Implications and Policy Recommendations Africa Economic Brief Volume 3, Issue 10.

Antras, P., Chor, D., Fally, T. and Hillbery, R. (2013),"Measuring the Upstreamness of Production and Trade Flow", American Economic Rewiev: Papers and Proceedings 2012, 102(3): 412-416.

Arvin-Rad, H., Basu, A. and Willumsen, M. (2010) Economic Reform, Informal-Formal Sector Linkages and Intervention in the Informal Sector in Developing Countries: A Paradox, Discussion Paper No. 5229. Bargain, O., El Badaoui, E., Strobl, E. and Walsh, F. (2012), The Formal Sector Wage Premium and Firm Size for Self-employed Workers, IZA DP No. 6604.

Barrosa, C. and Chivangue, A. (2017), " Poverty Reduction and Informal Trade", Working Paper CEsA CSG 15 .

Becker, K. (2004), "The Informal Economy", Stockholm: SIDA Public ations.

Benjamin, N. (2014) Informal Economy and the World Bank, The World Bank Poverty Reduction and Economic Management Network Economic Policy and Debt Department, Policy Research Working Paper 6888 .

Botero, J., Djankov, S., Porta, R., Lopez de Silanes, F., and Shleifer, A. (2004), The Regulation of Labor. Quarterly Journal of Economics, 119, 13391382.

Bohme, M. and Thiele, R. (2014), "Informal-formal Linkages and Informal Enterprise Performance in Urban West Africa", The European Journal of Development Research, September 2014, Volume 26, Issue 4, pp 473489.

Cantens at al. (2016), "Introduction: Borders, Informality, International Trade and Customs", Journal of Borderlands Studies, ISSN: 0886-5655, 2159-1229.

Chan, K. (2013), Contract Labour in Global Supply Chain, WIEGO.

Chen, A. (2007) Rethinking the Informal Economy: Linkages with the Formal Economy and the Formal Regulatory Environment, DESA Working Paper No. 46 ST/ESA/2007/DWP/46. 
Currie, J. and A. Harrison (1997) Sharing the Costs: The Impact of Trade Reform on Capital and Labor in Morocco. Journal of Labor Economics Vol. 15, No. S3.

Cunat, A. and Melitz, M. (2007), Volatility, Labor Market Flexibility, and the Pattern of Comparative Advantage. NBER Working Paper 13062.

Dix-Carneir, R. (2014), "Trade Liberalization and Labour Market Dynamics", Econometrica Volume 82, Issue 3, pages 825,885 .

De Soto, H. 1989. The Other Path: The Invisible Revolution in the Third World. New York: Harper and Row.

Dornbusch, R., Fischer, S., and Samuelson, P.A. (1977), Paul A. Comparative Advantage, Trade, and Payments in a Ricardian Model with a Continuum of Goods. A.E.R. 67: 82339.

Eder, M., Yakovlev, A. arkoglu, A. (2003), " The Suitcase Trade between Turkey and Russia: Microeconomic and Institutional Structure" , Moscow: State University Higher School of Economics, 2003. 32 p.

Elgin, C. and Sezgin, B. (2017), Sectoral Estimates of Informality: A New Method and An Application to Turkish Economy, The Developing Economies 55(4):261-289

Ercan, H. (2010) EEO Review: Self-Employment in Turkey, European Employment Observatory.

Mois-Leeman, E. and Lesser,C. (2008) "Informal Cross-Border Trade Facilitation Reform in Sub-Saharan Africa", OECD Trade Policy Working Paper No. 86.

Filho N. and Muendler, M. (2011) "Labor Reallocation in Response to Trade Reform", NBER Working Paper No. 17372

Gibson, B. and Kelley, B. (1994.) A Classical Theory of the Informal Sector, The Manchester School (1) pp. 81-96.

Goldberg ,P. and Pavcnik, N. (2003) "The response of the informal sector to trade liberalization" Journal of Development Economics 72 pp 463-496.

Haan, C.(2006). "Training for Work in the Informal Micro-Enterprise Sector: Fresh Evidence from Sub-Sahara Africa", Technical and Vocational Education and Training Series: Issues, Concerns, and Prospects, vol. 3 .

Kambourov, G. (2008) "Labor Market Regulations and the Sectoral Reallocation of Workers: The Case of Trade Reforms", Review of Economic Studies, 76(4) (2009), pp. 1321-1358.

Kovak, B. and Dix-Carneir, R. (2015) "Trade Reform and Regional Dynamics: Evidence From 25 Years of Brazilian Matched Employer-Employee”, NBER Working Paper No. 20908.

Krugman, P. R. (1979): "Increasing Returns, Monopolistic Competition, and International Trade ", Journal of Intemational Economics,9, 469-479.

La Porta, R. and Shleifer, A. (2014), " The Unofficial Economy in Africa", NBER Working Paper Series, 16821.

Levy, S. (2008), "Good Intentions, Bad Outcomes: Social Policy, Informality, and Economic Growth in Mexico", Brookings Institution Pres 
Lourenco, S. P. (2014), "The impacts of trade liberalization on informal labor markets: A theoretical and empirical evaluation of the Brazilian case", Journal of International Economics Volume 92, Issue 2, March 2014, Pages 330-348.

Maloney, W. F. (2004), Informality Revisited, World Development Vol. 32, No. 7, pp. 11591178.

Manjul, B. (1999), Invisible Workers, Visible Contribution. A Study of Home Based Workers in Five Sectors across South Asia, Background paper presented at Regional Policy Seminar on Women Workers in the Informal Sector in South Asia: Creating an Enabling Policy Environment.

Marjit, S. and Maiti, D.S. (2005), Globalization, Reform and the Informal Sector, Research Paper No.12, United Nation University.

Martha, A. C. (2007), Rethinking the Informal Economy: Linkages with the Formal Economy and the Formal Regulatory Environment, DESA Working Paper No. 46 ST/ESA/2007/DWP/46.

Martha, A. C. (2014), The Urban Informal Workforce: Home-Based Workers. IEMS Sector Summary. Cambridge, MA, USA: WIEGO.

Melitz, M.J. (2003), The impact of trade on intra-industry reallocations and aggregate industry productivity, Econometrica 71(6), 16951725.

Mrozek, M. and Mays, L. (2011), "Formal and Informal Cooperation within Supply Chains and Company Performance", ARGUMENTA OECONOMICA No 2 (29), PL ISSN 1233-583.

Paz, L. (2013), The Impacts of Trade Liberalization on Informal Labour Markets: A Theoretical and Empirical Evaluation of the Brazilian Case. MPRA Paper 45726.

Raveendran, G. and Vanek, J. (2013), Statistics on Home-Based Workers in Nepal, WIEGO Statistical Brief No. 11.

Satchi, M. and Temple, J. (2009), "Labour markets and productivity in developing countries", Review of Economic Dynamics 83204.

Schneider, F. (2012), "The Shadow Economy and Work in the Shadow: What Do We (Not) Know?", IZA DP No. 6423.

Schneider, F. and Enste, D. (2012), "Shadow Economies: Size, Causes and Consequences", Journal of Economic Literature, Vol. XXXVIII, pp 77-114", IZA DP No. 6423.

Shleifer, A. (2004): "The Regulation of Labor", Quarterly Journal of Economics, 119, 1339-1382.

Sinha, S. (2013), Housing and Urban Service Needs of Home-Based Workers: Findings from a Seven-Country Study, WIEGO Policy Brief (Urban Policies) No. 15.

Sinha, S. (2013), Supporting Women Home- Based Workers: The Approach of the Self-Employed Womens Association in India ,WIEGO Policy Brief (Urban Policies) No. 13.

Steel, W. and Snodgrass, D. (2008), Raising Productivity and Reducing Risks of Household Enterprises, Diagnotic Methodology Framework, World Bank.

Oviedo, A. M., Thomas, M. R. and Karakurum-Ozdemir, K. (2009), Economic informality : causes, costs, and policies - a literature survey, World Bank working paper; no. 167.

Tansel, A. and Acar, E. O.(2014), "Defining and Measuring Informality in the Turkish Labor Market", 
MPRA Paper No. 57739.

Tansel, A. and Kan, E. O. (2012), "Labour Mobility across the formal/informal divide in Turkey: Evidence from Individual Level Data ", Ko University-TUSIAD Economic Research Forum Working Papers 1201, Koc University-TUSIAD Economic Research Forum.

Turkish Statistical Institute (TURKSTAT) (2003). Household Labour Force Survey.

Turkish Statistical Institute (TURKSTAT) (2013) Household Labour Force Survey.

The Micro and Small Enterprise Survey (MSE) (2003), conducted by the Economic Research Forum $(\mathrm{ERF})$.

World Trade Report (2015) conducted by World Trade Organization (WTO).

World Trade Organization (WTO) (2016), Trade Policy Review, WT/TPR/G/331/Rev.1.

World Bank (WTO) (2010), "Turkey - Country economic memorandum: informality - causes, consequences, and policies".

Wacziarg R. and J S. Wallack (2004), "Trade liberalization and intersectoral labor movements", Journal of International Economics 64, 411-439.

Yi, K. (2003), "Can Vertical Specialization Explain the Growth of World Trade?" Journal of Political Economy, Vol. 111.

Zenou, Y. (2008), "Job search and mobility in developing countries. Theory and policy implications", Journal of Development Economics 86, 336355 